IZA DP No. 5321

Fiscal Policy and the Labour Market: The Effects of Public Sector Employment and Wages

Pedro Gomes

November 2010 


\title{
Fiscal Policy and the Labour Market: The Effects of Public Sector Employment and Wages
}

\author{
Pedro Gomes \\ London School of Economics \\ and IZA
}

Discussion Paper No. 5321

November 2010

\author{
IZA \\ P.O. Box 7240 \\ 53072 Bonn \\ Germany \\ Phone: +49-228-3894-0 \\ Fax: +49-228-3894-180 \\ E-mail: iza@iza.org
}

Any opinions expressed here are those of the author(s) and not those of IZA. Research published in this series may include views on policy, but the institute itself takes no institutional policy positions.

The Institute for the Study of Labor (IZA) in Bonn is a local and virtual international research center and a place of communication between science, politics and business. IZA is an independent nonprofit organization supported by Deutsche Post Foundation. The center is associated with the University of Bonn and offers a stimulating research environment through its international network, workshops and conferences, data service, project support, research visits and doctoral program. IZA engages in (i) original and internationally competitive research in all fields of labor economics, (ii) development of policy concepts, and (iii) dissemination of research results and concepts to the interested public.

IZA Discussion Papers often represent preliminary work and are circulated to encourage discussion. Citation of such a paper should account for its provisional character. A revised version may be available directly from the author. 


\section{ABSTRACT \\ Fiscal Policy and the Labour Market: The Effects of Public Sector Employment and Wages*}

I build a dynamic stochastic general equilibrium model with search and matching frictions and two sectors in order to study the labour market effects of public sector employment and wages. Public sector wages plays an important role in achieving the efficient allocation. High wages induce too many unemployed to queue for public sector jobs, while if they are low, the government faces recruitment problems. The optimal steady-state wage premium depends mainly on the labour market friction parameters. In response to technology shocks, it is optimal to have procyclical public sector wages. Deviations from the optimal policy can increase the volatility of unemployment significantly. Public sector wage and employment shocks have mixed effects on unemployment. A wage shock raises the unemployment rate, while a reduction in the separations lowers it. Hiring more people can increase or decrease the unemployment rate. All shocks raise the wage and crowd out employment in the private sector. In the empirical part, I employ Bayesian methods to estimate the parameters of the model for the United States. I find that the direct search mechanism between the two sectors is an important element to explain business cycle fluctuations of the labour market variables.

\section{NON-TECHNICAL SUMMARY}

Public sector employment is a sizable element of the labour market, but the wage setting process is different from the private sector. In this paper I discuss the role of public sector wages. If the government offers very high wages to its workers it induces too many unemployed to queue for public sector jobs, raising unemployment. If the wages are very low, the government faces recruitment problems. Because government jobs tend to be more secure than private sector jobs it is optimal to have lower wages in the public sector. Over the business cycle it is optimal to have procyclical public sector wages. In other words, public sector wages should follow closely the wages in the private sector. Deviations from the optimal policy can increase the volatility of unemployment significantly.

JEL Classification: E24, E32, E62, J31, J45

Keywords: $\quad$ public sector employment, public sector wages, unemployment, fiscal shocks

Corresponding author:

Pedro Gomes

London School of Economics

STICERD

Houghton Street

London WC2A 2AE

United Kingdom

E-mail: p.gomes@Ise.ac.uk

\footnotetext{
* I would like to thank participants at the London School of Economics, University Pompeu Fabra, Lisbon Technical University, European Central Bank and Bank of England seminars; and the $40^{\text {th }} \mathrm{MMF}$ conference, the PEUK PhD workshop, the EDP-Jamboree, the RES conference, the IZA summer school, the $5^{\text {th }}$ European Workshop in Macroeconomics, the SED annual meeting and the $24^{\text {th }}$ Annual Congress of the EEA. I want to give particular thanks to Chris Pissarides, Frank Cowell, António Afonso, Thijs Van Rens, Davide Debortoli, Jordi Gali, Francesco Caselli, Rachel Ngai and Bernardo Guimarães, Stephen Millard, Luís Costa, Clare Leaver, Javier Fernandez Blanco, Mathias Trabandt, Wouter den Haan, Albert Marcet, Holly Holder and Jill Miller. Pedro Gomes acknowledges financial support from FCT.
} 


\section{Introduction}

If you seek advice from a macroeconomist on how to model government consumption, you are likely to hear: government consumption should be modelled as goods bought from the private sector. ${ }^{1}$ However, the main component of government consumption is compensation to employees. As shown in Table 1, in most OECD countries the public sector wage bill represents between 50 to 60 percent of government consumption expenditures. Government employment is an important aspect of fiscal policy, but it is also a sizable element of the labour market. In OECD economies, between 10 to 30 percent of all employees are working in the public sector. Given its relevance, it seems plausible that part of the transmission mechanism of fiscal policy occurs through the labour market.

The level of employment and wages in the public sector are relevant, not just because of their weight in the economy or in the government budget, but also because they play an important role over the business cycle. Since 2004, the Internet search engine Google releases a weekly index of keyword searches. Figure 1 shows the growth rate of keyword searches of "Jobs" and "Government jobs" for the United States, relative to the previous year. From August 2008, as the recession worsened, the number of searches for jobs has increased dramatically, but it is clear that since February 2009, people are turning more towards government jobs. The difference between the growth rates is around 20 percentage points. Repeating the exercise for the United Kingdom gives a similar picture. Indeed, the change in the searching patterns of the unemployed has gained such proportions that it has been noticed by the press. The following quote is particularly insightful regarding its causes:

Wall Street may be losing its luster for new U.S. college graduates who are increasingly looking to the government for jobs that enrich their social conscience, if not their wallet. In the boom years, New York's financial center lured many of the brightest young stars with the promise of high salaries and bonuses. But the financial crisis has tainted the image of big banks, and with fewer financial jobs available, Uncle Sam may be reaping the benefit. (Reuters, $11^{\text {th }}$ of June 2009)

The quote hints that in the current recession more people are searching for public sector jobs for two reasons. First, as the wages in the private sector have fallen, more people are

${ }^{1}$ At least this is the approach taken by most articles that study the aggregate effects of government spending. Barro (1990) studies the effects of productive and unproductive spending in an endogenous growth model. Baxter and King (1993) examine their effects in a Neo-Classical setting, Linnemann and Schabert (2003) extends it to the New Keynesian model and Galí, López-Salido, and Vallés (2007) introduces rule of thumb agents. All these papers share the feature of considering government spending as goods bought from the private sector. 
Table 1: Public sector and the labour market

\begin{tabular}{lcccc}
\hline \hline & $\begin{array}{c}\text { Public wage bill } \\
\text { (\% gov. consumption) }\end{array}$ & $\begin{array}{c}\text { Public Employment } \\
\text { (\% total employment) }\end{array}$ & $\begin{array}{c}\text { Unemployment } \\
\text { rate }\end{array}$ & $\begin{array}{c}\text { Correlation } \\
\left(u_{t}, l_{t}^{g}\right)\end{array}$ \\
\hline Australia & $52.2 \%$ & $14.1 \%$ & $6.3 \%$ & 0.51 \\
Austria & $53.4 \%$ & $13.1 \%$ & $4.7 \%$ & 0.34 \\
Belgium & $53.8 \%$ & $17.9 \%$ & $6.9 \%$ & 0.91 \\
Canada & $59.8 \%$ & $20.5 \%$ & $6.8 \%$ & 0.55 \\
Denmark & $67.8 \%$ & $30.5 \%$ & $4.4 \%$ & 0.78 \\
Finland & $63.2 \%$ & $24.8 \%$ & $9.9 \%$ & 0.76 \\
France & $58.4 \%$ & $22.5 \%$ & $9.4 \%$ & 0.95 \\
Germany & $41.5 \%$ & $11.6 \%$ & $7.5 \%$ & 0.82 \\
Iceland & $60.0 \%$ & $19.0 \%$ & $2.3 \%$ & 0.74 \\
Ireland & $57.0 \%$ & $12.7 \%$ & $4.3 \%$ & 0.84 \\
Italy & $55.6 \%$ & $16.9 \%$ & $10.7 \%$ & -0.40 \\
Japan & $37.7 \%$ & $8.4 \%$ & $4.7 \%$ & 0.35 \\
Luxembourg & $49.1 \%$ & $15.0 \%$ & $2.6 \%$ & 0.88 \\
Netherlands & $42.2 \%$ & $10.9 \%$ & $2.6 \%$ & 0.80 \\
Norway & $63.1 \%$ & $33.6 \%$ & $3.4 \%$ & 0.82 \\
Portugal & $72.8 \%$ & $14.3 \%$ & $4.0 \%$ & 0.22 \\
Spain & $59.2 \%$ & $14.1 \%$ & $11.4 \%$ & 0.13 \\
Sweden & $59.2 \%$ & $31.1 \%$ & $4.7 \%$ & 0.33 \\
United Kingdom & $53.3 \%$ & $18.0 \%$ & $5.5 \%$ & 0.19 \\
United States & $66.5 \%$ & $15.2 \%$ & $4.1 \%$ & 0.66 \\
Average & $56.3 \%$ & $18.2 \%$ & $5.9 \%$ & 0.49 \\
\hline \hline
\end{tabular}

Note: Public wage bill, public employment and unemployment rate refer to the year 2000. The correlation between public sector employment and the unemployment rate is computed from quarterly data (1970 to 2007). Source: OECD.

Figure 1: Growth rate of Google keyword searches in the United States

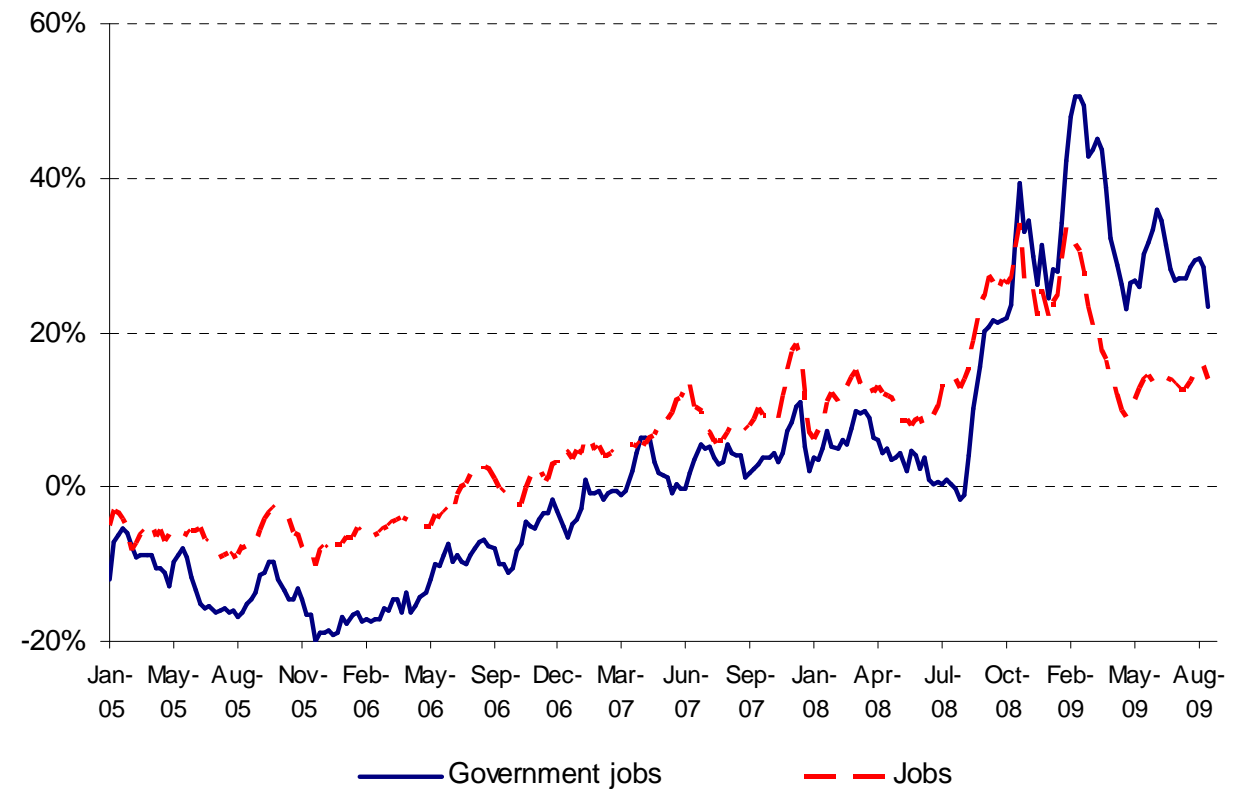

Note: The growth rate of the four-weeks average index of keyword searches, relative the same four weeks in the previous year. 
turning to the public sector where the wages are insulated from the market forces. Second, there are less jobs available in the private sector relative to the public sector. Indeed, as shown in the fourth column of Table 1, in all but one country, public sector employment goes up during recessions. These two facts suggest that government employment and wages are important elements in explaining the business cycle fluctuations of unemployment.

Compared to the theoretical research that focusses on government spending as buying part of the production of the economy, the literature that studies the effects of public sector employment and wages is scarce. Finn (1998) finds that in an RBC model with a perfectly competitive labour market, contrary to government purchases of goods and services, the purchase of hours reduces output, employment and investment in the private sector. Cavallo (2005) extends the model to include capital adjustment cost and exogenous growth in technology and Pappa (2009) to allow for nominal rigidities. Both conclude that private sector hours and output go down and real wages go up after an increase in government hours. Ardagna (2007) study the issue in a dynamic general equilibrium model with a unionised labour market. In her setting, an increase in public sector employment, wages or unemployment benefits, raises the wage in the private sector and thus unemployment. Algan, Cahuc, and Zylberberg (2002) in a partial equilibrium version find that, if public sector wages are low, an increase in public sector employment can reduce unemployment.

Looking at this issue in a frictionless labour market framework might be a useful starting point, but as Figure 1 shows clearly, to fully understand the transmission mechanisms of fiscal policy through the labour market it is crucial to model the existing search and matching frictions. There have been some attempts to do it. According to Holmlund and Linden (1993), an increase in public employment has a direct negative effect in unemployment but crowds out private employment due to an increase in wages. But, for all realistic calibrations, the direct effect of reducing unemployment is stronger than the indirect effect through wages. Quadrini and Trigari (2007) examine the impact of public sector employment on business cycle volatility and find that the presence of the public sector increases the volatility of both private and total employment. Hörner, Ngai, and Olivetti (2007) study the effect of turbulence on unemployment when the wages in the public sector are insulated. They conclude that an increase in turbulence induces more unemployed, who are risk averse, to search for jobs in public companies, resulting in higher aggregate unemployment than if the companies were privately managed.

The aim of this work is to provide a comprehensive, yet simple, framework to study the macroeconomic effects of public sector employment and wages, and their role over the business cycle. I build a dynamic stochastic general equilibrium model with search and matching 
frictions along the lines of Pissarides (2000) with both public and private sectors. The model shares several features with Quadrini and Trigari (2007). One of its main difficulties is the calibration of the friction parameters in the public sector. In order to do it accurately, I explore information from several sources from the United States and the United Kingdom.

In a first stage, I solve the social planner's problem to find the constrained efficient allocation. I then solve the decentralized equilibrium and determine the public sector wage consistent with the optimal steady-state allocation. The optimal wage premium depends mainly on the differences of the labour market frictions parameters of the public sector relative to the private sector. For the chosen calibration, the optimal wage is 3 percent lower than in the private sector. If the government sets a higher wage, it induces too many unemployed to queue for public sector jobs and raises private sector wages, thus reducing private sector job creation and increasing unemployment. Conversely, if it sets a lower wage, few unemployed want a public sector job and the government faces recruitment problems.

I also examine the properties of the model when subject to technology shocks. The optimal government policy consists of a countercyclical vacancy posting and a procyclical wage. If the public sector wages are acyclical, in recessions they become more attractive relative to the wages in the private sector, inducing more unemployed to queue for public sector jobs. This further dampens job creation in the private sector and amplifies the business cycle. Deviations from the optimal policy can entail significant welfare losses. If, for instance, the public sector wage does not respond to the cycle, unemployment volatility doubles relative to the scenario under optimal policy.

The model allows us to disaggregate fiscal shocks into wage and employment shocks and the latter into separation and hiring shocks. The response to the three shocks varies. Paying more to public sector workers raises unemployment through two channels. On the one hand, more unemployed direct their search towards the public sector. On the other hand, as it increases the value of unemployment, it spills over to private sector wages. These two channels are also in place under a separation or hiring shock, but they are offset by the direct effect of increasing public sector employment. In general, reducing separations always lowers unemployment, but increasing hiring can have opposite effects on unemployment, depending on the steady-state level of public sector wages. If the wages are high, when the government opens new vacancies it induces many more unemployed to search for these new jobs, enhancing the crowding out effect in the private sector and raising unemployment.

The opposite effects of the different components of fiscal policy is one of the key results of the paper. The extensive empirical literature that evaluates the macroeconomic effects 
of government spending tends to find mixed effects on private consumption, real wage or private employment. $^{2}$ As a consequence, the center of the debate has been on the technical methodology, particularly on the identification of fiscal shocks. I argue that the mixed evidence might be more related to the data, rather than the methodological strategy used. Fiscal shocks can have distinct effects depending on the type of expenditure we are considering: employment, wages, purchases of privately produced goods or government investment. By including all components together, some in particular or using different samples in which the composition of spending has changed, we cannot expect to identify properly one type of fiscal shock. This hypothesis is consistent with evidence from Caldara and Kamps (2008) who, using the same variables and sample, conclude that alternative identification strategies yield similar results.

The argument that the various types of spending can have mixed macroeconomic effects is not new. In their seminal paper, Baxter and King (1993) find that government investment has different quantitative and qualitative effects than government consumption because it affects the marginal productivity of factors. As mentioned above, Finn (1998) find that, contrary to government purchases of goods and services, an increase in government hours reduces output, employment and investment in the private sector. I show that if we disaggregate employment compensation into employment and into per-employee wage, they can have opposite effects on unemployment. To strengthen my argument, I do a simple extension to the model, replacing public sector employment with services bought directly from the private sector. In such an economy, increases in the government purchase of goods lowers the wage and raises employment in the private sector, contrary to shocks in employment and wages.

Some of the model's results are driven by the assumption that the unemployed direct their search towards the private or the public sector. The purpose of the rest of the paper is to argue that this is a relevant mechanism. First, I review the evidence from microeconometric studies on public sector wages that suggest that individuals self-select into the private or public sector based on the expected wage differential. Then, I employ Bayesian methods to estimate the parameters of the model for the United States, between 1948 and 2007, using quarterly data on: government employment and wages, private sector wages, unemployment rate, job-separation and job-finding rates. I find evidence that the share of unemployed searching for public sector jobs fluctuates over the business cycle. Additionally, the government follows a countercyclical vacancy and a slightly procyclical wage policy.

\footnotetext{
${ }^{2}$ See Caldara and Kamps (2008) for an overview.
} 


\section{Model}

\subsection{General setting}

The model is a dynamic stochastic general equilibrium model with public and private sectors. The only rigidities present in the model are due to search and matching frictions. Public sector variables are denoted by the superscript $g$ while private sector variables are denoted by $p$. Time is denoted by $t=0,1,2, \ldots$

The labour force consists of many individuals $j \in[0,1]$. Part of them are unemployed $\left(u_{t}\right)$, while the remaining are working either in the public $\left(l_{t}^{g}\right)$ or in the private $\left(l_{t}^{p}\right)$ sectors.

$$
1=l_{t}^{p}+l_{t}^{g}+u_{t}
$$

Total employment is denoted by $l_{t}$. The presence of search and matching frictions in the labour market prevents some unemployed from finding jobs. The evolution of employment in both sectors depends on the number of new matches $m_{t}^{p}$ and $m_{t}^{g}$ and on the separations. In each period, jobs are destroyed at constant fraction $\lambda^{i}$, potentially different across sectors.

$$
l_{t+1}^{i}=\left(1-\lambda^{i}\right) l_{t}^{i}+m_{t}^{i}, i=p, g
$$

The new matches are determined by two Cobb-Douglas matching functions:

$$
m_{t}^{i}=\mu^{i}\left(u_{t}^{i}\right)^{\eta^{i}}\left(v_{t}^{i}\right)^{1-\eta^{i}}, i=p, g
$$

I assume the unemployed choose which sector they want to search in, so $u_{t}^{i}$ represents the number of unemployed searching in sector $i$. The vacancies in each sector are denoted by $v_{t}^{i}$. The parameter $\eta^{i}$ is the matching elasticity with respect to unemployment and $\mu^{i}$ the matching efficiency. An important part of the analysis focuses on the behaviour of the share of unemployed searching for a public sector job, defined as: $s_{t}=\frac{u_{t}^{g}}{u_{t}}$.

From the matching functions we can define the probabilities of vacancies being filled $q_{t}^{i}$, the job-finding rates conditional on searching in a particular sector $p_{t}^{i}$, and the unconditional job-finding rates $f_{t}^{i}$ :

$$
q_{t}^{i}=\frac{m_{t}^{i}}{v_{t}^{i}}, p_{t}^{i}=\frac{m_{t}^{i}}{u_{t}^{i}}, f_{t}^{i}=\frac{m_{t}^{i}}{u_{t}}, i=p, g
$$

The assumption of directed search implies that the number of vacancies posted in one sector only affects contemporarily the probability of filling a vacancy in the other sector through the endogenous reaction of $s_{t}$. 


\subsection{Households}

In the presence of unemployment risk we would observe consumption differences across different individuals. Following Merz (1995), I assume all the income of the members is pooled so the private consumption is equalised across members. The household is infinitely-lived and has preferences over private consumption goods, $c_{t}$, and public goods $g_{t}$. It also has utility from unemployment $\nu\left(u_{t}\right)$, which captures leisure and home production.

$$
E_{t} \sum_{t=0}^{\infty} \beta^{t}\left[u\left(c_{t}, g_{t}\right)+\nu\left(u_{t}\right)\right]
$$

where $\beta \in(0,1)$ is the discount factor. The budget constraint in period $t$ is given by:

$$
c_{t}+B_{t}=\left(1+r_{t-1}\right) B_{t-1}+w_{t}^{p} l_{t}^{p}+w_{t}^{p} l_{t}^{g}+\Pi_{t}
$$

where $r_{t-1}$ is the real interest rate from period $t-1$ to $t$ and $B_{t-1}$ are the holdings of one period bonds. $w_{t}^{i} l_{t}^{i}$ is the total wage income from the members working in sector $i$. Finally, $\Pi_{t}$ encompasses the lump sum taxes that finance the government's wage bill and possible transfers from the private sector firms. I assume there are no unemployment benefits.

The household chooses $c_{t}$ to maximize the expected utility subject to the sequence of budget constraints, taking the public goods as given. The solution is the Euler equation:

$$
u_{c}\left(c_{t}, g_{t}\right)=\beta\left(1+r_{t}\right) E_{t}\left[u_{c}\left(c_{t+1}, g_{t+1}\right)\right]
$$

\section{$2.3 \quad$ Workers}

The value of each member to the household depends on their current state. The value of being employed in sector $i$ is given by:

$$
W_{t}^{i}=w_{t}^{i}+E_{t} \beta_{t, t+1}\left[\left(1-\lambda^{i}\right) W_{t+1}^{i}+\lambda^{i} U_{t+1}\right], i=p, g
$$

where $\beta_{t, t+k}=\beta^{k} \frac{u_{c}\left(c_{t+k}, g_{t+k}\right)}{u_{c}\left(c_{t}, g_{t}\right)}$ is the stochastic discount factor. The value of being employed in a sector depends on the current wage, as well as, the continuation value of the job that depends on the separation probability. Under the assumption of directed search, the unemployed are searching for a job either in the private or in the public sector, with value functions given by:

$$
U_{t}^{i}=\frac{\nu_{u}\left(u_{t}\right)}{u_{c}\left(c_{t}, g_{t}\right)}+E_{t} \beta_{t, t+1}\left[p_{t}^{i} W_{t+1}^{i}+\left(1-p_{t}^{i}\right) U_{t+1}\right], i=p, g
$$


Beside the marginal utility from unemployment, the value of being unemployed and searching in a particular sector, depends on the probabilities of finding a job and the value of working in that sector. Optimality implies that there are movements between the two segments that guarantee that there is no additional gain of searching in one sector vis-à-vis the other:

$$
U_{t}^{p}=U_{t}^{g}=U_{t}
$$

This equality determines the share of unemployed searching in each sector. We can re-write it as:

$$
\frac{m_{t}^{p} E_{t}\left[W_{t+1}^{p}-U_{t+1}\right]}{\left(1-s_{t}\right)}=\frac{m_{t}^{g} E_{t}\left[W_{t+1}^{g}-U_{t+1}\right]}{s_{t}},
$$

which implicitly defines $s_{t}$. An increase in the value of being employed in the public sector, driven either by an increase in the wage or by a decrease in the separation rate, raises $s_{t}$, until there is no extra gain from searching in that sector. Under the directed search assumption the public sector wage plays a key role in determining $s_{t}$. If the search was random between sectors, the public sector wage would not affect any variable of the model.

\subsection{Private sector firms}

The representative firm hires labour to produce the private consumption goods. The production function is linear in labour, but part of the resources produced have to be used to pay the cost of posting vacancies $\varsigma^{p} v_{t}^{p}$.

$$
y_{t}=a_{t}^{p} l_{t}^{p}-\varsigma^{p} v_{t}^{p}
$$

At time $t$, the level of employment is predetermined and the firm can only control the number of vacancies it posts. The value of opening a vacancy is given by:

$$
V_{t}=E_{t} \beta_{t, t+1}\left[q_{t}^{p} J_{t+1}+\left(1-q_{t}^{p}\right) V_{t+1}\right]-\varsigma^{p},
$$

where $J_{t}$ is the value of a job for the firm, given by:

$$
J_{t}=a_{t}^{p}-w_{t}^{p}+E_{t} \beta_{t, t+1}\left[\left(1-\lambda^{p}\right) J_{t+1}\right] .
$$

Free entry guarantees that the value of posting a vacancy is zero $\left(V_{t}=0\right)$, so we can combine the two equations into:

$$
\frac{\varsigma^{p}}{q_{t}^{p}}=E_{t} \beta_{t, t+1}\left[a_{t+1}^{p}-w_{t+1}^{p}+\left(1-\lambda^{p}\right) \frac{\varsigma^{p}}{q_{t+1}^{p}}\right]
$$


The condition states that the expected cost of hiring a worker must equal its expected return. The benefit of hiring an extra worker is the discounted value of the expected difference between its marginal productivity and its wage, plus the continuation value, knowing that with a probability $\lambda^{p}$ the match is destroyed.

Finally, I consider the private sector wage is the outcome of a Nash bargaining between workers and firms. The sharing rule is given by:

$$
(1-b)\left(W_{t}^{p}-U_{t}\right)=b J_{t}
$$

\subsection{Government}

The government produces its goods using a linear technology on labour. As in the private sector, the costs of posting vacancies are deducted from production.

$$
g_{t}=a_{t}^{g} l_{t}^{g}-\varsigma^{g} v_{t}^{g}
$$

The government collects lump sum taxes to finance the wage bill:

$$
\tau_{t}=w_{t}^{g} l_{t}^{g}
$$

The numeraire of this economy is the private consumption good. As the public good is not sold, it has no actual price. However, there is an implicit relative price given by the marginal rate of substitution. The formulation of the production function (16) implies that the cost of recruiting is given in units of the public good. Alternatively, if the cost was included in the budget constraint it would be expressed in units of private consumption.

Finally, the government sets a policy for the sequence of vacancies and wage $\left\{v_{t}^{g}, w_{t+1}^{g}\right\}_{t=o}^{\infty}$. I assume it sets the wage one period in advance, at the time it posts the vacancies. As $s_{t}$ is determined based on the expected future wages in the two sectors, the current public sector wage does not affect any variable in the model. There is no time inconsistency problem because, as taxes are lump sum, the government does not gain from setting a current wage different than promised. Throughout the paper I contrast two types of policies: exogenous policies to help us understand the functioning of the model and the transmission mechanisms of fiscal policy and the optimal policy - the one arising from the social planner's problem. 


\subsection{Decentralised equilibrium}

Definition 1 A decentralised equilibrium is a sequence of prices $\left\{r_{t}, w_{t}^{p}\right\}_{t=o}^{\infty}$ such that, given a sequence of government vacancies and wages $\left\{v_{t}^{g}, w_{t+1}^{g}\right\}_{t=o}^{\infty}$, the household chooses a sequence of consumption $\left\{c_{t}\right\}_{t=o}^{\infty}$, and the fraction of unemployed members searching in the public sector $s_{t}$ and firms choose private sector vacancies $v_{t}^{p}$, such that: (i) the household maximises its lifetime utility; (ii) the share of unemployed searching in the public sector is such that the values of searching in the two sectors equalise (equation 10); (iii) private sector vacancies satisfy the free entry condition (14); (iv) the private wage $w_{t}^{p}$ solves the bargaining condition (15); $(v)$ the private goods market clears: $c_{t}=y_{t}$; and (vi) the lump sum taxes $\tau_{t}$ are chosen to balance the government budget (equation 17).

\subsection{Social planner's solution}

As a benchmark for analysis, I consider the constrained efficient solution. The social planner's problem is to maximize the consumers lifetime utility (4) subject to the labour market and technology constraints (1)-(3), (11) and (16). The first order conditions are given by:

$$
\begin{gathered}
\frac{\varsigma^{p}}{q_{t}^{p}}=\beta E_{t}\left\{\frac{u_{c}\left(c_{t+1}, g_{t+1}\right)}{u_{c}\left(c_{t}, g_{t}\right)}\left[\left(1-\eta^{p}\right) a_{t+1}^{p}-\left(1-\eta^{p}\right) \frac{\nu_{u}\left(u_{t+1}\right)}{u_{c}\left(c_{t+1}, g_{t+1}\right)}+\left(1-\lambda^{p}\right) \frac{\varsigma^{p}}{q_{t+1}^{p}}-\frac{\eta^{p} \varsigma^{p} v_{t+1}^{p}}{\left(1-s_{t+1}\right) u_{t+1}}\right]\right\} \\
\frac{\varsigma^{g}}{q_{t}^{g}}=\beta E_{t}\left\{\frac{u_{g}\left(c_{t+1}, g_{t+1}\right)}{u_{g}\left(c_{t}, g_{t}\right)}\left[\left(1-\eta^{g}\right) a_{t+1}^{g}-\left(1-\eta^{g}\right) \frac{\nu_{u}\left(u_{t+1}\right)}{u_{g}\left(c_{t+1}, g_{t+1}\right)}+\left(1-\lambda^{g}\right) \frac{\varsigma^{g}}{q_{t+1}^{g}}-\frac{\eta^{g} \varsigma^{g} v_{t+1}^{g}}{s_{t+1} u_{t+1}}\right]\right\} \\
\frac{u_{g}\left(c_{t}, g_{t}\right) \varsigma^{g} v_{t}^{g} \eta^{g}}{\left(1-\eta^{g}\right) s_{t}}=\frac{u_{c}\left(c_{t}, g_{t}\right) \varsigma^{p} v_{t}^{p} \eta^{p}}{\left(1-\eta^{p}\right)\left(1-s_{t}\right)}
\end{gathered}
$$

Conditions (18) and (19) describe the optimal private and public sector vacancies. On the left hand side we have the expected cost of hiring an extra worker. The right hand side gives us the marginal social benefit of hiring an additional worker. It consists of its expected marginal productivity minus the utility cost of working, weighted by the matching elasticity with respect to vacancies, plus the continuation value. The last element that enters with a negative sign reflects the fact that hiring an additional worker makes it harder for both sectors to recruit a worker in the future.

The optimal split of the unemployed between sectors, pinned down in (20), depends on the marginal utility of consumption of both goods, on the number of vacancies and their cost, and on the matching elasticity with respect to unemployment in both sectors. 


\section{Calibration}

To solve the model, I assume a CES utility function in logs, which allows us to address different elasticities of substitution between the two consumption goods. The utility of unemployment is linear.

$$
u\left(c_{t}, g_{t}\right)=\frac{1}{\gamma} \ln \left[c_{t}^{\gamma}+\zeta g_{t}^{\gamma}\right], \nu\left(u_{t}\right)=\chi u_{t} .
$$

The model is calibrated to match the US economy at a quarterly frequency. The first graph in Figure 2 shows the government employment in the United States since 1940. Under the baseline calibration, the steady-state vacancies in the public sector are such that public sector employment corresponds to the sample average i.e. 16 percent of total employment.

The second graph shows the monthly separation rate for the two sectors, taken from the Job Opening and Labour Turnover Survey (JOLTS). The separation rate in the private sector is almost 3 times higher than in the government: 4.3 against 1.5 percent. The last graph plots the new hires of each sector as a share on the total unemployed, a proxy for the job-finding rate. The probability of finding a job in the government sector is only 4.5 percent compared with 62.5 percent in the private sector. To retrieve the quarterly separation rate, I first calculate the aggregate monthly separation rate (0.038) and job-finding rate (0.67). I then compute the quarterly transition probabilities, allowing for multiple transitions within the quarter. ${ }^{3}$ I find that an employed person has a 5.3 percent probability of being unemployed in the following quarter. I fix the separation rate in the private and public sectors at 0.06 and 0.03. These values imply an aggregate separation rate close to 0.053 while preserving the difference between the two sectors. ${ }^{4}$

To estimate the matching elasticity with respect to vacancies, I regress for each sector the $\log$ of the job-finding rate (the ratio between hires in that sector and unemployment) on the log of tightness (the ratio between job openings in that sector and unemployment). The estimated coefficients are 0.63 for the private sector and 0.79 for the public sector which suggest that vacancies are more important determinants of matches in the public sector. ${ }^{5} \mathrm{I}$

\footnotetext{
${ }^{3}$ I compute these probabilities using the following formulas:

$\lambda^{q}=\left(\lambda^{m}\right)\left(f^{m}\right)\left(\lambda^{m}\right)+\left(\lambda^{m}\right)\left(1-f^{m}\right)\left(1-f^{m}\right)+\left(1-\lambda^{m}\right)\left(1-\lambda^{m}\right)\left(\lambda^{m}\right)+\left(1-\lambda^{m}\right)\left(\lambda^{m}\right)\left(1-f^{m}\right)$, $f^{q}=\left(f^{m}\right)\left(\lambda^{m}\right)\left(f^{m}\right)+\left(f^{m}\right)\left(1-\lambda^{m}\right)\left(1-\lambda^{m}\right)+\left(1-f^{m}\right)\left(1-f^{m}\right)\left(f^{m}\right)+\left(1-f^{m}\right)\left(f^{m}\right)\left(1-\lambda^{m}\right)$.

${ }^{4}$ In the United Kingdom, close to 22 percent of total employment is government employment. As in the United States, the turnover is higher in the private sector. Each quarter, workers are 3 times more likely to lose their jobs (1.6 against 0.6 percent), but the unemployed are seven times more likely to find one there (23.6 against 3.4 percent). See Gomes (2009) for a detailed study on UK labour market flows.

${ }^{5}$ Strictly speaking, these regressions are only correct if the share of unemployed searching in the public sector is constant. However, in Section $8 \mathrm{I}$ estimate the structural model and find similar values.
} 
Figure 2: Evidence for the United States
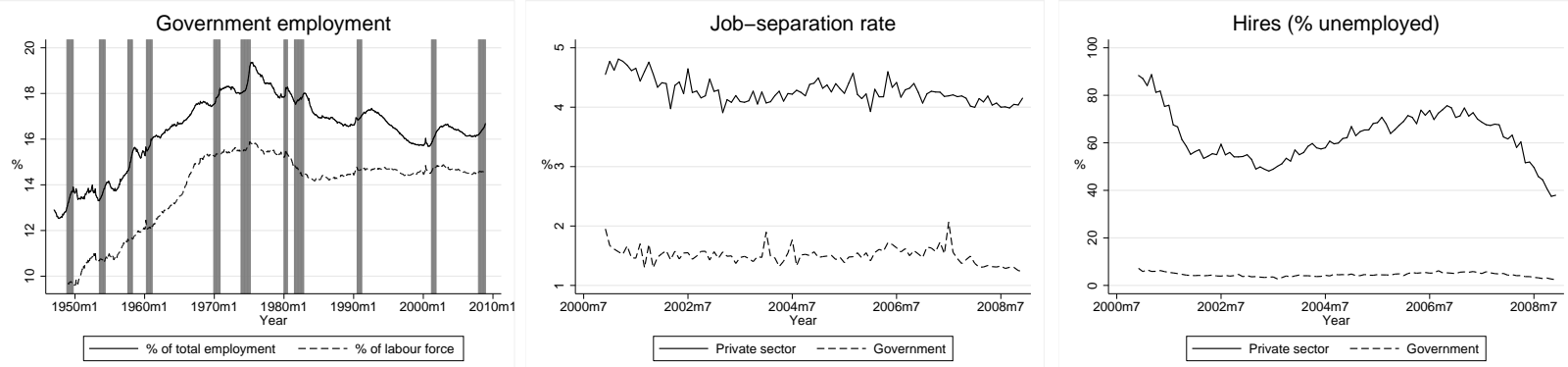

Note: The government employment series is taken from the Current Employment Statistics survey (Bureau of Labor Statistics). The grey bars indicate the NBER recession dates. The job-separation and job-finding rates are calculated from the Job Opening and Labour Turnover Survey.

set the public sector matching elasticity with respect to unemployment, $\eta^{g}$, at 0.2 and $\eta^{p}$ at 0.5 , slightly higher than the estimated value but in line with estimates from the literature (Petrongolo and Pissarides (2001)).

A recent paper by Davis, Faberman, and Haltiwanger (2009) provides some insights into the duration of vacancies by sector. They use JOLTS data to study the behaviour of vacancies and hiring. After adjusting the data, they estimate that the duration of a vacancy is 30 days for the government and 20 days for the private sector. I calibrate the matching efficiency $\mu^{i}$ to reproduce these numbers $\left(\bar{q}^{p}=3.9\right.$ and $\left.\bar{q}^{g}=2.5\right)$.

The United Kingdom has a unique source of data on recruitment costs. Every year, the Chartered Institute of Personal Development carries out a survey of recruitment practices of around 800 organizations from different sectors: manufacturing and production, private sector services, public sector services and voluntary, community and not-for-profit (CIPD (2009)). The costs of recruiting a worker, which encompass advertising and agency costs, are for the median firm around $£ 4000$, corresponding to roughly 8 weeks of the median income in the United Kingdom. On average, these costs are 40 percent lower in the public sector. ${ }^{6}$ I take these values as indicative that the cost per hire is lower in the public sector. I consider the cost of posting a vacancy $\varsigma^{i}$ to be 2 in the private sector and 1.1 in the public sector. Given that the duration of a vacancy is higher in the public sector, these values imply that the average cost of recruiting expressed in the same units is 15 percent lower than in the private sector. Under this calibration, the sum of recruitment costs is close to 3 percent of the total labour costs, value found in Russo, Hassink, and Gorter (2005). It also

\footnotetext{
${ }^{6}$ Also, the median firm takes 12 weeks to recruit a new worker while in the public sector it takes 30 percent longer. See appendix for the disaggregated values. Another study by the National Audit Office (2009) that analyses the recruitment practices in the central government finds that it takes 16 weeks to recruit a new worker, costing between $£ 1600$ and $£ 2200$, which is consistent with the CIPD study.
} 
implies that the cost of recruiting per hire equals to around 5 to 7 weeks of wages, which is consistent with the evidence for the United Kingdom and with the study by Boca and Rota (1998).

Estimates of public sector wage premium have proved quite sensitive to the country choice, education and sex of a worker or even the sub-sector of the government. The survey by Gregory and Borland (1999) places the premium between 0 and 10 percent. I set it close to the lower bound, at 2 percent $\left(\pi \equiv \frac{\bar{w}^{g}}{\bar{w}^{p}}=1.02\right)$.

The empirical evidence relative to the substitution elasticity between private and government consumption is not conclusive. Evans and Karras (1998) find that private consumption is complement to military expenditure and substitute to non-military expenditure. Fiorito and Kollintzas (2004) disaggregate expenditure into "public goods" (defence, public order, and justice) and "merit goods" (health, education, and other services). They find that "public goods" are substitutes and "merit goods" are complements to private consumption. As it is hard to select one value for $\gamma$, I consider an elasticity of substitution of $1(\gamma=0.0)$. In Section 7 I discuss the cases where the goods are substitutes $(\gamma=0.5)$ and complements $(\gamma=-0.5)$. The parameter $\zeta$, that reflects the preference for government services, is chosen such that the optimal level of public sector employment is 0.15 .

For the model to satisfy the Hosios condition in the private sector, the worker's share in the Nash bargaining is set at 0.5 . The value of leisure in the utility function is calibrated, such that the unemployment rate in steady-state is 0.06 and implies an outside option equivalent to 42 percent of the average wage. Technology in both sectors is normalised to 1 and the discount factor is set at 0.99 . Table 2 summarises the baseline calibration and the implied steady-state values for some of the variables.

\section{Table 2: Baseline calibration}

\begin{tabular}{cccccccccccc}
\hline \hline & \multicolumn{10}{c}{ Parameters } \\
$a^{p}$ & 1 & $\eta^{p}$ & 0.5 & $\varsigma^{p}$ & 2.0 & $\mu^{p}$ & 1.71 & $\lambda^{p}$ & 0.06 & $\bar{l}^{g}$ & 0.15 \\
$a^{g}$ & 1 & $\eta^{g}$ & 0.2 & $\varsigma^{g}$ & 1.1 & $\mu^{g}$ & 1.97 & $\lambda^{g}$ & 0.03 & $\pi$ & 1.02 \\
$\gamma$ & 0 & $\zeta$ & 0.18 & $\chi$ & 0.46 & $\beta$ & 0.99 & $b$ & 0.5 & & \\
\hline \multicolumn{10}{c}{ Steady-state variables } \\
$\bar{u}$ & 0.06 & $\bar{q}^{g}$ & 2.5 & $\bar{f}^{g}$ & 0.075 & $\bar{p}^{g}$ & 0.37 & $\bar{s}$ & 0.20 & $\frac{\varsigma^{p} \bar{v}^{p}+\varsigma^{g} \bar{v}^{g} \frac{u_{g}}{u_{c}}}{\sum_{\bar{w}^{i}} \bar{l}^{i}}$ & 0.029 \\
$\bar{l}^{p}$ & 0.79 & $\bar{q}^{p}$ & 3.9 & $\bar{f}^{p}$ & 0.79 & $\bar{p}^{g}$ & 0.99 & $\frac{\nu_{l}}{u_{c} \bar{w}^{g}}$ & 0.42 & $\frac{\bar{W}^{g}-\bar{U}}{\bar{W}^{p}-\bar{U}}$ & 2.69 \\
\hline \hline
\end{tabular}




\section{Attaining the steady-state constrained efficient allo- cation}

The constrained efficient steady-state allocation consists of a triplet of $\left\{\bar{v}^{p}, \bar{v}^{g}, \bar{s}\right\}$. In order to achieve it, the government can post the optimal number of vacancies directly, but it still has to induce an optimal share of the unemployed searching for public sector jobs. The government can do so by choosing an appropriate level of the public sector wage.

Proposition 1 If the government sets the optimal level of public sector vacancies and sets a wage such that the share of unemployed searching for public sector jobs is optimal then, if the bargaining power of the workers is equal to the matching elasticity with respect to unemployment in the private sector $\left(b=\eta^{p}\right)$, the steady-state level of vacancies in the private sector is optimal.

The proof is in the companion appendix. In a one-sector model, the firm's vacancy posting behaviour entails a positive and a negative externality: it increases the probability of an unemployed finding a job but reduces the other firms' probability of filling a vacancy. The decentralised equilibrium is efficient if the share of the surplus of a match that goes to the firm $(1-b)$ is equal to the importance of vacancies in the matching process $\left(1-\eta^{p}\right)$, in what is usually called the Hosios condition. When we include the public sector, besides the externalities of public sector vacancies there are also the ones arising from the directed search. If more unemployed search in the public sector, the probability of filling a vacancy is higher in the public sector but lower for private sector firms. What this proposition states is that if the government is able to internalise the externalities in $\bar{v}^{g}, \bar{w}^{g}$, the vacancies in the private sector will also be efficient, provided that the Hosios condition is satisfied.

Let us assume the government sets its wage as a premium over the private sector wage: $\bar{w}^{g}=\pi \bar{w}^{p}$. Even though we cannot get an analytical solution for the optimal wage ratio, we can find it numerically. Under the baseline calibration the optimal public sector wage is $3 \%$ lower than in the private sector. This value depends mainly on the difference between the friction parameters in the public and private sectors. Figure 3 shows how the optimal wage ratio varies with the parameters of the public sector. ${ }^{7}$

When the cost of posting vacancies is lower or when the matching depends more on vacancies (lower $\eta^{g}$ ), it is more efficient to have more vacancies and fewer unemployed searching in the public sector. In order to induce it, the government should pay less to its workers. When

\footnotetext{
${ }^{7}$ The companion appendix shows how the optimal share of unemployed searching in the two sectors, unemployment rate and wages in the two sectors vary with the parameters.
} 
Figure 3: Optimal steady-state public-private wage ratio
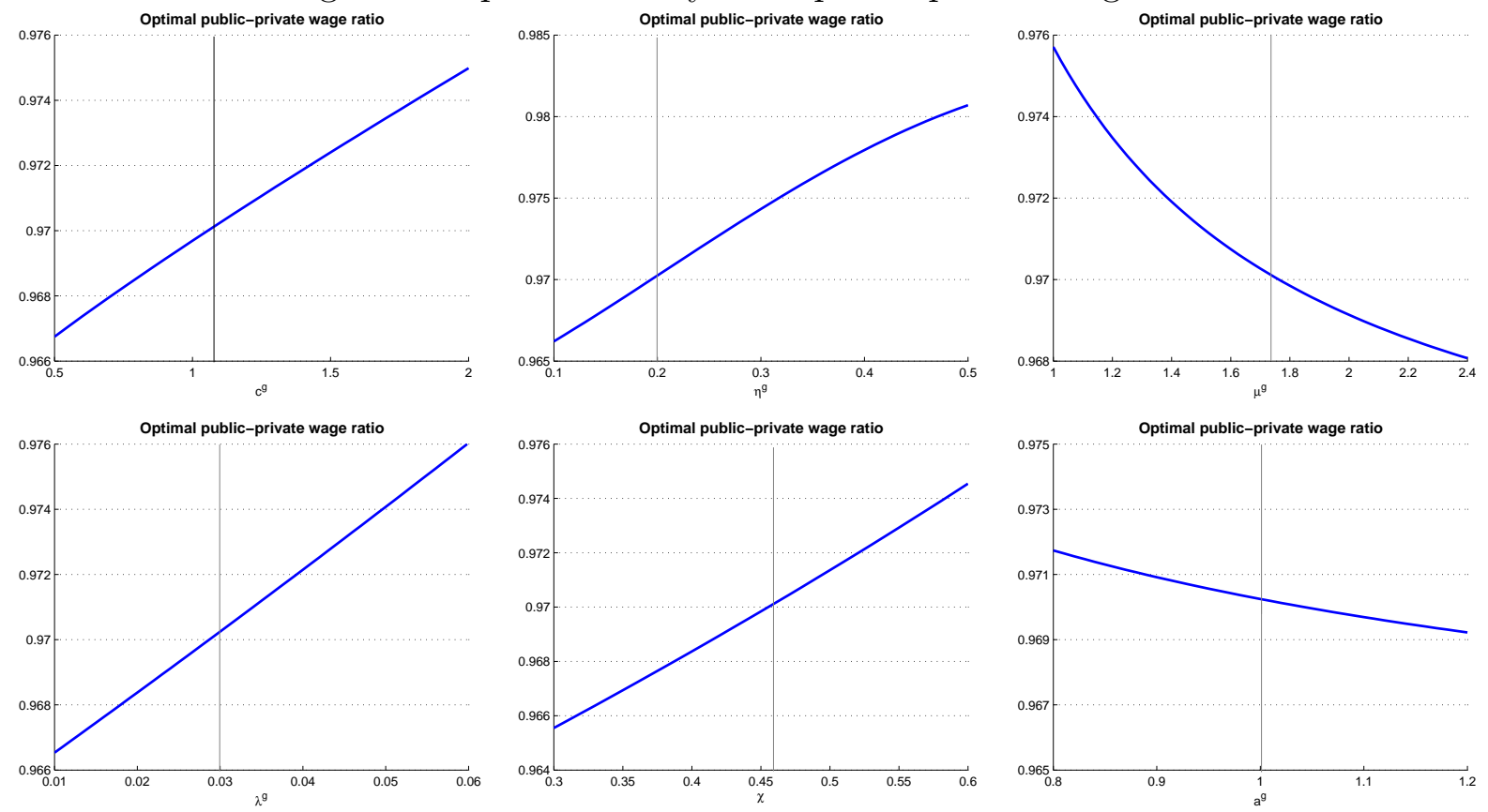

the separation rate decreases or the matching becomes more efficient, more unemployed turn into the public sector, but it is optimal to have fewer. The private incentive is not efficient and, thus, the government should offer lower wages to correct it.

The optimal wage ratio does not depend on the coefficients of the utility function: $\gamma$ and $\zeta$, but it depends on the disutility of working $(\chi)$ and on the productivity of the public sector. Higher $\chi$, raises the value of employment in the private sector relative to the public sector, because people are more likely to have another spell of unemployment there. As it induces more unemployed to search in the private sector, the government needs to offer higher wages to offset it. If government jobs are less productive, the relative cost of posting vacancies is higher because the marginal utility of public sector goods goes up. Although the social planner wants fewer government jobs, it prefers the new matches to be driven by the unemployment side, which requires higher public sector wages.

To investigate the consequences of paying more to public sector employees, I compare the unemployment rate and households' welfare when the public sector wage is optimal (a gap of 3 percent) with the baseline case (a premium of 2 percent). The unemployment rate which was calibrated to 6 percent in the baseline steady-state, falls to 5 percent when the government sets the optimal wage. This happens because many unemployed that were queuing for public sector jobs, now find it more attractive to search in the private sector (from 20 to 3 percent), boosting job creation. The public sector wage is an important determinant 
of equilibrium unemployment. In terms of welfare, moving to the optimal wage generates a gain of 0.6 percent of steady-state consumption.

\section{The effects of fiscal shocks}

In this framework there are several fiscal shocks. We can distinguish shocks to wages from shocks to employment. Furthermore, an employment shock can be driven by hirings or by separations. We can represent the fiscal shocks as:

$$
\begin{gathered}
\ln \left(\lambda_{t}^{g}\right)=\ln \left(\lambda^{g}\right)+\epsilon_{t}^{l}, w_{t}^{g}=\bar{w}^{g}, v_{t}^{g}=\bar{v}^{g} ; \\
\ln \left(v_{t}^{g}\right)=\ln \left(\bar{v}^{g}\right)+\epsilon_{t}^{v}, w_{t}^{g}=\bar{w}^{g} ; \\
\ln \left(w_{t}^{g}\right)=\ln \left(\bar{w}^{g}\right)+\epsilon_{t}^{w}, \quad l_{t}^{g}=\bar{l}^{g} .
\end{gathered}
$$

The shocks $\epsilon_{t}^{i}$ follow and AR(1) process with autocorrelation coefficient of 0.8 . We start from the baseline steady-state. I assume that, under a hiring shock, the government holds the public sector wage constant, while under a wage shock it maintains the level of employment constant. $^{8}$ Finally, under the separation shock, I consider that both the wage and vacancies are kept at their steady-state level.

Figure 4 shows the impulse responses of the variables to a separation rate and a vacancies shock that generate an increase of 6.6 percent of public sector employment, equivalent to 1 percentage point of the labour force. The peak in government employment takes place 10 quarters after the shock. For comparison, I consider a shock to wages of 6.6 percent. In terms of magnitude, they are equivalent to a fiscal stimulus of 1 percent of aggregate income.

Both employment shocks crowd out private sector employment through three channels. First, as there are fewer unemployed available, the cost of hiring an extra worker increases. Second, either because the probability of getting a job is higher or the separation rate is lower, more unemployed search in the public sector, which further reduces the firms' vacancy-filling probability. Finally, as the overall job-finding probability increases so does the value of being unemployed, which raises the private sector wage through the wage bargaining.

Now, the question is whether the crowding out of private sector employment is partial, or whether it outweighs the increase in public sector employment and raises unemployment. Fol-

\footnotetext{
${ }^{8} \mathrm{I}$ could alternatively assume that under the wage shock the vacancies are constant. If the government sets the number of vacancies, as more unemployed search for government jobs, public sector employment increases after a wage shock. Under this policy, the shock to wages also incorporates a shock to employment. This does not change qualitatively the results.
} 
Figure 4: Response to fiscal shocks (Baseline steady-state)
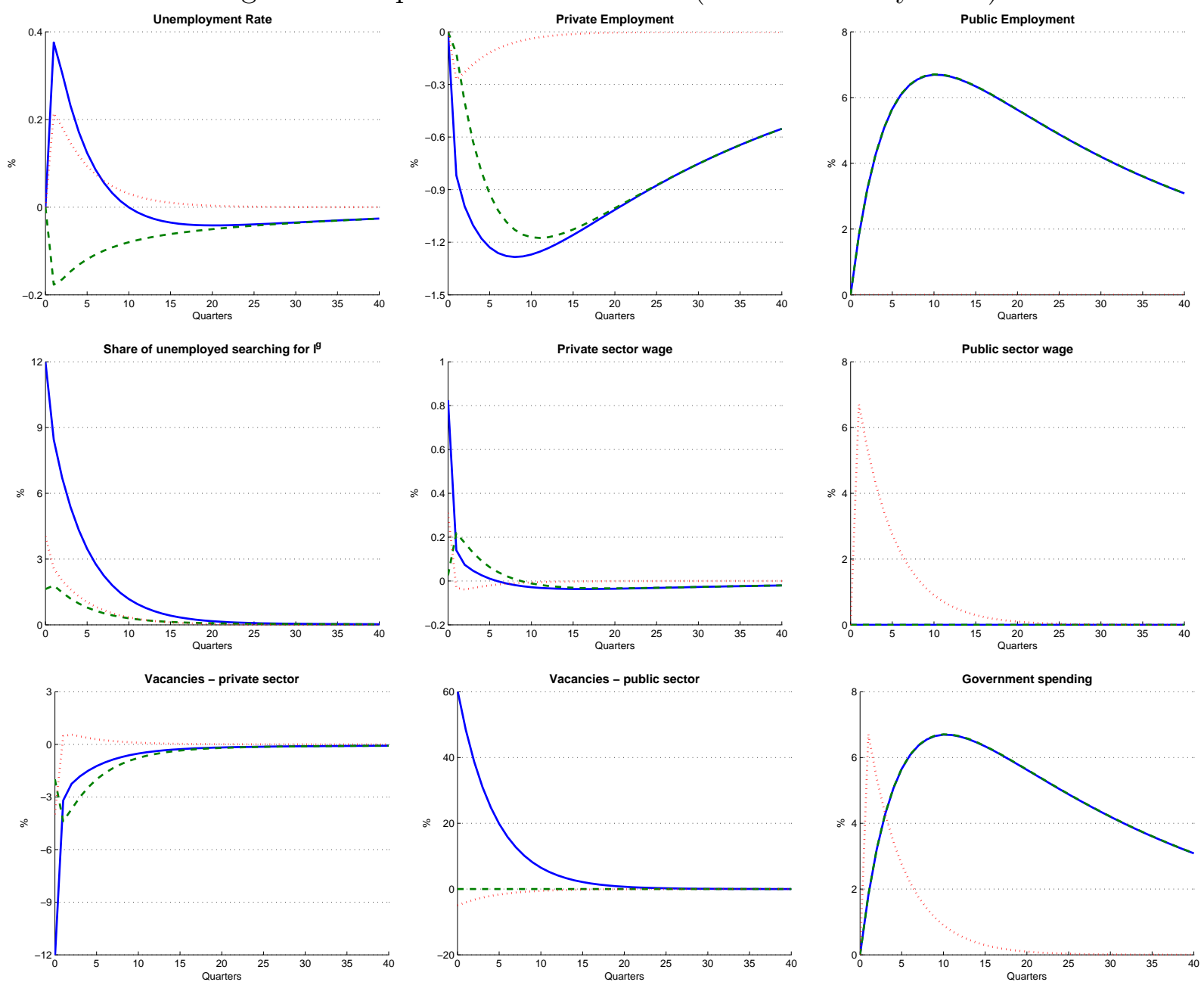

Note: Solid line (vacancies shock); dash line (separations shock) and dotted line (wage shock). The response of the variables is in percentage of their steady-state value, except for the unemployment rate and the share of unemployed searching for public sector jobs, which is in percentage points difference from the steady-state.

lowing the separation rate shock, the unemployment rate declines by 0.2 percentage points, but a vacancies shock raises the unemployment rate by 0.4 percentage points. There are two explanations for these reversed effects. First, an increase in employment through hiring induces many more unemployed to look for public sector jobs, rather than if it is done through retention of workers. Under the hiring shock, the share of unemployed searching for public sector jobs goes up by 12 percentage points, but only by 2 percentage points following a separation shock. Additionally, the effect of a vacancy shock on the private sector wage is four times stronger than the shock to separations.

An increase in the public sector wage reduces private sector employment via two channels. On the one hand, the increase of the public sector wage spills over to the private sector, with an elasticity of around 0.05 . On the other hand, it induces more unemployed to search for a 
job in the public sector, which reduces the probability of filling a vacancy for the firms. As a consequence, they posts fewer vacancies and unemployment rises.

All the fiscal shocks raise the private sector wage, even in the presence of a negative wealth effect. As they crowd out private production, they raise the marginal utility of private consumption lowering the relative value of leisure. The increase in the probability of finding a job in the public sector or its value is large enough to offset this effect.

Figure 5 compares the response of the unemployment rate to fiscal shocks when we start from the efficient steady-state. With lower steady-state public sector wages, a hiring shock reduces unemployment, as opposed to when we start from the baseline steady-state. When the government opens new vacancies, if the wage rate is high, many more unemployed queue for these positions, thus enhancing the crowding out effect on private sector job creation.

The opposite effect of the different types of fiscal shocks on unemployment is an important result. The vast literature that tries to understand the effects of government spending tends to be inconclusive. Rotemberg and Woodford (1992) find that after a military expenditure shock (both military purchases and employment) real wages go up, but Edelberg, Eichenbaum, and Fisher (1999) and Ramey and Shapiro (1998) find that after a government military purchases shock real wages go down. Blanchard and Perotti (2002), as well as Fatás and Mihov (2001) find that private consumption increases after a government consumption shock but Mountford and Uhlig (2008) and Ramey (2009) report a negative or zero response. Most of the discussion has focused on the technical methodology, particularly on the identification of fiscal shocks. In light of my results, I think the contradictory evidence might not due to methodological issues. Fiscal policy shocks can have different effects depending on the type of expenditure considered. Increasing the wage of all employees by 1 percent is different from increasing employment by 1 percent. The model even suggests that the

Figure 5: Response of unemployment rate to fiscal shocks (baseline and efficient steady-state)
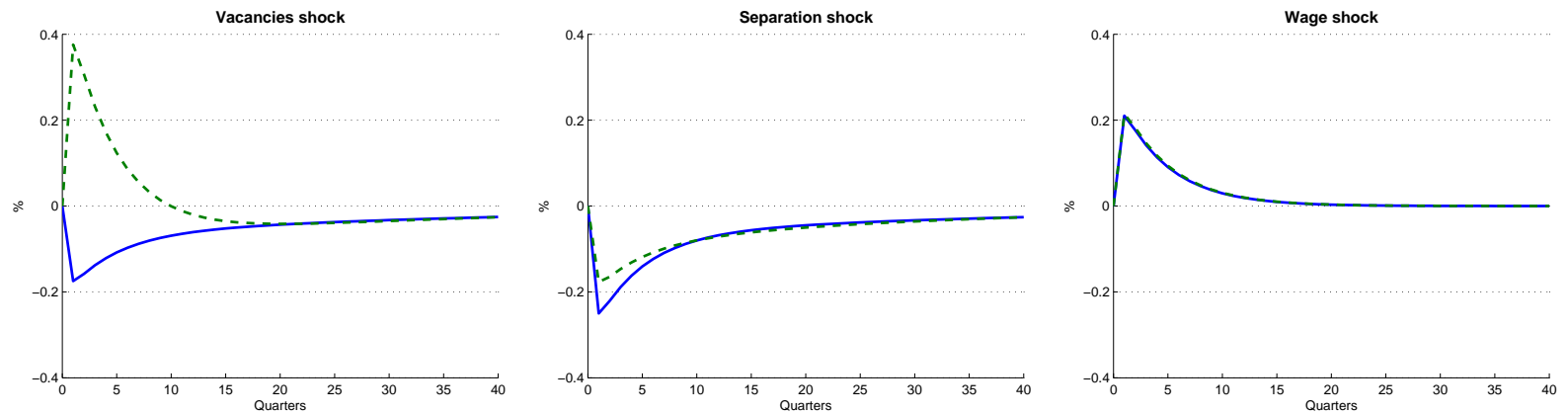

Note: Solid line (efficient steady-state) and dash line (baseline steady-state). The response is in percentage points difference from the steady-state. 
effects of government employment can be different, depending if the adjustment takes place through hiring or separations.

\section{Public sector policies and the business cycle}

One of the main conclusions of the Real Business Cycle literature is that governments should not pursue active business cycle policies. Although the model is, in essence, a real business cycle model with only real frictions, the policy prescription is quite different. Let us examine the effects of a 1 percent negative private technology shock on the economy, under alternative government policies. I again consider an $\mathrm{AR}(1)$ shock with autoregressive coefficient of 0.9.

$$
\ln \left(a_{t}^{p}\right)=\ln \left(\bar{a}^{p}\right)+\epsilon_{t}^{a}
$$

Figure 6 shows the impulse responses, starting from the efficient steady-state, when the government follows the optimal rule. I contrast the optimal policy with simple rules for vacancies and wage as follows:

$$
\begin{aligned}
\log \left(v_{t}^{g}\right) & =\log \left(\bar{v}^{g}\right)+\psi^{v}\left[\log \left(v_{t}^{p}\right)-\log \left(\bar{v}^{p}\right)\right] \\
\log \left(w_{t+1}^{g}\right) & =\log \left(\bar{w}^{g}\right)+\psi^{w}\left[\log \left(w_{t}^{p}\right)-\log \left(\bar{w}^{p}\right)\right] .
\end{aligned}
$$

Existing evidence by Lane (2003) and Lamo, Pérez, and Schuknecht (2008) suggest that public sector wages are less procyclical than private sector wages, particularly in the United States. $^{9}$ For the sake of simplicity, I consider two cases where the public sector wage is acyclical $\left(\psi^{w}=0\right)$. In the first one, the public sector vacancies decline proportionally to increases in private sector vacancies $\left(\psi^{v}=-1\right)$. In the second, they are acyclical $\left(\psi^{v}=0\right)$.

After the negative productivity shock, private sector firms post fewer vacancies, the probability of finding a job there falls and the unemployed increase their search for public sector jobs. The unemployment rate increases at most by 0.05 percentage points, much less than after fiscal shocks. As pointed out by Shimer (2005), search and matching models are not able to generate enough fluctuations on unemployment in response to technology shocks.

The optimal government policy is to have countercyclical vacancies and procyclical wages. The argument for hiring more people in recessions is one of sector reallocation, different from the traditional demand argument (bringing to mind the famous metaphor of digging holes

\footnotetext{
${ }^{9}$ Additionally, a study by Devereux and Hart (2006) using micro data for the United Kingdom finds that for job movers in the private sector the wages are procyclical but for the public sector they are acyclical.
} 
Figure 6: Response to a private sector technology shock under the optimal policy
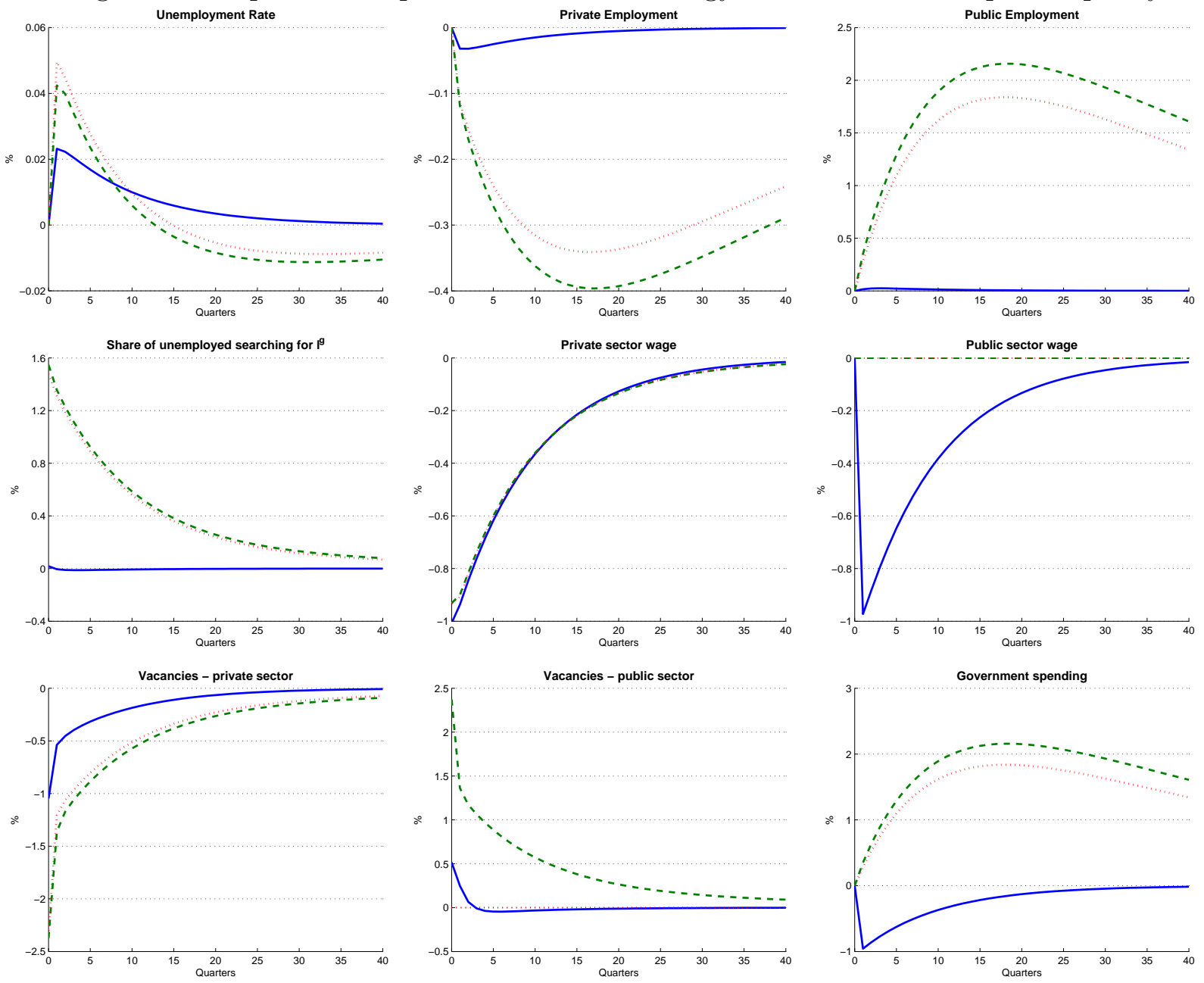

Note: Solid line (optimal policy); dash line (countercyclical vacancies and acyclical wages) and dotted line (acyclical vacancies and wages). The response of the variables is in percentage of their steady-state value, except for the unemployment rate and the share of unemployed searching for public sector jobs, which is in percentage points difference from the steady-state.

and covering them). If the private sector has lower productivity, it is better for the economy to absorb part of the unused labour force into the public sector. If the government jobs were not productive, it would not be optimal to hire anyone in the first place.

On the other hand, the public sector wage should follow the decline of the private sector wage. In recessions, if the government keeps its wage constant, it becomes more attractive relative to the private sector, thus increasing the share of unemployed searching for public sector jobs. This reduces the vacancy-filling probability in the private sector, which further dampens job creation and amplifies the business cycle. We can see that under the two exogenous rules, the response of unemployment is much stronger. There is an increase of 1.6 percentage points of the share of unemployed searching of public sector jobs, much higher 
Table 3: Business cycle properties under the different policies

\begin{tabular}{lcccccc}
\hline \hline Policy & \multicolumn{4}{c}{ Standard deviations } & Correl & Welfare \\
& $l_{t}^{p}$ & $l_{t}^{g}$ & $u_{t}$ & $w_{t}^{p}$ & $\left(l_{t}^{g}, u_{t}\right)$ & cost \\
\hline No government & 0.0007 & - & 0.0007 & 0.024 & - & $0.028 \%$ \\
Optimal policy & 0.0008 & 0.0007 & 0.0006 & 0.024 & 0.97 & $0.023 \%$ \\
Rule $\left(\psi^{w}=0, \psi^{v}=-1\right)$ & 0.0159 & 0.0830 & 0.0014 & 0.023 & 0.18 & $0.101 \%$ \\
Rule $\left(\psi^{w}=0, \psi^{v}=0\right)$ & 0.0132 & 0.0673 & 0.0014 & 0.023 & 0.27 & $0.077 \%$ \\
\hline \hline
\end{tabular}

than under the optimal policy (0.02 percentage points).

Table 3 compares the standard deviation of the key variables under the alternative policies, as well as when there is no public sector. If the government follows the optimal rule, the presence of public sector employment stabilises unemployment. However, if public sector wages are acyclical the volatility of unemployment increases twofold. The effects of the presence of public sector employment on the volatility of unemployment depends crucially on the government's business cycle policy. The last column presents the welfare cost of business cycles under the different scenarios. ${ }^{10}$ When the public sector is absent, the welfare cost of fluctuations is very small - around 0.028 percent of steady-state consumption. This is a well known result. When the public sector is present, under the optimal policy, the welfare cost of fluctuations is lower, but if the government wages do not respond to the cycle, it can be up to four times higher.

In their paper, Quadrini and Trigari (2007) have two conclusions contrary to mine. First, that the best policy to stabilize total employment is to have procyclical public sector employment. Second, that the presence of the public sector increases the volatility of unemployment. In their model, the government does not choose their wage optimally. Instead, it sets a wage premium exogenously, which explains the disparity of the conclusions. As we have seen in the previous section, under a high public sector wage premium, after a hiring shock, the crowding out of the private sector employment can be more than complete, resulting in higher unemployment. This switch alters the policy recommendations for government employment.

\section{$7 \quad$ Extensions $^{11}$}

\subsection{Government services as goods bought from the private sector}

To compare the results with the ones from a typical model of government consumption, I construct an extension where there is no public sector employment $\left(l_{t}^{g}=0\right)$, but where

\footnotetext{
${ }^{10}$ See the companion appendix for details.

${ }^{11}$ All figures can be found in the companion appendix.
} 
the government buys its goods from the private sector $\left(c_{t}+g_{t}=y_{t}\right)$. I am interested in the response to a government consumption shock of 6.6 percent (Figure 7) and the optimal response of government consumption to a negative technology shock.

There are three main differences relative to the benchmark model. Notice first that the effects of a fiscal shock on private sector employment and wages are the opposite from the model with public sector employment. The wages go down because the reduction of private consumption raises its marginal utility, lowering the value of unemployment. Because of the direct stimulus, private employment goes up and unemployment goes down.

The second difference is the magnitude of the response of unemployment. A shock of 6.6 percent in government spending only reduces unemployment by 0.008 percentage points. Both technology and government consumption shocks have a small quantitative effect on unemployment. However, as public sector employment or wage shocks strike directly in the labour market, they have a much stronger effect. Finally, the differences are also visible in the optimal business cycle policy. In recessions, the government should buy fewer goods from the private sector, in order to equate the marginal utility of the two goods.

Figure 7: Response to a government consumption shock
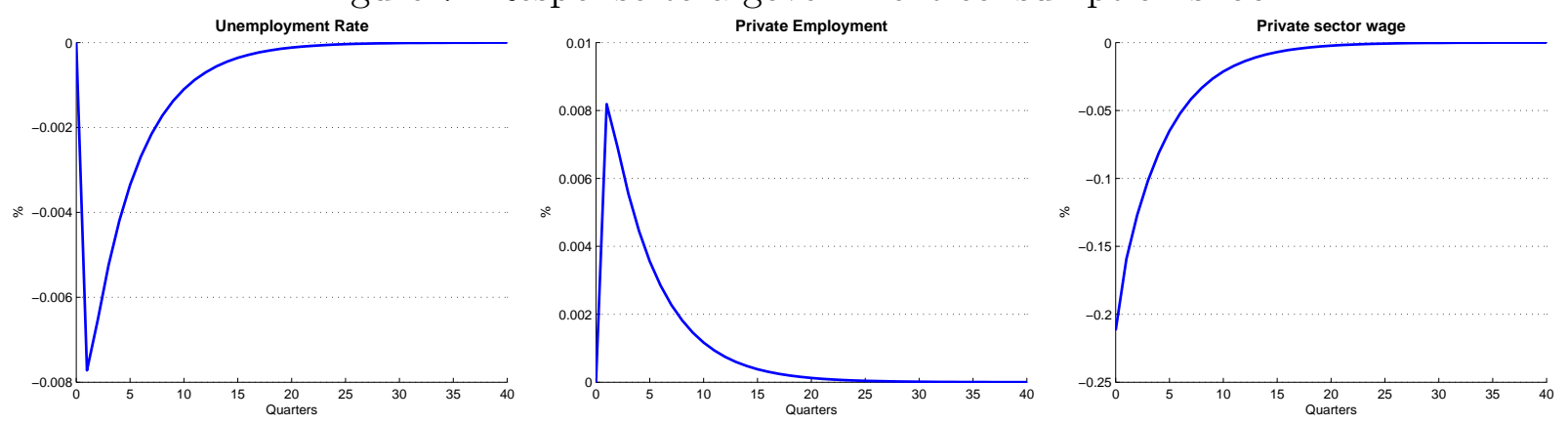

Note: The response of the variables is in percentage of their steady-state value, except for the unemployment rate which is shown as percentage points difference from the steady-state.

\subsection{Productive sector public employment}

A recent paper by Linnemann (2009) finds, in the context of a VAR, that a government employment shock generates a positive response in the private sector employment. I want to see if this can be generated within the model, if we consider that public sector employment affects the productivity of the private sector. I consider that private sector technology follows:

$$
\ln \left(a_{t}^{p}\right)=\ln \left(\bar{a}^{p}\right)+\alpha\left[\ln \left(l_{t}^{g}\right)-\ln \left(\bar{l}^{g}\right)\right]
$$


I look at the responses of unemployment and private sector employment to a separation and vacancies shocks for different values of $\alpha$. For higher levels of $\alpha$, the crowding out effect on private employment is lower and, therefore, it has a larger negative impact on unemployment. However, even with a value as high as 0.4 , the crowding out is still substantial.

\subsection{Different elasticities of substitution between goods}

I have also re-done the exercises for the cases where the goods are substitutes or complements. Regarding employment shocks, the qualitative results do not depend on $\gamma$, and even quantitatively the differences are small. If the goods are complements, the increase in government services raises the marginal utility of the private good, so the negative effect on private sector employment is smaller. If they are substitutes, the household reduces more private consumption, leading to a bigger crowding out of private sector employment.

With respect to the optimal business cycle policy, the result of counter-cyclical vacancies is only overturned if the goods are strong complements. If that is the case, during a recession, as the marginal utility of the government services falls with the consumption of the private good, the government should also decrease its vacancies. However, in all scenarios the public sector wage should follow the decline of the private sector wage.

\subsection{Optimal policy under alternative sources of fluctuations}

When discussing the optimal policy along the business cycle, I assumed it was generated by technology shocks from which the public sector was isolated. Now, I consider two alternative sources of fluctuations: an aggregate technology shock and a shock to the discount factor.

The result of procyclical wages holds for the two shocks, but the result of countercyclical vacancies is reversed. Following an economy-wide technological shock, as the public sector is also less productive, the argument for sector reallocation does not hold and the government should also decrease its vacancies. If people become more impatient, the present discounted value of a vacancy goes down. As it affects both sectors symmetrically, both the private sector and the government should decrease their vacancies and wages. 


\section{How important is the directed search between the public and the private sector?}

The theoretical model has one important policy prescription: government wages should keep track of the private sector wages over the business cycle. If not, the volatility of unemployment is higher because of the fluctuation of the share of unemployed searching for public sector jobs. It is clear that this result is entirely driven by the directed search assumption. The aim of this section is to show that the assumption is realistic. I begin by presenting some evidence from micro-econometric studies.

As mentioned previously, public sector wage premium varies substantially within groups. As reported in Gregory and Borland (1999), the premium is much higher for females, veterans and minorities, and it is higher for federal government employees compared to state or local government employees. There are also differences across education levels. Katz and Krueger (1991) find that in the previous twenty years, more educated individuals tend to be paid less in the public sector, while individuals with less education tend to receive a higher premium. If people can direct their search, these differences should have repercussions.

Gregory and Borland (1999) report a number of studies that have found the existence of queues for federal public jobs. For example, Venti (1985) finds that for each federal government job opening, there are 2.8 men and 6.1 times as many women that want the job. Katz and Krueger (1991) find that blue collar workers are willing to queue to obtain public sector jobs, whereas highly-skilled workers are difficult to recruit and retain in the public sector. A recent study for the United Kingdom by Postel-Vinay and Turon (2007) also finds evidence of job queuing for public sector jobs among low-employability individuals, who face larger potential premia from working there.

Most studies that estimate the public sector wage premium use switching regression models. The idea is that the unemployed can self-select to work in the sectors in which they have more advantages. Blank (1985) finds that, among other factors, sectoral choice is influenced by wage comparison. Heitmueller (2006) manages to quantify this effect and

finds that an increase of 1 percent in the expected wage in the public sector increases the probability of being employed in that sector by 1.3 for men and 2.9 percent for women.

The micro evidence supports the directed search assumption, but it does not imply that, from a macroeconomic perspective, the mechanism plays a role over the business cycle. In this section, I estimate a log-linearized version of the model using Bayesian methods as in Smets and Wouters (2007) and Sala, Söderström, and Trigari (2008). The main purpose is 
to evaluate the mechanism of directed search between the two sectors. Additionally, I can also assess the cyclicality of the public sector wages and vacancies, as well as get estimates for some of the key friction parameters.

\subsection{Estimation preliminaries}

In order to test if the share of unemployed searching for public sector jobs fluctuates over the business cycle, I modify the equation determining it (10). The log-linearised expression is:

$$
\tilde{s}_{t}=\kappa(1-\bar{s}) E_{t}\left(\tilde{x}_{t+1}^{g}-\tilde{x}_{t+1}^{p}-\tilde{m}_{t}^{p}+\tilde{m}_{t}^{g}\right)
$$

where $\tilde{x}_{t}^{i}$ is the log-deviations from steady-state of $W_{t}^{i}-U_{t}^{i}$. From the original expression, I have added the parameter $\kappa$ that measures the significance of the mechanism. If it is close to 0 , the data does not support the assumption. As in the theoretical section, I assume two rules for public sector wages and vacancies. However, I consider that each variable responds to a moving average of the private counterpart:

$$
\begin{gathered}
\ln \left(v_{t}^{g}\right)=\ln \left(\bar{v}^{g}\right)+\psi^{v}\left[\frac{\sum_{i=0}^{3} \ln \left(v_{t-i}^{p}\right)}{4}-\ln \left(\bar{v}^{p}\right)\right]+\ln \left(\omega_{t}^{v}\right), \\
\ln \left(w_{t+1}^{g}\right)=\ln \left(\bar{w}^{g}\right)+\psi^{w}\left[\frac{\sum_{i=0}^{3} \ln \left(w_{t-1}^{p}\right)}{4}-\ln \left(\bar{w}^{p}\right)\right]+\ln \left(\omega_{t}^{w}\right) .
\end{gathered}
$$

Following one of the extensions, I allow the private sector technology to depend partially on the level of public sector employment, though a coefficient $\alpha$, to be estimated.

$$
\ln \left(a_{t}^{p}\right)=\ln \left(\bar{a}^{p}\right)+\alpha\left(\ln \left(l_{t}^{g}\right)-\ln \left(\bar{l}^{g}\right)\right)+\ln \left(\omega_{t}^{a}\right) .
$$

I use US quarterly data from 1948:1 to 2007:1 for 6 variables: unemployment rate, government employment (\% of labour force), government per employee real wage, private sector per hour real wage, aggregate job-separation rate and aggregate job-finding rate. The series of government per employee real wage is calculated by dividing the compensation of government workers from the NIPA tables by the government employment. The monthly job-finding and job-separation rates are taken from Shimer (2007) and are transformed into quarterly, by allowing for multiple transitions between the two states within the quarter. All other variables are taken from the Bureau of Labor Statistics.

I include 6 different shocks: government vacancies, government wages, separation rates in both sectors, bargaining power and private sector technology. The variables enter the 
estimation in demeaned log-differences. ${ }^{12}$

I calibrate the utility function parameter $\zeta$ to be equal to $0.18, \beta$ to 0.99 and I normalise the technology in both sectors to 1 . In each iteration, the steady-state public sector vacancies are set such that, in equilibrium, the employment in the sector is 0.15 while the steady-state public sector wage is set as a premium over the private sector. Instead of establishing the prior over the matching efficiencies, I opt for doing it on the steady-state probability of filling a vacancy $\bar{q}^{i}$.

I assume that the matching elasticities with respect to unemployment, the steady-state bargaining power of the unemployed and the autoregressive coefficients of the shock process have a Beta distribution. I assume that the standard deviations of the shocks have an inverse gamma distribution. All other parameters are assumed to be normally distributed. Given the strong evidence presented in Section 3, the prior mean for the separation rates is 0.06 for the private and 0.03 for the public sector. Also, the prior mean of $\bar{q}^{i}$ is 3.9 for the private (duration of a vacancy of 20 days) and 2.5 for the public sector (30 days). However, as the matching elasticity in the public sector came from a back-of-the-envelope calculation, I start with the prior that the mean and standard deviation are the same across sectors. The prior distribution of $\kappa$ and of the business cycle policy parameters is centered around 0 with a standard deviation of 0.3 .

\subsection{Results}

I estimate the model with Bayesian methods (see An and Schorfheide (2007) for a review). The likelihood function of the model is combined with the prior distribution of the parameters to obtain the posterior distribution. Subsequently, 2,000,000 draws of the posterior are generated with the Metropolis Hastings algorithm, where the step size is chosen such that the acceptance rate is around $1 / 3$. The draws are divided into two chains with different starting values. The first 2,500 draws of each chain are dropped. Given the recent studies alerting for identification problems in DSGE models (Canova and Sala (2009)), I have done estimations with simulated data. Although there are several parameters that are not identified using the data, the main parameters of interest are, namely: $\kappa, \psi^{w}, \psi^{v}, \eta^{p}, \eta^{g}$ and all the parameters of the shock processes.

\footnotetext{
${ }^{12}$ With the exception of the wages, all other variables are stationary. As a robustness check, I have also estimated the model with the stationary variables entering in levels and the wages in demeaned logdifferences. The posterior distributions are quite close between the two versions. The results, as well as all the equations of the model in its log-linearized form and the relation of the observable variables to the model's variables can be found in the companion appendix.
} 
Table 4: Prior and posterior distribution of structural parameters

\begin{tabular}{|c|c|c|c|c|}
\hline \multirow[t]{3}{*}{$\overline{\text { Parameters }}$} & & \multirow{3}{*}{$\begin{array}{l}\text { Prior } \\
\text { distribution }\end{array}$} & \multicolumn{2}{|c|}{ Posterior distribution } \\
\hline & & & \multirow[t]{2}{*}{ Mean } & 5 th- 95 th \\
\hline & & & & Percentil \\
\hline \multicolumn{5}{|l|}{ Structural parameters } \\
\hline Elasticity of substitution (public and private goods) & $\gamma$ & Normal $(0,0.1)$ & 0.014 & $(-0.129,0.146)$ \\
\hline Utility of unemployment & $\chi$ & Normal $(0.5,0.1)$ & 0.352 & $(0.245,0.470)$ \\
\hline Separation rate (private sector) & $\lambda^{p}$ & Normal $(0.06,0.01)$ & 0.016 & $(0.010,0.023)$ \\
\hline Separation rate (public sector) & $\lambda^{g}$ & Normal $(0.03,0.01)$ & 0.015 & $(0.011,0.019)$ \\
\hline Cost of posting vacancy (private sector) & $\varsigma^{p}$ & Normal $(2,0.3)$ & 1.628 & $(1.136,2.121)$ \\
\hline Cost of posting vacancy (public sector) & $\varsigma^{g}$ & Normal $(1.1,0.2)$ & 1.200 & $(0.886,1.512)$ \\
\hline Vacancy filling probability (private sector) & $\bar{q}^{p}$ & Normal $(3.9,0.2)$ & 3.989 & $(3.700,4.300)$ \\
\hline Vacancy filling probability (public sector) & $\bar{q}^{g}$ & Normal $(2.5,0.2)$ & 2.486 & $(2.152,2.796)$ \\
\hline Matching elasticity w.r.t unemployment (private) & $\eta^{p}$ & Beta $(0.5,0.15)$ & 0.647 & $(0.560,0.753)$ \\
\hline Matching elasticity w.r.t unemployment (public) & $\eta^{g}$ & $\operatorname{Beta}(0.5,0.15)$ & 0.159 & $(0.060,0.258)$ \\
\hline Bargaining power & $b$ & $\operatorname{Beta}(0.5,0.10)$ & 0.638 & $(0.537,0.735)$ \\
\hline Public sector wage premium & $\pi$ & Normal $(1.02,0.01)$ & 1.031 & $(1.017,1.043)$ \\
\hline Productivity of public employment & $\alpha$ & Normal $(0,0.1)$ & 0.167 & $(0.082,0.249)$ \\
\hline Business cycle response of public sector wages & $\psi^{w}$ & Normal $(0,0.3)$ & 0.428 & $(0.165,0.685)$ \\
\hline Business cycle response of public sector vacancies & $\psi^{v}$ & Normal $(0,0.3)$ & -0.937 & $(-1.225,-0.656)$ \\
\hline Importance of directed search & $\kappa$ & Normal $(0,0.3)$ & 0.479 & $(0.381,0.579)$ \\
\hline \multicolumn{5}{|l|}{ Autoregressive parameters } \\
\hline Productivity & $\rho^{a}$ & $\operatorname{Beta}(0.5,0.15)$ & 0.987 & $(0.980,0.994)$ \\
\hline Public sector wage & $\rho^{w}$ & Beta $(0.5,0.15)$ & 0.973 & $(0.956,0.990)$ \\
\hline Public sector vacancies & $\rho^{v}$ & Beta $(0.5,0.15)$ & 0.281 & $(0.182,0.383)$ \\
\hline Private sector separation rate & $\rho^{l p}$ & $\operatorname{Beta}(0.5,0.15)$ & 0.952 & $(0.917,0.988)$ \\
\hline Public sector separation rate & $\rho^{l g}$ & Beta $(0.5,0.15)$ & 0.500 & $(0.265,0.768)$ \\
\hline Bargaining power & $\rho^{b}$ & Beta $(0.5,0.15)$ & 0.936 & $(0.892,0.977)$ \\
\hline \multicolumn{5}{|l|}{ Standard deviations } \\
\hline Productivity & $\sigma^{a}$ & $\operatorname{IGamma}(0.01,0.15)$ & 0.008 & $(0.007,0.008)$ \\
\hline Public sector wage & $\sigma^{w}$ & $\operatorname{IGamma}(0.01,0.15)$ & 0.011 & $(0.010,0.012)$ \\
\hline Public sector vacancies & $\sigma^{v}$ & $\operatorname{IGamma}(0.01,0.15)$ & 0.439 & $(0.305,0.554)$ \\
\hline Private sector separation rate & $\sigma^{l p}$ & $\operatorname{IGamma}(0.01,0.15)$ & 0.071 & $(0.064,0.077)$ \\
\hline Public sector separation rate & $\sigma^{l g}$ & $\operatorname{IGamma}(0.01,0.15)$ & 0.011 & $(0.002,0.021)$ \\
\hline Bargaining power & $\sigma^{b}$ & $\operatorname{IGamma}(0.01,0.15)$ & 0.033 & $(0.017,0.056)$ \\
\hline
\end{tabular}

Table 4 reports the prior distribution and the mean, the 5th and the 95th percentile of the posterior distribution of the parameters. The mean of the posterior distribution of $\kappa$ is close 0.5 with a 90 percent interval between 0.4 and 0.6. This suggests that, although $s_{t}$ does not fluctuate as much as the model predicts, the mechanism still has explanatory power. With respect to the policy, there is a strong countercyclical policy in vacancies with an estimated mean close to -0.9 . Public sector wage policy seems slightly procyclical, with the posterior mean of $\psi^{w}$ of around 0.4 .

The elasticity of the matching function with respect to unemployment is much lower in the public sector. The posterior mean for the private sector is around 0.65 , but only 0.16 in the public sector. The steady-state vacancy filling probability in both sectors do not seem to be identified, as well as the cost of posting vacancies in the public sector and the elasticity of 
substitution between the two consumption goods. The posterior mean of the cost of posting vacancies in the private sector is around 1.6. The posterior distributions of both separation rates are very similar, both centered at 0.015 .

The posterior mean of the flow value of unemployment is around 0.35 , while of the bargaining power is around 0.6. The posterior distribution of $\alpha$ is centered around 0.15 . This value suggests that public employment might increase the productivity of the private sector or, alternatively, it might be capturing demand effects that are absent from the model. ${ }^{13}$

\subsection{Model Comparison}

To show how the model with directed search performs, I compare it with two alternative models: one, where there are no fluctuations in the share of unemployed searching in the public sector $(\kappa=0)$ and the other with random search, where the new matches depend only on the relative number of vacancies. ${ }^{14} \mathrm{I}$ compare them from two angles. First, to see how well they explain the variables used in the estimation, I compare the logarithms of the marginal data density, computed using the Mean-Harmonic Estimator. An alternative way to compare the models is to look at the predictions for an unobserved variable. I use the Help-Wanted index as a proxy for private sector vacancies and look at its correlation with the predicted series, as well as compare the volatility of the two series. I also compare the prediction for labour market tightness. The results are shown in Table 5.

The marginal data density is higher for the directed search model. The numbers imply that we would need a prior probability over the directed search model parameters $5.8 * 10^{14}(=$ $\exp (3185-3151))$ times larger than our prior over the random search model in order to reject the fact that the share of unemployed searching for public sector jobs fluctuates in response to shocks. The Random search model does slightly better than the Directed search model in terms of the correlation of predicted vacancies with the actual values, but it does poorly in predicting the volatility of vacancies, as well as the moments of labour market tightness.

\footnotetext{
${ }^{13}$ I have also estimated the model for three subsamples of roughly 20 years: 1948:1 to 1967:3, 1967:4 to 1987:2 and 1987:3 to 2007:1. The results can be found in the companion appendix. The parameter $\kappa$ was important in the first two subperiods (posterior mean close to 0.5), but its importance has diminished during the period of the great moderation. The parameter $\alpha$ was quite high during the first period (posterior mean close to 0.25 ), suggesting that there were strong complementarities in the production function which have disappeared in the last two decades. All other parameters are quite stable.

${ }^{14}$ Details in the companion appendix.
} 
Table 5: Model Comparison

\begin{tabular}{lccccc}
\hline \hline & $\begin{array}{c}\text { Marginal } \\
\text { Data }\end{array}$ & \multicolumn{2}{c}{ Prediction of vacancies } & \multicolumn{2}{c}{ Prediction of tightness } \\
& Density & $\frac{S t d\left(v^{e}\right)}{S t d\left(v^{d}\right)}$ & $\begin{array}{c}\text { Correlation } \\
\left(v^{e}, v^{d}\right)\end{array}$ & $\begin{array}{c}\text { Std }\left(\frac{v}{u}\right)^{e} \\
\text { Std }\left(\frac{v}{u}\right)^{d}\end{array}$ & $\begin{array}{c}\text { Correlation } \\
\left(\left(\frac{v}{u}\right)^{e},\left(\frac{v}{u}\right)^{d}\right)\end{array}$ \\
\hline Directed search & 3185.0 & 0.90 & 0.52 & 0.65 & 0.88 \\
Directed search $(\kappa=0)$ & 3154.0 & 0.90 & 0.49 & 0.67 & 0.88 \\
Random search & 3151.0 & 0.79 & 0.68 & 0.59 & 0.76 \\
\hline \hline
\end{tabular}

Note: $v$ represents private sector vacancies. The superscript e refers to the estimated series and $d$ refers to the data (Help-wanted index).

\section{Conclusion}

This paper examines the links between the public and the private sector through the labour market. I have built a dynamic stochastic general equilibrium model with search and matching frictions to analyse the effects of fiscal shocks, as well as to understand the optimal employment and wage policy.

The main normative conclusion is that the government's wage policy plays a key role in attaining the efficient allocation. In steady-state, the optimal public sector wage premium should reflect differences in the labour market friction parameters. Under the baseline calibration, the optimal wage is 3 percent below the private sector. In reality, all studies point to the existence of a wage premium in the public sector. Although there are other reasons for governments to set higher wages, namely to induce effort or to avoid corruption, they should weight its costs in terms of inefficiency in the labour market.

Over the business cycle, public sector wages should follow the wages in the private sector. Otherwise, in recessions too many people queue for public sector jobs and in expansions few people apply for them. Although I have abstracted from financing issues, a procyclical public sector wage policy has the advantage of requiring a lower tax burden in recessions. However, it also has problems. First, lowering public sector wages in recessions might be politically difficult to implement. Yet, to achieve efficiency in the labour market the only relevant wages are those of the new hires which are potentially easier to reduce in recessions. The second problem related to implementation is that wages in the public sector are usually decided annually. One possible solution is to index the wage growth in the public sector to private sector wage growth. Finally, I have ignored the insurance role of the government. If agents are risk averse, they would prefer to have a constant income profile throughout the business cycle, which is an argument for acyclical wages. While this is a valid line of reasoning, one has to realise that the intertemporal insurance is achieved at the cost of stronger fluctuations in unemployment. 
Additionally, the baseline model suggests that it is optimal to have a leaning-againstthe-wind vacancies policy. While the result of procyclical wages is very robust, the result of counter-cyclical vacancies should be interpreted with caution because it does not hold in a number of settings: if the goods are complements, if the shocks affect both sectors symmetrically or if the steady-state public sector wage is higher than optimum.

The main positive conclusion is that the response of the labour market variables to fiscal shocks depends on the type of shock considered. A reduction of separations lowers unemployment, an increase in wages raises it, while hiring more people can increase or decrease unemployment. All shocks raise the wage and crowd out employment in the private sector. Conversely, when the government buys goods from the private sector, a fiscal shock lowers the wage and increases employment in the private sector. The mixed effects of the different components of government consumption on the labour market might be one reason why many empirical studies on the effects of government spending find ambiguous results.

Many of the model's results rely on the assumption that unemployed can direct their search between the private and the public sector. I believe that this mechanism is playing a significant role during the current recession. A casual look through the newspapers gives the impression that the unemployed are turning to the public sector for jobs, but also that the wages there have not suffered as much as in the private sector. Albeit great praise for their reactions against the economic crises, governments can still do better.

\section{References}

Algan, Y., P. Cahuc, and A. Zylberberg (2002): "Public employment and labour market performance," Economic Policy, 17(34), 7-66.

An, S., And F. Schorfheide (2007): "Bayesian Analysis of DSGE Models," Econometric Reviews, 26(2-4), 113-172.

Ardagna, S. (2007): "Fiscal policy in unionized labor markets," Journal of Economic Dynamics and Control, 31(5), 1498-1534.

BARro, R. J. (1990): "Government Spending in a Simple Model of Endogenous Growth," Journal of Political Economy, 98(5), S103-26.

Baxter, M., And R. G. King (1993): "Fiscal Policy in General Equilibrium," American Economic Review, 83(3), 315-34. 
Blanchard, O., and R. Perotti (2002): "An Empirical Characterization Of The Dynamic Effects Of Changes In Government Spending And Taxes On Output," The Quarterly Journal of Economics, 117(4), 1329-1368.

Blank, R. M. (1985): “An analysis of workers' choice between employment in the public and private sectors," Industrial and Labor Relations Review, 38(2), 211-224.

Boca, A. D., and P. Rota (1998): "How Much Does Hiring and Firing Cost? Survey Evidence from a Sample of Italian Firms," LABOUR, 12(3), 427-449.

Caldara, D., And C. Kamps (2008): "What are the effects of fiscal shocks? A VAR-based comparative analysis," Working Paper Series 877, European Central Bank.

Canova, F., And L. SAla (2009): "Back to square one: Identification issues in DSGE models," Journal of Monetary Economics, 56(4), 431-449.

Cavallo, M. (2005): "Government employment expenditure and the effects of fiscal policy shocks," Working Paper Series 2005-16, Federal Reserve Bank of San Francisco.

CIPD (2009): "Recruitment, retention and turnover survey report," Available at http://www.cipd.co.uk/subjects/recruitmen/general/.

Davis, S. J., R. J. Faberman, and J. C. Haltiwanger (2009): "The establishmentlevel behavior of vacancies and hiring," Discussion paper.

Devereux, P. J., And R. A. Hart (2006): "Real wage cyclicality of job stayers, withincompany job movers, and between-company job movers," Industrial and Labor Relations Review, 60(1), 105-119.

Edelberg, W., M. Eichenbaum, and J. D. Fisher (1999): "Understanding the Effects of a Shock to Government Purchases," Review of Economic Dynamics, 2(1), 166-206.

Evans, P., and G. Karras (1998): "Liquidity Constraints and the Substitutability between Private and Government Consumption: The Role of Military and Non-military Spending," Economic Inquiry, 36(2), 203-14.

Fatás, A., And I. Mihov (2001): "The Effects of Fiscal Policy on Consumption and Employment: Theory and Evidence," CEPR Discussion Papers 2760.

Finn, M. G. (1998): "Cyclical Effects of Government's Employment and Goods Purchases," International Economic Review, 39(3), 635-57. 
Fiorito, R., and T. Kollintzas (2004): "Public goods, merit goods, and the relation between private and government consumption," European Economic Review, 48(6), 13671398.

Galí, J., J. D. López-Salido, and J. VAllés (2007): "Understanding the Effects of Government Spending on Consumption," Journal of the European Economic Association, $5(1), 227-270$.

Gomes, P. (2009): "Labour market flows: facts from the United Kingdom," Bank of England working papers 367.

Gregory, R. G., and J. Borland (1999): "Recent developments in public sector labor markets," in Handbook of Labor Economics, ed. by O. Ashenfelter, and D. Card, vol. 3, chap. 53, pp. 3573-3630. Elsevier.

Heitmueller, A. (2006): "Public-private sector pay differentials in a devolved Scotland," Journal of Applied Economics, IX, 295-323.

Holmlund, B., And J. Linden (1993): "Job matching, temporary public employment, and equilibrium unemployment," Journal of Public Economics, 51(3), 329-343.

Hörner, J., L. R. NGai, And C. Olivetti (2007): "Public Enterprises And Labor Market Performance," International Economic Review, 48(2), 363-384.

Katz, L. F., And A. B. Krueger (1991): "Changes in the Structure of Wages in the Public and Private Sectors," NBER Working Papers 3667.

Lamo, A., J. J. PÉrez, And L. Schuknecht (2008): "Public and private sector wages co-movement and causality," Working Paper Series 963, European Central Bank.

LAne, P. R. (2003): "The cyclical behaviour of fiscal policy: evidence from the OECD," Journal of Public Economics, 87(12), 2661-2675.

Linnemann, L. (2009): "Macroeconomic effects of shocks to public employment," Journal of Macroeconomics, 31(2), 252-267.

Linnemann, L., And A. Schabert (2003): "Fiscal Policy in the New Neoclassical Synthesis," Journal of Money, Credit and Banking, 35(6), 911-29.

Merz, M. (1995): "Search in the labor market and the real business cycle," Journal of Monetary Economics, 36(2), 269-300. 
Mountford, A., And H. Uhlig (2008): "What are the Effects of Fiscal Policy Shocks?," NBER Working Papers 14551.

National Audit Office (2009): "Recruiting Civil Servants efficiently," Available at http://www.nao.org.uk/publications/0809/recruiting_civil_servants_effi.aspx.

PAPPA, E. (2009): "The Effects Of Fiscal Shocks On Employment And The Real Wage," International Economic Review, 50(1), 217-244.

Petrongolo, B., and C. A. Pissarides (2001): "Looking into the Black Box: A Survey of the Matching Function," Journal of Economic Literature, 39(2), 390-431.

Pissarides, C. A. (2000): Equilibrium unemployment. MIT press, 2nd edn.

Postel-Vinay, F., and H. Turon (2007): "The Public Pay Gap in Britain: Small Differences That (Don't?) Matter," Economic Journal, 117(523), 1460-1503.

Quadrini, V., and A. Trigari (2007): "Public Employment and the Business Cycle," Scandinavian Journal of Economics, 109(4), 723-742.

Ramey, V. A. (2009): "Identifying Government Spending Shocks: It's All in the Timing," NBER Working Papers 15464.

Ramey, V. A., And M. D. Shapiro (1998): "Costly capital reallocation and the effects of government spending," Carnegie-Rochester Conference Series on Public Policy, 48(1), $145-194$.

Rotemberg, J. J., and M. Woodford (1992): "Oligopolistic Pricing and the Effects of Aggregate Demand on Economic Activity," Journal of Political Economy, 100(6), 11531207.

Russo, G., W. H. J. Hassink, and C. Gorter (2005): "Filling vacancies: an empirical analysis of the cost and benefit of search in the labour market," Applied Economics, 37(14), $1597-1606$.

Sala, L., U. Söderström, and A. Trigari (2008): "Monetary policy under uncertainty in an estimated model with labor market frictions," Journal of Monetary Economics, 55(5), 983-1006.

Shimer, R. (2005): "The Cyclical Behavior of Equilibrium Unemployment and Vacancies," American Economic Review, 95(1), 25-49. 
(2007): "Reassessing the ins and outs of unemployment," NBER Working Papers 13421.

Smets, F., And R. Wouters (2007): "Shocks and Frictions in US Business Cycles: A Bayesian DSGE Approach," American Economic Review, 97(3), 586-606.

Venti, S. F. (1985): "Wages in the Federal and Private Sectors," NBER Working Papers 1641. 


\section{Appendix I - Data}

Table A1: Data - CIPD

\begin{tabular}{|c|c|c|c|c|c|}
\hline & $\begin{array}{l}\text { All } \\
\text { sectors }\end{array}$ & $\begin{array}{l}\text { Manufacturing } \\
\text { and production }\end{array}$ & $\begin{array}{l}\text { Private sec- } \\
\text { tor services }\end{array}$ & $\begin{array}{l}\text { Public } \\
\text { services }\end{array}$ & $\begin{array}{l}\text { Voluntary and } \\
\text { not-for-profit }\end{array}$ \\
\hline \multicolumn{6}{|l|}{ Cost of recruiting $(£)$} \\
\hline Senior managers & 15123 & 13396 & 18964 & 10452 & 8534 \\
\hline Managers and professionals & 9738 & 8050 & 12393 & 6067 & 6471 \\
\hline $\begin{array}{l}\text { Administrative, secretarial } \\
\text { and technical }\end{array}$ & 4519 & 3680 & 5628 & 1935 & 4976 \\
\hline $\begin{array}{l}\text { Services (costumer, per- } \\
\text { sonal and sales) }\end{array}$ & 8996 & 4565 & 13980 & 2327 & 1399 \\
\hline Manual, craft workers & 2381 & 2498 & 2978 & 1898 & 1379 \\
\hline \multicolumn{6}{|c|}{ Time to fill a vacancy (weeks) } \\
\hline Senior managers & 17.1 & 16.8 & 16.5 & 18 & 16.6 \\
\hline Managers and professionals & 12.5 & 12.1 & 11.8 & 14.3 & 11.8 \\
\hline $\begin{array}{l}\text { Administrative, secretarial } \\
\text { and technical }\end{array}$ & 6.5 & 6.0 & 7.1 & 9.1 & 7.1 \\
\hline $\begin{array}{l}\text { Services (costumer, per- } \\
\text { sonal and sales) }\end{array}$ & 7.0 & 6.7 & 5.6 & 9.9 & 7.4 \\
\hline Manual, craft workers & 5.9 & 5.2 & 4.5 & 8.3 & 6.3 \\
\hline
\end{tabular}

Table A2: Data - definition and sources

\begin{tabular}{|c|c|c|c|}
\hline & Variable & Definition and source & Availability \\
\hline$l_{t}^{g}$ & $\begin{array}{l}\text { Government employ- } \\
\text { ment }\end{array}$ & All Employees: Government (BLS) & $1939 \mathrm{q} 1-2008 \mathrm{q} 3$ \\
\hline$w_{t}^{g}$ & $\begin{array}{l}\text { Government per em- } \\
\text { ployee real wage }\end{array}$ & $\begin{array}{l}\text { Government consumption expenditures: Com- } \\
\text { pensation of general government employees / gov- } \\
\text { ernment employees, deflated by CPI (BEA-NIPA } \\
\text { Tables and own calculation) }\end{array}$ & $1947 \mathrm{q} 1-2008 \mathrm{q} 2$ \\
\hline$w_{t}^{p}$ & $\begin{array}{l}\text { Business sector } \\
\text { hourly real wage }\end{array}$ & Business Sector: Compensation Per Hour (BLS) & $1947 q$ \\
\hline$u_{t}$ & Unemployment rate & Civilian Unemployment Rate (BLS) & $1948 q 1-2008 q 3$ \\
\hline$v_{t}^{p}$ & Vacancies & $\begin{array}{l}\text { Index of Help Wanted Advertising in Newspapers } \\
\text { (The Conference Board) }\end{array}$ & $1951 \mathrm{q} 1-2006 \mathrm{q} 2$ \\
\hline$\Lambda_{t}$ & Separation rate & $\begin{array}{l}\text { Job-separation rate (Shimer, own calculation for } \\
\text { quarterly aggregation) }\end{array}$ & 1948q1-2007q1 \\
\hline$f_{t}$ & Job-finding rate & $\begin{array}{l}\text { Job-finding rate (Shimer, own calculation for } \\
\text { quarterly aggregation) }\end{array}$ & 1948q1- 2007q1 \\
\hline
\end{tabular}


Figure A1: Looking at the data
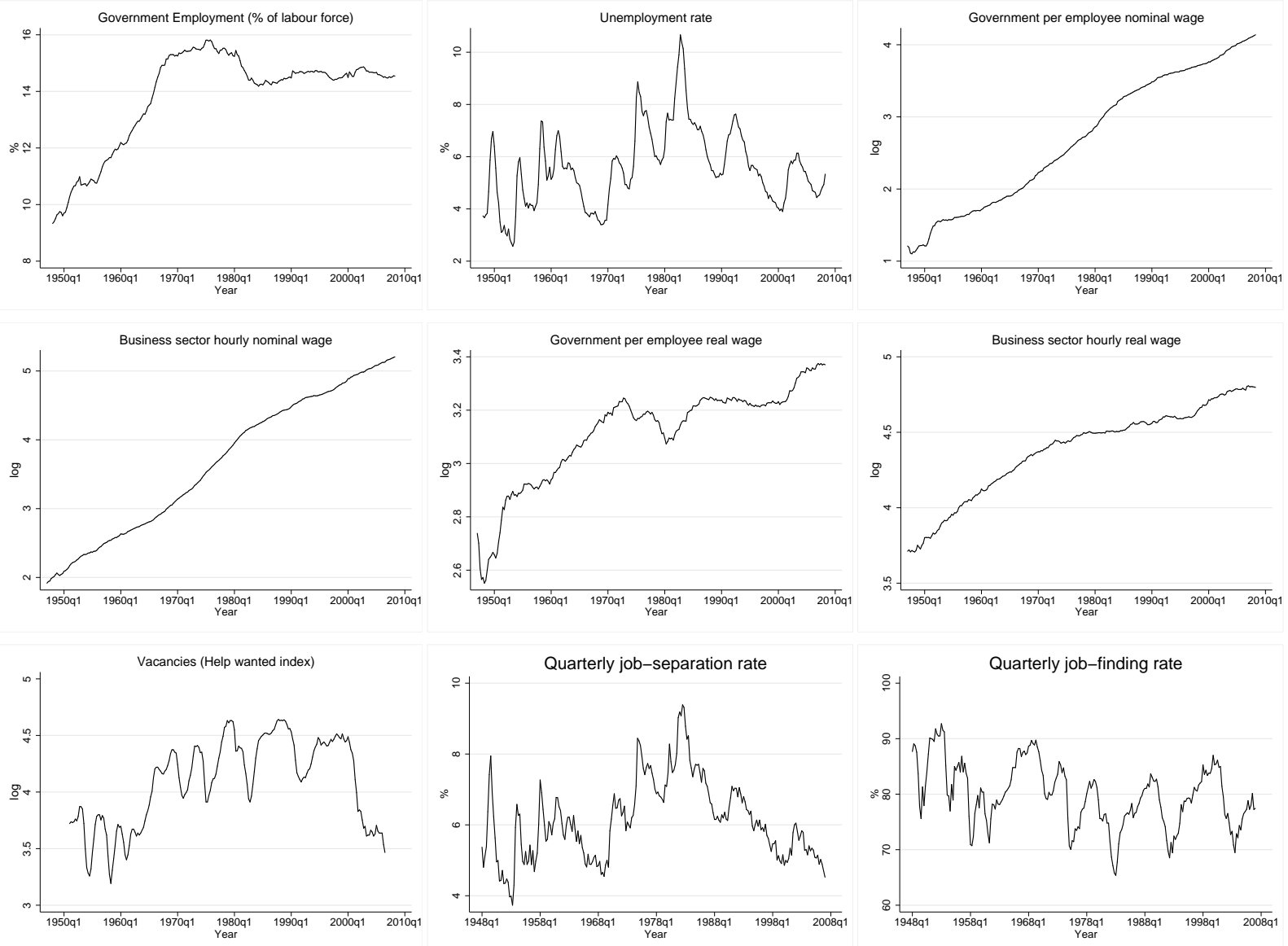

Figure A2: Growth rate of Google keyword searches in the United Kingdom

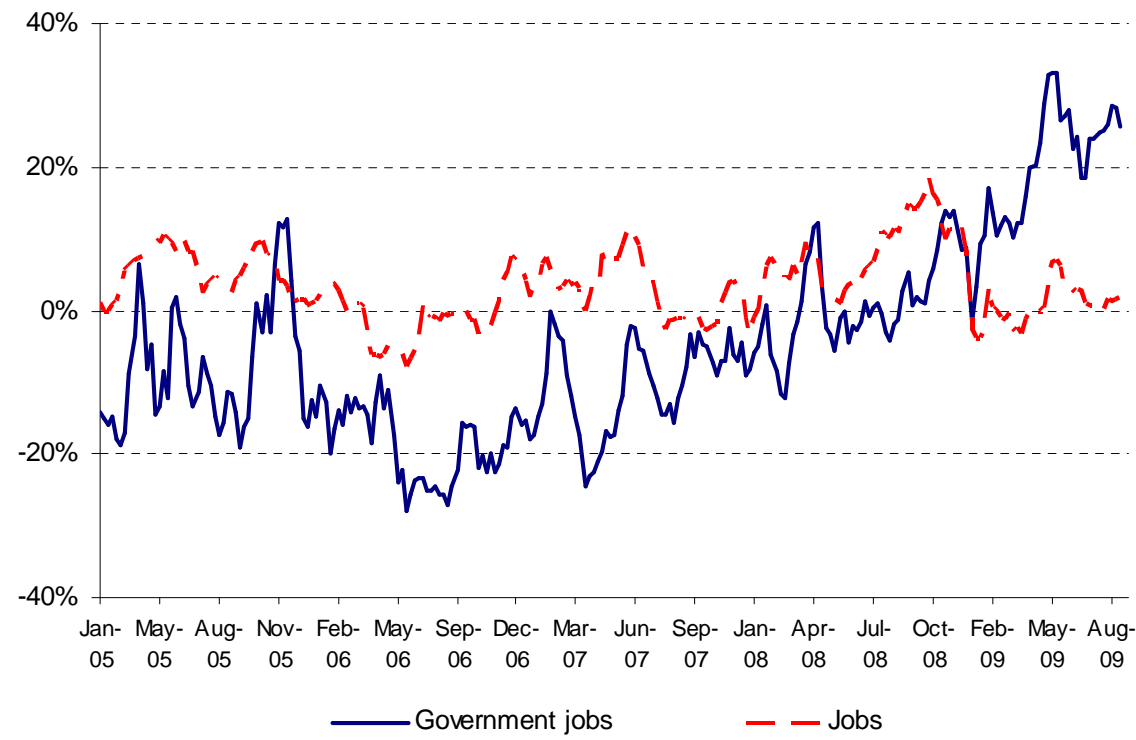

Note: The growth rate of the four-weeks average index of keyword searches, relative the same four weeks in the previous year. 


\section{Appendix II - Steady-state optimal wages, search and unemploy- ment}

Figures A3, A4 and A5 show the optimal steady-state wages in both sectors, the share of unemployed searching in the public sector and the unemployment rate as a function of the labour market friction parameters in the public sector, as well as the technology and utility function parameters.

Figure A3: Optimal steady-state public and private sector wages
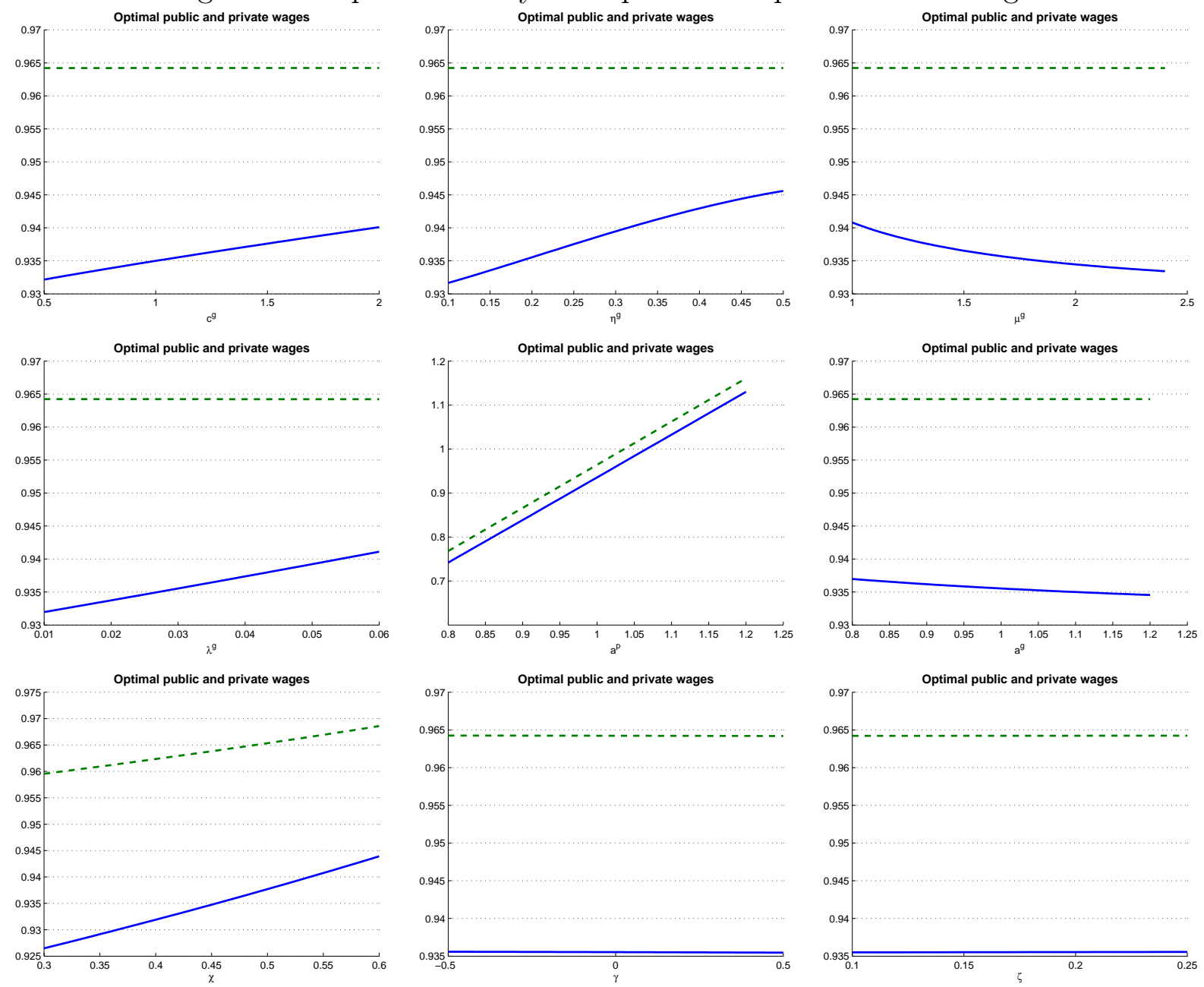

Note: The solid line is the optimal public sector wage and the dash line is the optimal private sector wages. 
Figure A4: Optimal steady-state share of unemployed searching in the public sector
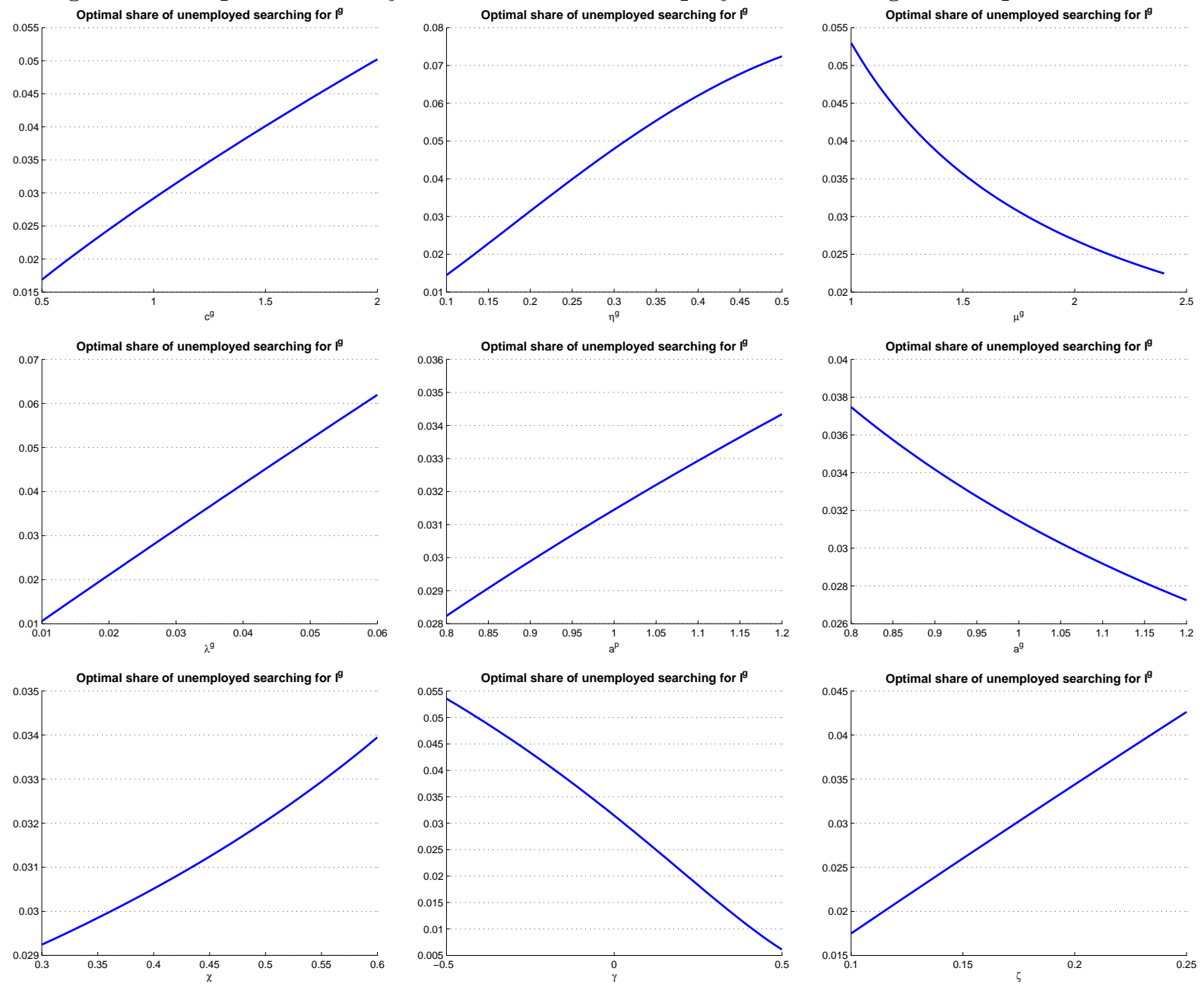
Figure A5: Optimal steady-state unemployment rate
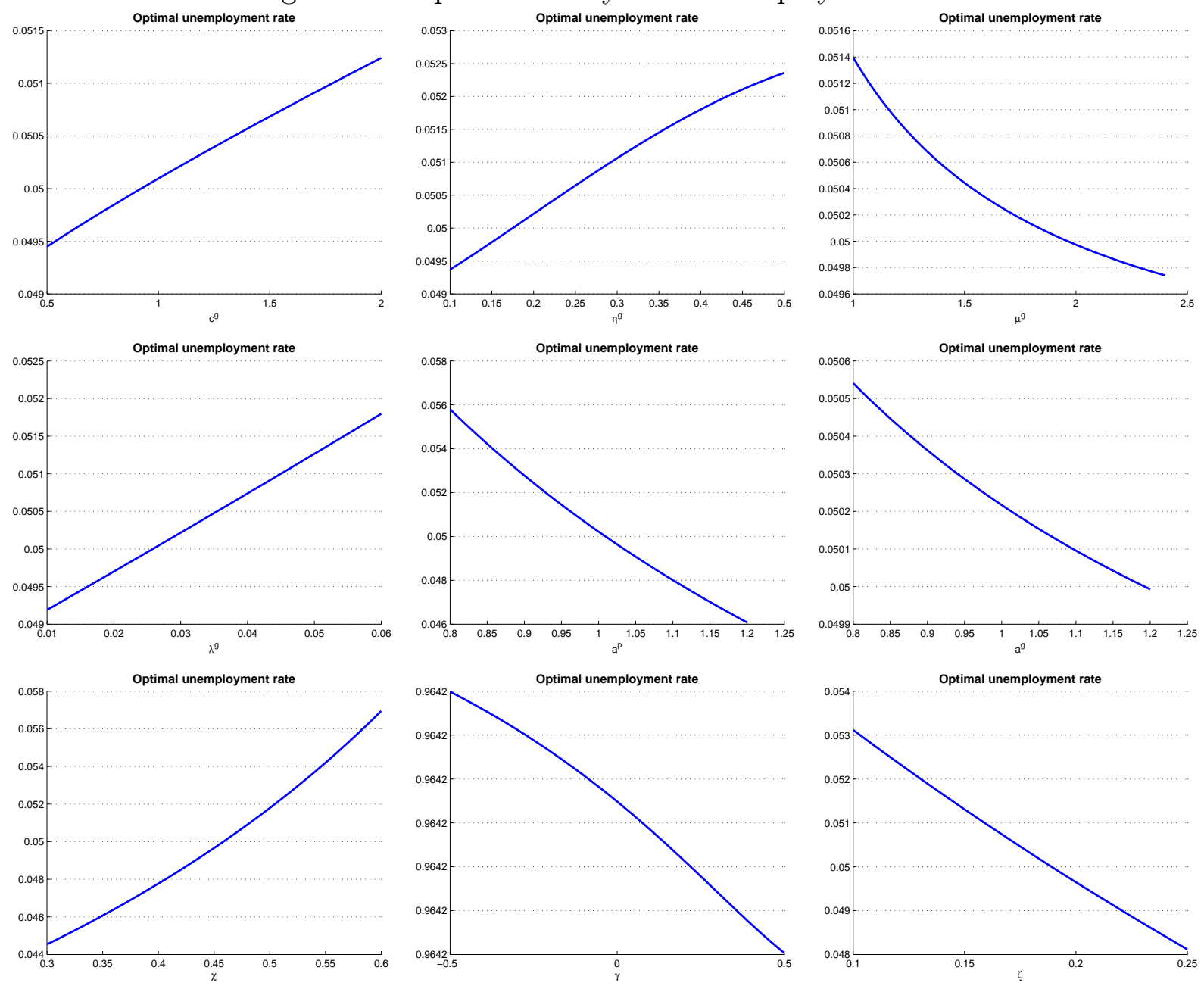


\section{Appendix III - Extensions}

\section{GOV. SERVICES AS GOODS BOUGHT FROM THE PRIVATE SECTOR}

Figure A6: Optimal policy with government consumption
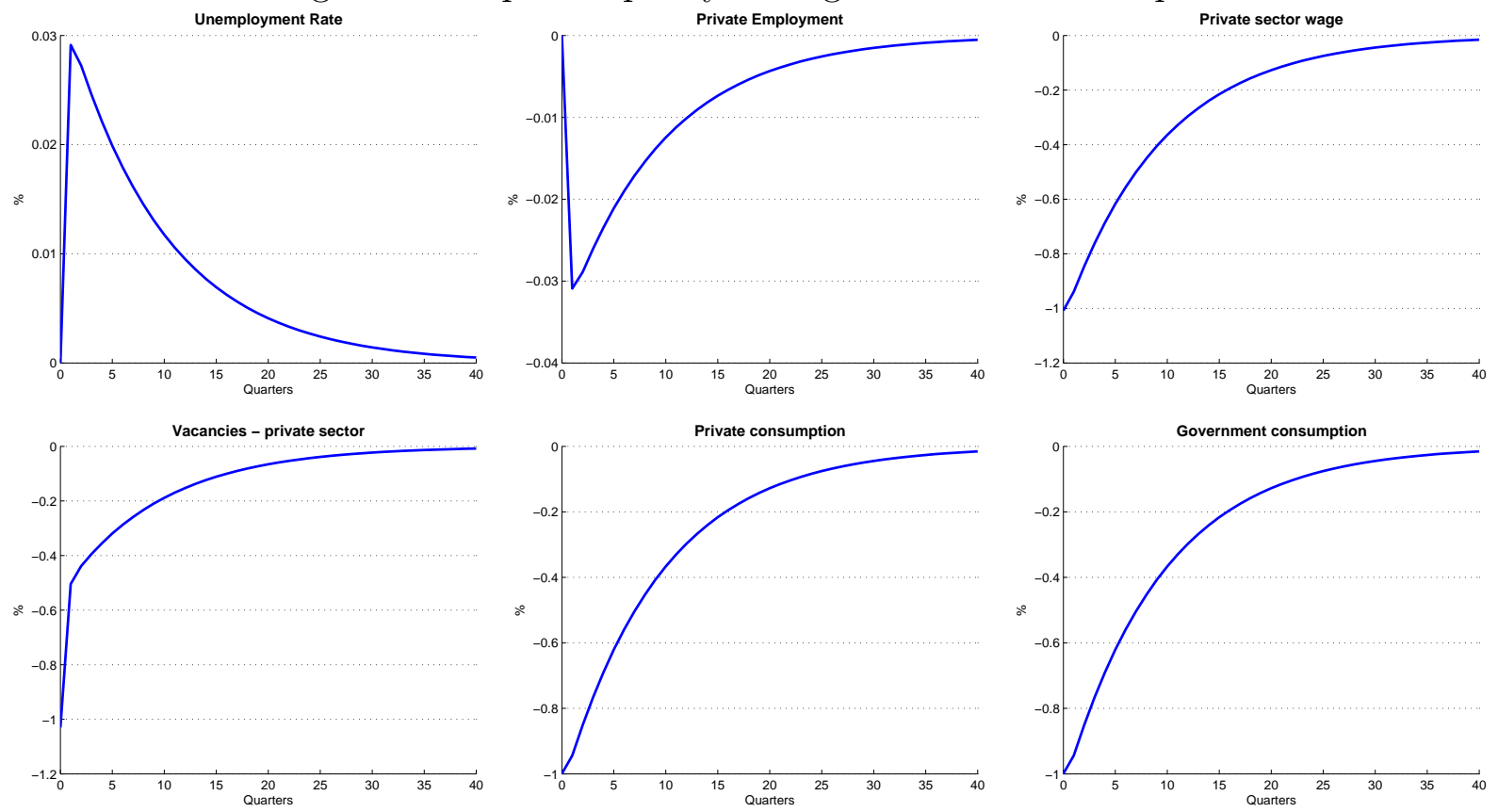

Note: The response of the variables is in percentage of their steady-state value, except for unemployment rate which is in percentage points difference from steady-state. 


\section{PRODUCTIVE SECTOR PUBLIC EMPLOYMENT}

Figure A7: Response to a public employment shock

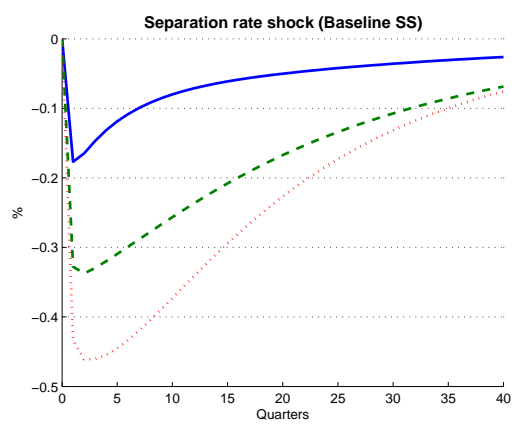

Unemployment rate
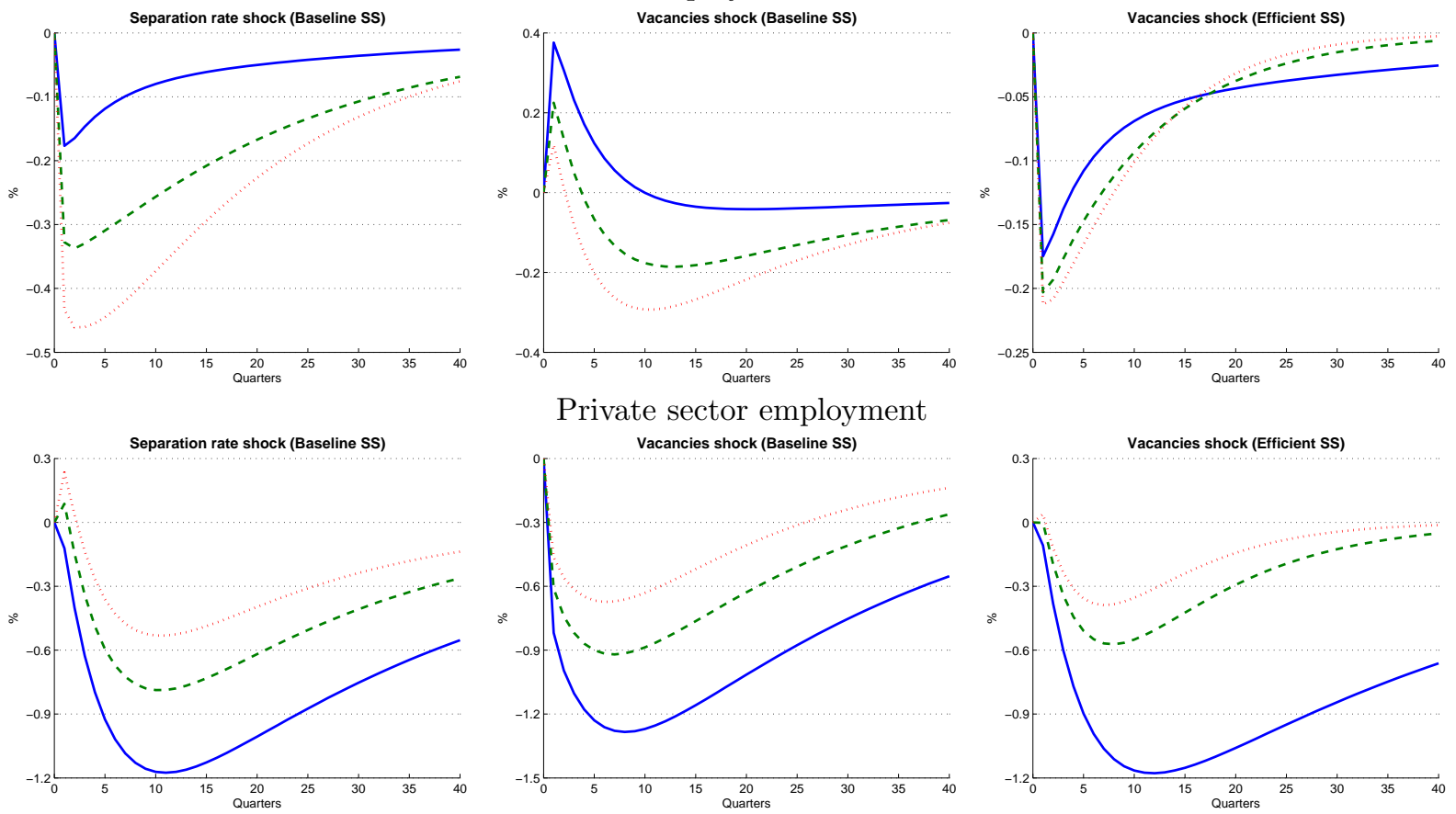

Private sector employment
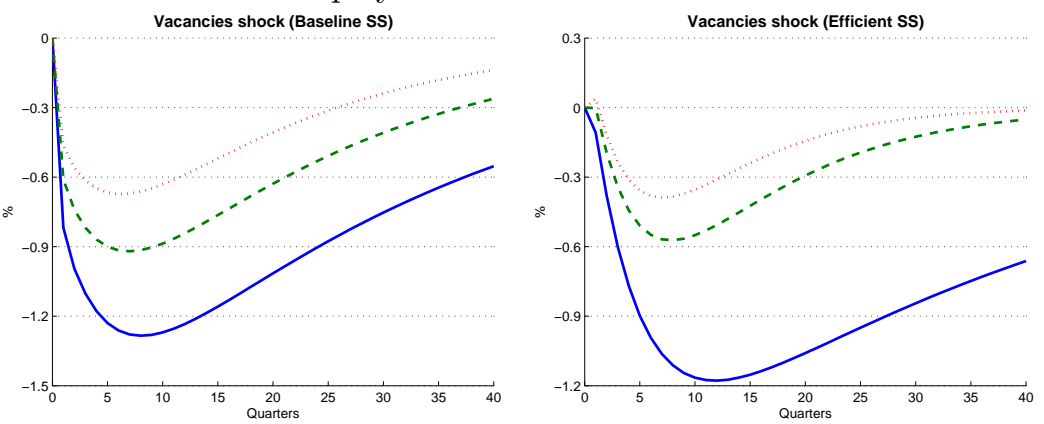

Note: Solid line $(\alpha=0.0)$; dash line $(\alpha=0.2)$ and dotted line $(\alpha=0.4)$. The response of the private employment is in percentage of its steady-state value and unemployment rate in percentage points difference from steady-state. 


\section{DIFFERENT ELASTICITIES OF SUBSTITUTION BETWEEN GOODS}

As it is hard to select one value for $\gamma$, I distinguish three cases: if the goods are substitutes $(\gamma=0.5)$, complements $(\gamma=-0.5)$ and one where the elasticity of substitution of $1(\gamma=0.0)$. Figures A8, A9 and A10 show the impulse responses to the different fiscal shocks, for different levels of $\gamma$.

Figure A8: Response to a public sector wage shock (Baseline steady-state)
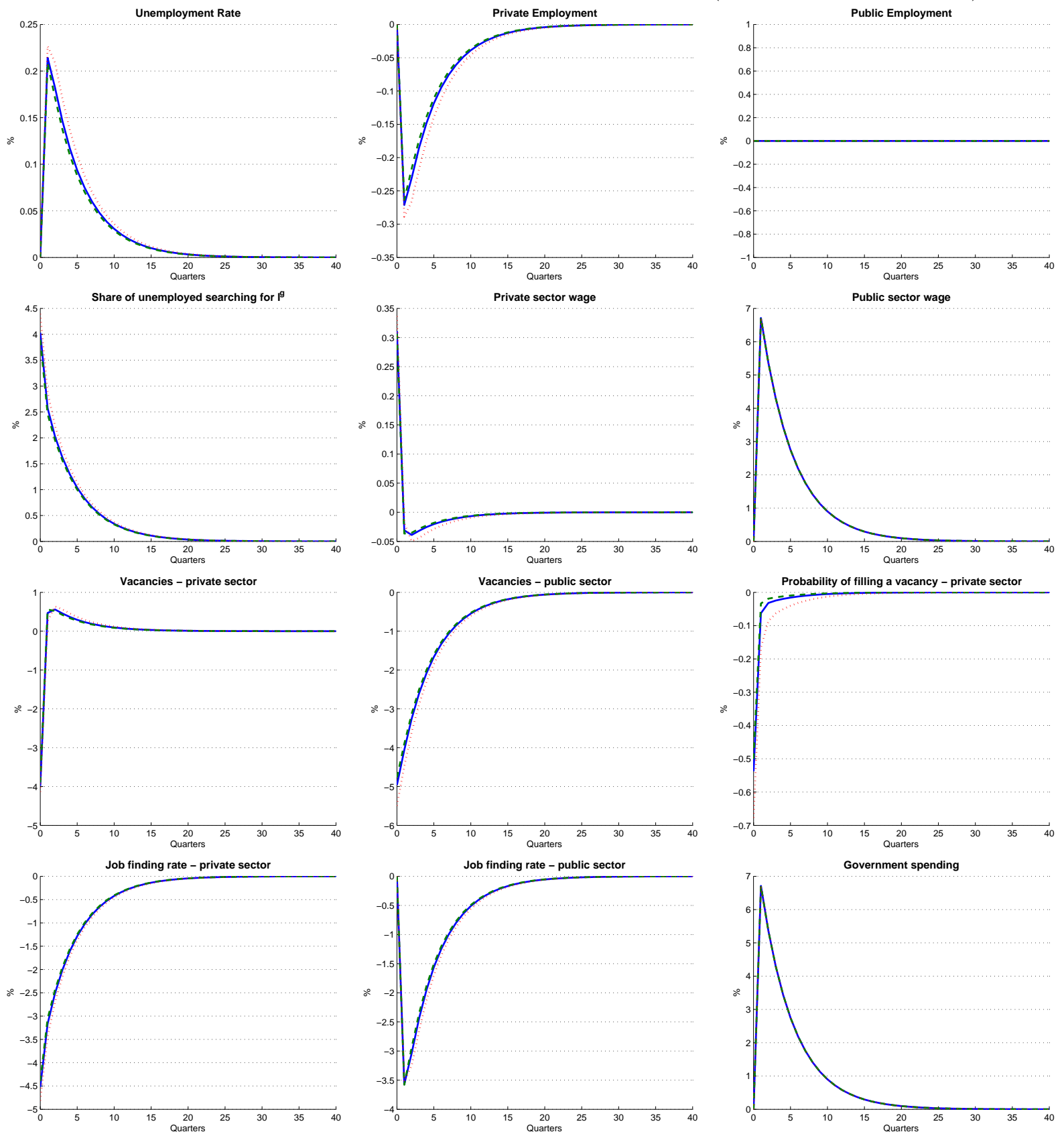

Note: Solid line $(\gamma=0.0)$; dash line $(\gamma=0.5)$ and dotted line $(\gamma=-0.5)$. The response of the variables is in percentage of their steady-state value, except for the unemployment rate and the share of unemployed searching for public sector jobs, which is in percentage points difference from the steady-state. 
Figure A9: Response to a public sector vacancies shock (Baseline steady-state)
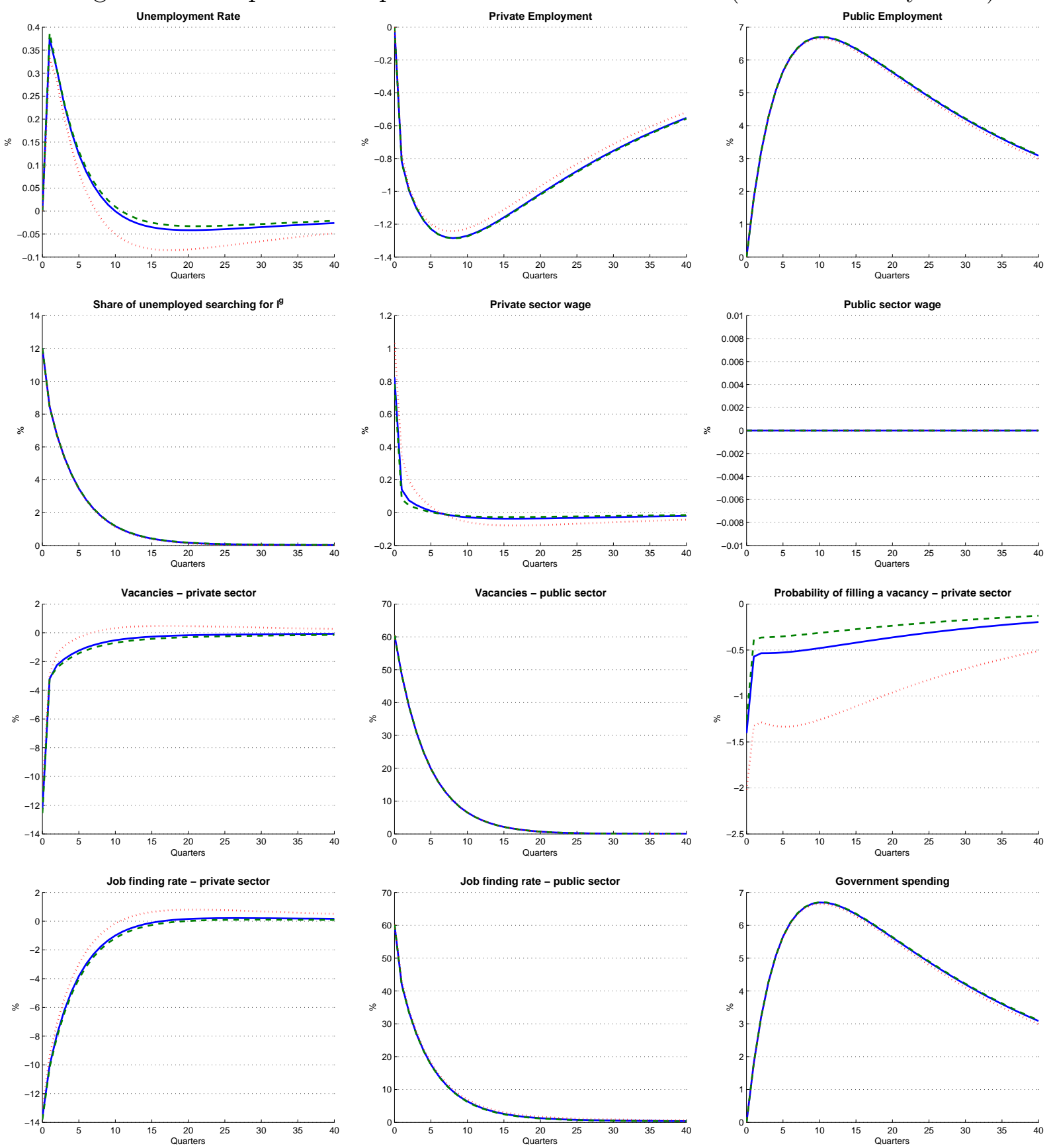

Note: Solid line $(\gamma=0.0)$; dash line $(\gamma=0.5)$ and dotted line $(\gamma=-0.5)$. The response of the variables is in percentage of their steady-state value, except for the unemployment rate and the share of unemployed searching for public sector jobs, which is in percentage points difference from the steady-state. 
Figure A10: Response to a public sector separation shock (Baseline steady-state)
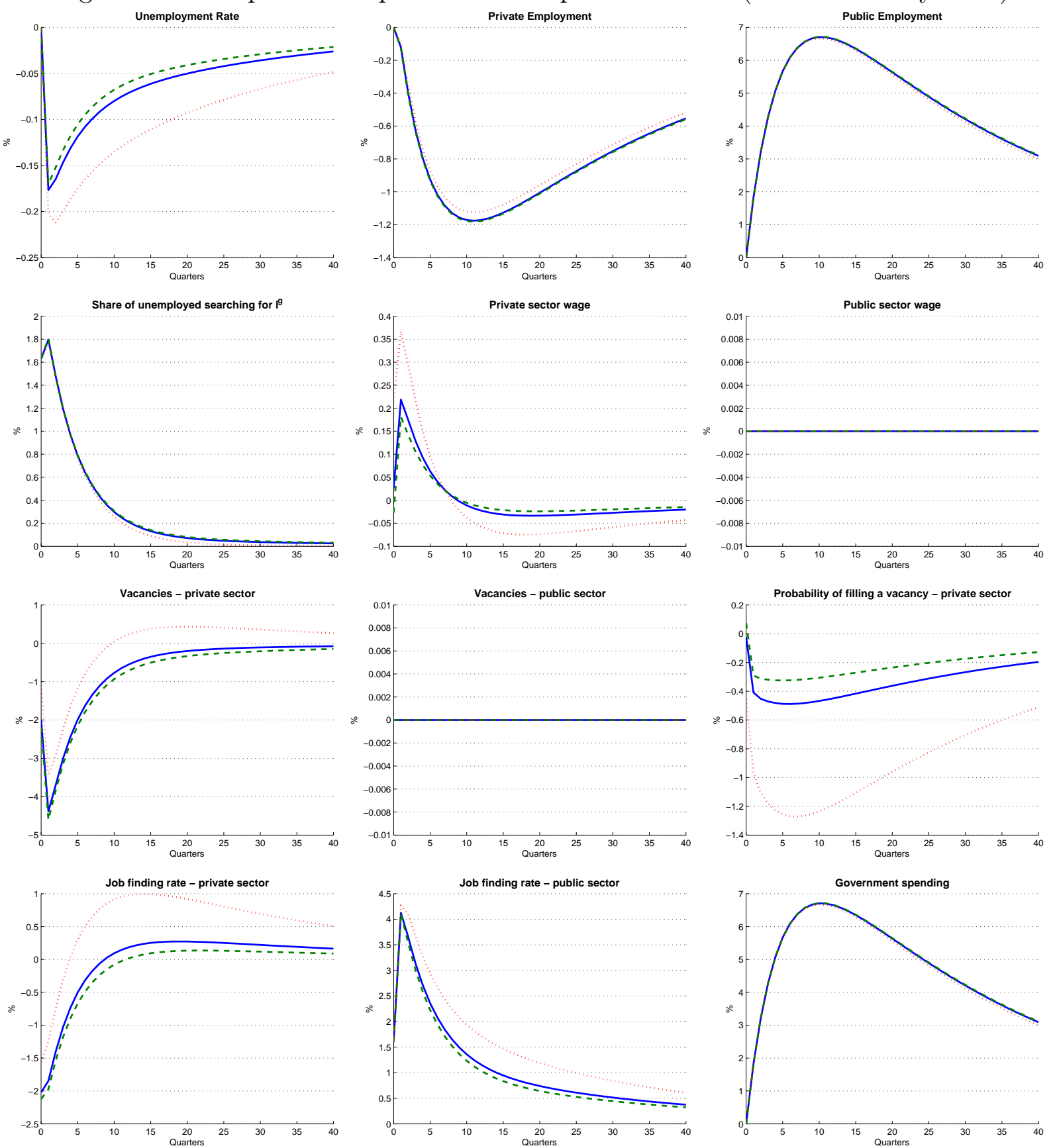

Note: Solid line $(\gamma=0.0)$; dash line $(\gamma=0.5)$ and dotted line $(\gamma=-0.5)$. The response of the variables is in percentage of their steady-state value, except for the unemployment rate and the share of unemployed searching for public sector jobs, which is in percentage points difference from the steady-state. 
Finally, Figure A11 shows the optimal business cycle policy for different elasticities. As we see the result of countercyclical vacancies does not hold if the private and public consumption good are complements.

Figure A11: Optimal business cycle policy under different elasticities
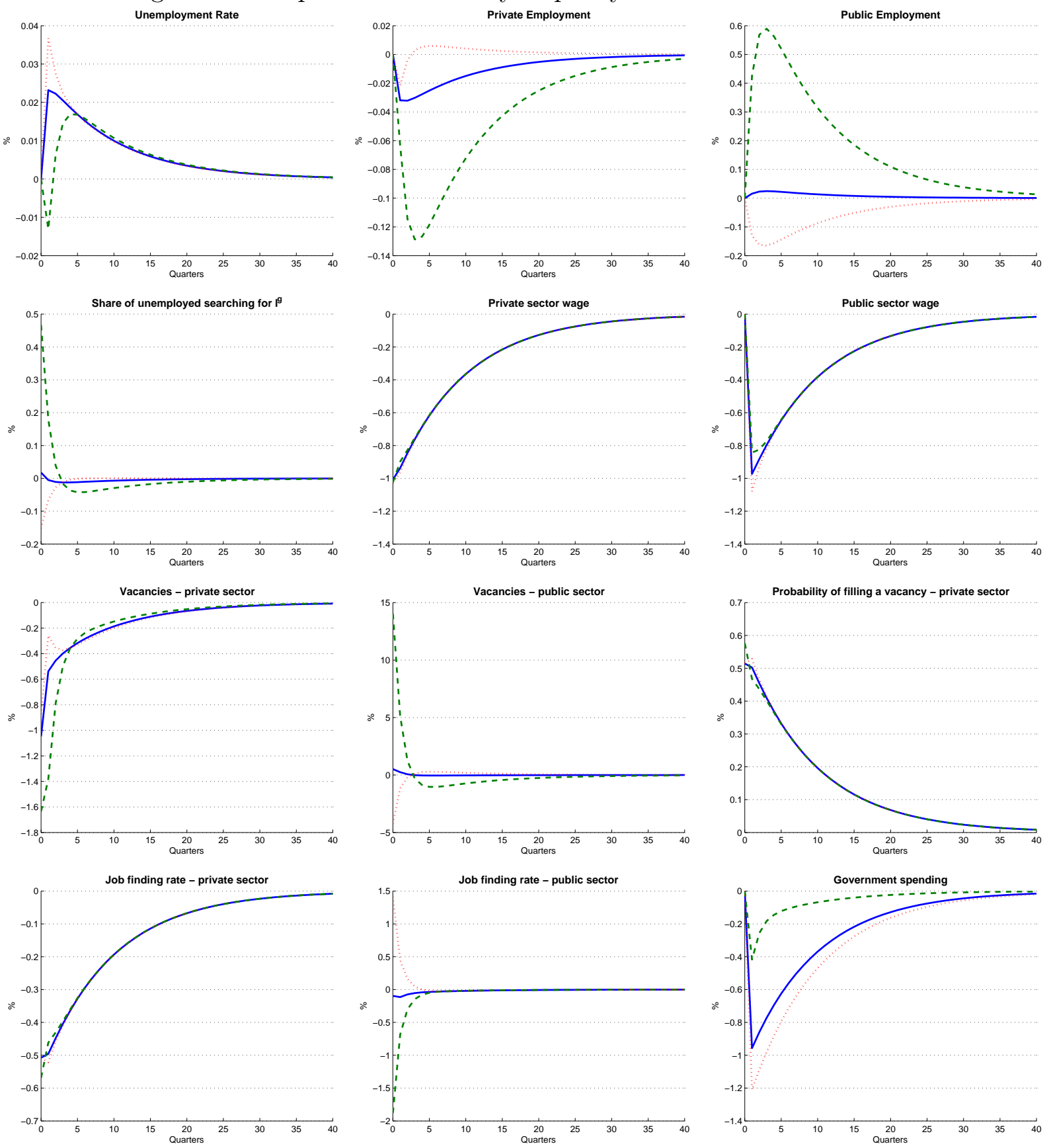

Note: Solid line $(\gamma=0.0)$; dash line $(\gamma=0.5)$ and dotted line $(\gamma=-0.5)$. The response of the variables is in percentage of their steady-state value, except for the unemployment rate and the share of unemployed searching for public sector jobs, which is in percentage points difference from the steady-state. 


\section{OPTIMAL POLICY UNDER ALTERNATIVE SOURCES OF FLUCTUATIONS}

Figure A12: Optimal policy under an economy-wide technology shock
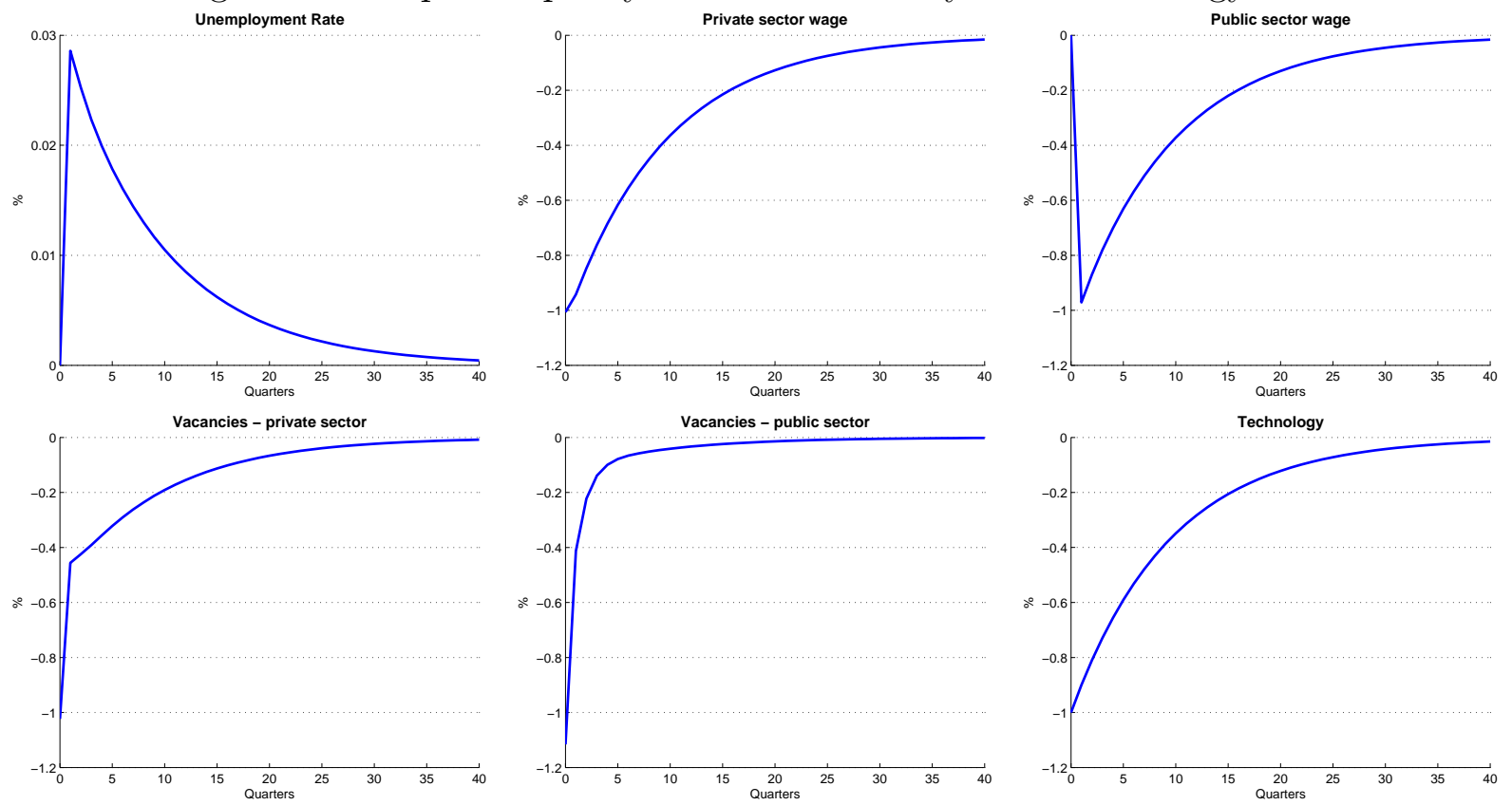

Note: The response of the variables is in percentage of their steady-state value, except for unemployment rate which is in percentage points difference from steady-state.

Figure A13: Optimal policy under a discount factor shock
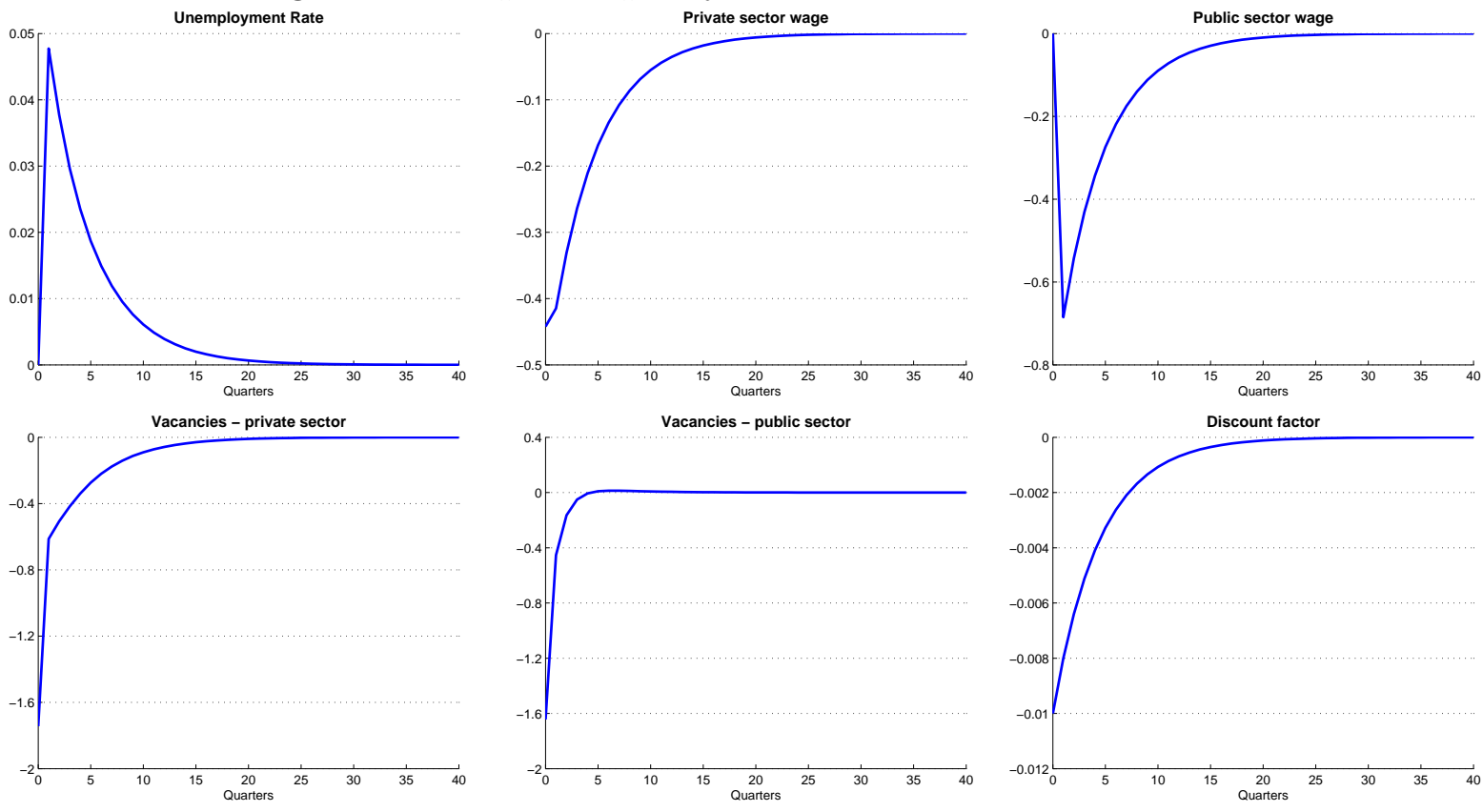

Note: The response of the variables is in percentage of their steady-state value, except for unemployment rate which is in percentage points difference from steady-state. 


\section{Appendix IV - Derivations}

\section{SOCIAL PLANNER'S PROBLEM}

The social planner maximises the consumer's utility (4) subject to the technology constraints (16) and (11) and the labour market frictions (1)-(3). Setting up the Lagrangian:

$$
\begin{aligned}
& \sum_{k=0}^{\infty} \beta^{t+k}\left\{u\left(a_{t+k}^{p} l_{t+k}^{p}-\varsigma^{p} v_{t+k}^{p}, a_{t+k}^{g} l_{t+k}^{g}-\varsigma^{g} v_{t+k}^{g}\right)+\nu\left(1-l_{t+k}^{p}-l_{t+k}^{g}\right)\right. \\
& -\Omega_{t+k}^{1}\left[l_{t+k+1}^{p}-\left(1-\lambda^{p}\right) l_{t+k}^{p}-\mu^{p}\left(\left(1-s_{t+k}\right)\left(1-l_{t+k}^{p}-l_{t+k}^{g}\right)\right)^{\eta^{p}}\left(v_{t+k}^{p}\right)^{1-\eta^{p}}\right] \\
& -\Omega_{t+k}^{2}\left[l_{t+k+1}^{g}-\left(1-\lambda^{g}\right) l_{t+k}^{g}-\mu^{g}\left(s_{t+k}\left(1-l_{t+k}^{p}-l_{t+k}^{g}\right)\right)^{\left.\left.\eta^{g}\left(v_{t+k}^{g}\right)^{1-\eta^{g}}\right]\right\} .}\right.
\end{aligned}
$$

The first order conditions are given by:

$$
\begin{aligned}
& v_{t}^{c} \quad: \quad u_{c}\left(c_{t}, g_{t}\right) \varsigma^{p}=\Omega_{t}^{1}\left(1-\eta^{p}\right) q_{t}^{p} \\
& v_{t}^{g} \quad: \quad u_{g}\left(c_{t}, g_{t}\right) \varsigma^{g}=\Omega_{t}^{2}\left(1-\eta^{g}\right) q_{t}^{g} \\
& s_{t}: \frac{\Omega_{t}^{2} \eta^{g} m_{t}^{g}}{s_{t}}=\frac{\Omega_{t}^{1} \eta^{p} m_{t}^{p}}{1-s_{t}} \\
& l_{t+1}^{p}: \Omega_{t}^{1}=\beta\left\{a_{t+1}^{p} u_{c}\left(c_{t+1}, g_{t+1}\right)-\nu_{u}\left(u_{t+1}\right)+\Omega_{t+1}^{1}\left(1-\lambda^{p}\right)-\Omega_{t+1}^{1} \eta^{p} \frac{m_{t+1}^{p}}{u_{t+1}}-\Omega_{t+1}^{2} \eta^{g} \frac{m_{t+1}^{g}}{u_{t+1}}\right\} \\
& l_{t+1}^{g}: \Omega_{t}^{2}=\beta\left\{a_{t+1}^{g} u_{g}\left(c_{t+1}, g_{t+1}\right)-\nu_{u}\left(u_{t+1}\right)+\Omega_{t+1}^{2}\left(1-\lambda^{g}\right)-\Omega_{t+1}^{1} \eta^{p} \frac{m_{t+1}^{p}}{u_{t+1}}-\Omega_{t+1}^{2} \eta^{g} \frac{m_{t+1}^{g}}{u_{t+1}}\right\} .
\end{aligned}
$$

Plugging the first two equations in the third one gives the implicit expression for optimal level of search in each sector:

$$
\frac{u_{g}\left(c_{t}, g_{t}\right) \varsigma^{g} \eta^{g} v_{t}^{g}}{\left(1-\eta^{g}\right) s_{t}}=\frac{u_{c}\left(c_{t}, g_{t}\right) \varsigma^{p} \eta^{p} v_{t}^{p}}{\left(1-\eta^{p}\right)\left(1-s_{t}\right)} .
$$

If we rewrite the third condition as $\Omega_{t}^{2} \eta^{g} m_{t}^{g}+\Omega_{t}^{1} \eta^{p} m_{t}^{p}=\frac{\Omega_{t}^{2} \eta^{g} m_{t}^{g}}{s_{t}}=\frac{\Omega_{t}^{1} \eta^{p} m_{t}^{p}}{1-s_{t}}$, we can use it to simplify the last two conditions and get:

$$
\begin{aligned}
\frac{\varsigma^{p}}{q_{t}^{p}} & \left.=\beta \frac{u_{c}\left(c_{t+1}, g_{t+1}\right)}{u_{c}\left(c_{t}, g_{t}\right)}\left\{\left(1-\eta^{p}\right) a_{t+1}^{p}-\left(1-\eta^{p}\right) \frac{\nu_{u}\left(u_{t+1}\right)}{u_{c}\left(c_{t+1}, g_{t+1}\right)}+\left(1-\lambda^{p}\right) \frac{\varsigma^{p}}{q_{t+1}^{p}}-\frac{\eta^{p} \varsigma^{p} v_{t+1}^{p}}{\left(1-s_{t+1}\right) u_{t+1}}\right]\right\}, \\
\frac{\varsigma^{g}}{q_{t}^{g}} & \left.=\beta \frac{u_{g}\left(c_{t+1}, g_{t+1}\right)}{u_{g}\left(c_{t}, g_{t}\right)}\left\{\left(1-\eta^{g}\right) a_{t+1}^{g}-\left(1-\eta^{g}\right) \frac{\nu_{u}\left(u_{t+1}\right)}{u_{g}\left(c_{t+1}, g_{t+1}\right)}+\left(1-\lambda^{g}\right) \frac{\varsigma^{g}}{q_{t+1}^{g}}-\frac{\eta^{g} \varsigma^{g} v_{t+1}^{g}}{s_{t+1} u_{t+1}}\right]\right\} .
\end{aligned}
$$

\section{Proof of Proposition 1}

Plugging the steady-state expressions for the value of job, unemployment and employment in the Nash sharing rule gives us:

$$
(1-b) \frac{\bar{w}^{p}-\frac{\nu_{u}}{u_{c}}}{1-\beta\left(1-\lambda^{p}-\frac{\bar{m}^{p}}{(1-\bar{s}) \bar{u}}\right)}=b \frac{\bar{a}^{p}-\bar{w}^{p}}{1-\beta\left(1-\lambda^{p}\right)} .
$$


The decision rule for private sector vacancies is given by the free-entry condition of firms:

$$
\frac{\varsigma^{p}}{\beta \bar{q}^{p}}\left(1-\beta\left(1-\lambda^{p}\right)\right)=\left[\bar{a}^{p}-\bar{w}^{p}\right] .
$$

Combining the two equations using $\left(\bar{a}^{p}-\bar{w}^{p}\right)$ we get the following expression:

$$
\bar{w}^{p}-\frac{\nu_{u}}{u_{c}}=\left(1-\beta\left(1-\lambda^{p}-\frac{\bar{m}^{p}}{(1-\bar{s}) \bar{u}}\right)\right) \frac{b \varsigma^{p}}{(1-b) \bar{q}^{p} \beta} .
$$

Adding it to the free-entry condition:

$$
\left[\bar{a}^{p}-\frac{\nu_{u}}{u_{c}}\right]=\left(1-\beta\left(1-\lambda^{p}-\frac{\bar{m}^{p}}{(1-\bar{s}) \bar{u}}\right)\right) \frac{b \varsigma^{p}}{(1-b) \bar{q}^{p} \beta}+\frac{\varsigma^{p}}{\beta \bar{q}^{p}}\left(1-\beta\left(1-\lambda^{p}\right)\right) .
$$

We can simplify it into

$$
\left[\bar{a}^{p}-\frac{\nu_{u}}{u_{c}}\right]=\left(1-\beta\left(1-\lambda^{p}\right)\right) \frac{\varsigma^{p}}{(1-b) \bar{q}^{p} \beta}+\frac{b \varsigma^{p} \bar{m}^{p}}{(1-\bar{s}) \bar{u}(1-b) \bar{q}^{p}},
$$

which can be re-written as:

$$
\left(1-\beta\left(1-\lambda^{p}\right)\right) \frac{\varsigma^{p}}{\bar{q}^{p}}=\beta\left[(1-b)\left(\bar{a}^{p}-\frac{\nu_{u}}{u_{c}}\right)-\frac{b \varsigma^{p} \bar{v}^{p}}{(1-\bar{s}) \bar{u}}\right] .
$$

This is equivalent to the social planner's first order condition for private vacancies if $b=\eta^{p}$.

\section{WELFARE COSTS OF HIGH PUBLIC SECTOR WAGES}

Let $\left\{c_{o p t}, g_{\text {opt }}, u_{\text {opt }}\right\}$ be the steady-state private and government consumption, and unemployment under the optimal public sector wage. The $\{\bar{c}, \bar{g}, \bar{u}\}$ is the allocation under an exogenous public sector wage. We want to find what is the welfare gain as a percentage of steady-state private consumption of having the optimal steady-state public sector wage (Section 4). This is given by $x$ that solves the following equation:

$$
u\left(c_{\text {opt }}, g_{\text {opt }}\right)+\nu\left(u_{\text {opt }}\right)=u((1+x) \bar{c}, \bar{g})+\nu(\bar{u})
$$

Using the utility function:

$$
x=\frac{\left[\exp \left[\ln \left(c_{o p t}^{\gamma}+\zeta g_{o p t}^{\gamma}\right)+\gamma \chi\left(u_{o p t}-\bar{u}\right)\right]-\zeta \bar{g}^{\gamma}\right]^{\frac{1}{\gamma}}}{\bar{c}}-1, \gamma \neq 0 .
$$

If $\gamma=0$, the utility function is not defined, so I use the equivalent $u\left(c_{t}, g_{t}\right)=\ln \left(c_{t}\right)+\zeta \ln \left(g_{t}\right)$. The welfare cost in terms of steady state consumption is then given by:

$$
x=\frac{\exp \left[\ln \left(c_{o p t}\right)+\zeta\left(\ln g_{o p t}-\ln \bar{g}\right)+\chi\left(u_{o p t}-\bar{u}\right)\right]}{\bar{c}}-1, \gamma=0 .
$$




\section{WELFARE COSTS OF BUSINESS CYCLES}

In Section 6 I show the welfare costs of business cycles under different policies for $\left\{v_{t}^{g}, w_{t}^{g}\right\}$. Let us start by defining the variables in log-deviations from the steady-state:

$$
\begin{aligned}
& \tilde{c}_{t}=\log \left(\frac{c_{t}}{\bar{c}}\right) \quad c_{t}=\bar{c} \exp \left(\tilde{c}_{t}\right) \\
& \tilde{g}_{t}=\log \left(\frac{g_{t}}{\bar{g}}\right) \quad g_{t}=\bar{g} \exp \left(\tilde{g}_{t}\right) \\
& \tilde{u}_{t}=\log \left(\frac{u_{t}}{\bar{u}}\right) \quad u_{t}=\bar{u} \exp \left(\tilde{u}_{t}\right) \text {. }
\end{aligned}
$$

If we do a second-order approximation to the variables around the steady state $\{\bar{c}, \bar{g}, \bar{u}\}$ :

$$
\begin{gathered}
c_{t}=\bar{c}\left(1+\tilde{c}_{t}+\frac{1}{2} \tilde{c}_{t}^{2}\right)+o(3), \\
g_{t}=\bar{g}\left(1+\tilde{g}_{t}+\frac{1}{2} \tilde{g}_{t}^{2}\right)+o(3), \\
u_{t}=\bar{u}\left(1+\tilde{u}_{t}+\frac{1}{2} \tilde{u}_{t}^{2}\right)+o(3) .
\end{gathered}
$$

The second-order approximation of the utility function gives:

$$
\begin{aligned}
U\left(c_{t}, g_{t}, u_{t}\right)= & U(\bar{c}, \bar{g}, \bar{u})+U_{c}(\bar{c}, \bar{g}, \bar{u})\left[c_{t}-\bar{c}\right]+U_{g}(\bar{c}, \bar{g}, \bar{u})\left[g_{t}-\bar{g}\right]+U_{u}(\bar{c}, \bar{g}, \bar{u})\left[u_{t}-\bar{u}\right]+ \\
& \frac{1}{2} U_{c c}(\bar{c}, \bar{g}, \bar{u})\left[c_{t}-\bar{c}\right]^{2}+\frac{1}{2} U_{g g}(\bar{c}, \bar{g}, \bar{u})\left[g_{t}-\bar{g}\right]^{2}+\frac{1}{2} U_{u u}(\bar{c}, \bar{g}, \bar{u})\left[u_{t}-\bar{u}\right]^{2}+ \\
& U_{c g}(\bar{c}, \bar{g}, \bar{u})\left[c_{t}-\bar{c}\right]\left[g_{t}-\bar{g}\right]+U_{c u}(\bar{c}, \bar{g}, \bar{u})\left[c_{t}-\bar{c}\right]\left[u_{t}-\bar{u}\right]+U_{g u}(\bar{c}, \bar{g}, \bar{u})\left[g_{t}-\bar{g}\right]\left[u_{t}-\bar{u}\right]+o(3)
\end{aligned}
$$

But for it to be correct, we have to plug in the second-order approximation of the variables. Given the additive separability of the utility functions, we can drop the cross-terms between the consumption goods and unemployment.

$$
\begin{aligned}
U\left(c_{t}, g_{t}, u_{t}\right)= & U(\bar{c}, \bar{g}, \bar{u})+U_{c}(\bar{c}, \bar{g}, \bar{u})\left[\bar{c}\left(\tilde{c}_{t}+\frac{1}{2} \tilde{c}_{t}^{2}\right)\right]+U_{g}(\bar{c}, \bar{g}, \bar{u})\left[\bar{g}\left(\tilde{g}_{t}+\frac{1}{2} \tilde{g}_{t}^{2}\right)\right]+U_{u}(\bar{c}, \bar{g}, \bar{u})\left[\bar{u}\left(\tilde{u}_{t}+\frac{1}{2} \tilde{u}_{t}^{2}\right)\right] \\
& +\frac{1}{2} U_{c c}(\bar{c}, \bar{g}, \bar{u})\left[\bar{c}\left(\tilde{c}_{t}+\frac{1}{2} \tilde{c}_{t}^{2}\right)\right]^{2}+\frac{1}{2} U_{g g}(\bar{c}, \bar{g}, \bar{u})\left[\bar{g}\left(\tilde{g}_{t}+\frac{1}{2} \tilde{g}_{t}^{2}\right)\right]^{2}+\frac{1}{2} U_{u u}(\bar{c}, \bar{g}, \bar{u})\left[\bar{u}\left(\tilde{u}_{t}+\frac{1}{2} \tilde{u}_{t}^{2}\right)\right]^{2} \\
& +U_{c g}(\bar{c}, \bar{g}, \bar{u})\left[\bar{c}\left(\tilde{c}_{t}+\frac{1}{2} \tilde{c}_{t}^{2}\right)\right]\left[\bar{g}\left(\tilde{g}_{t}+\frac{1}{2} \tilde{g}_{t}^{2}\right)\right]+o(3) .
\end{aligned}
$$

Collecting terms and substituting the derivatives,

$$
\begin{aligned}
U\left(c_{t}, g_{t}, u_{t}\right)= & U(\bar{c}, \bar{g}, \bar{u})+u_{c} \bar{c} \tilde{c}_{t}+u_{g} \bar{g} \tilde{g}_{t}+\nu_{u} \bar{u} \tilde{u}_{t}+ \\
& \frac{\bar{c}}{2}\left(\bar{c} u_{c c}+u_{c}\right) \tilde{c}_{t}^{2}+\frac{\bar{g}}{2}\left(\bar{g} u_{g g}+u_{g}\right) \tilde{g}_{t}^{2}-\frac{\bar{u}}{2}\left(\bar{u} \nu_{u u}+\nu_{u}\right) \tilde{u}_{t}^{2}+u_{c g}(\bar{c}, \bar{g}) \bar{c} \bar{g} \tilde{c}_{t} \tilde{g}_{t}+o(3) .
\end{aligned}
$$

Taking the unconditional expectation, we can write the welfare cost in terms of the moments of the variables:

$$
\begin{aligned}
E\left[u\left(c_{t}, g_{t}\right)+\nu\left(u_{t}\right)-u(\bar{c}, \bar{g})-\nu(\bar{u})\right] \approx & u_{c} \bar{c} E\left[\tilde{c}_{t}\right]+u_{g} \bar{g} E\left[\tilde{g}_{t}\right]+\nu_{u} \bar{u} E\left[\tilde{u}_{t}\right]+\frac{\bar{c}}{2}\left(\bar{c} u_{c c}+u_{c}\right) E\left[\tilde{c}_{t}^{2}\right]+ \\
& \frac{\bar{g}}{2}\left(\bar{g} u_{g g}+u_{g}\right) E\left[\tilde{g}_{t}^{2}\right]+\frac{\bar{u}}{2}\left(\bar{u} \nu_{u u}+\nu_{u}\right) E\left[\tilde{u}_{t}^{2}\right]+u_{c g}(\bar{c}, \bar{g}) \bar{c} \bar{g} E\left[\tilde{c}_{t} \tilde{g}_{t}\right] \equiv \Xi .
\end{aligned}
$$

I solve the model up to a second-order using perturbation methods and compute the moments of the variables to find the value of $\Xi$. To express the welfare costs as a percentage of steady- 
state consumption, we solve the following equation:

$$
u((1-x) \bar{c}, \bar{g})-u(\bar{c}, \bar{g})=\Xi .
$$

For the CES function, the derivatives are given by:

$$
\begin{gathered}
u_{c}(\bar{c}, \bar{g})=\frac{\bar{c}^{\gamma-1}}{\bar{c}^{\gamma}+\zeta \bar{g}^{\gamma}}, \\
u_{g}(\bar{c}, \bar{g})=\frac{\zeta \bar{g}^{\gamma-1}}{\bar{c}^{\gamma}+\zeta \bar{g}^{\gamma}}, \\
u_{c c}(\bar{c}, \bar{g})=\frac{(\gamma-1) \bar{c}^{\gamma-2}}{\bar{c}^{\gamma}+\zeta \bar{g}^{\gamma}}-\frac{\gamma \bar{c}^{2 \gamma-2}}{\left(\bar{c}^{\gamma}+\zeta \bar{g}^{\gamma}\right)^{2}}, \\
u_{g g}(\bar{c}, \bar{g})=\frac{(\gamma-1) \zeta \bar{g}^{\gamma-2}}{\bar{c}^{\gamma}+\zeta \bar{g}^{\gamma}}-\frac{\zeta^{2} \gamma \bar{g}^{2 \gamma-2}}{\left(\bar{c}^{\gamma}+\zeta \bar{g}^{\gamma}\right)^{2}}, \\
u_{c g}(\bar{c}, \bar{g})=\frac{-\gamma \zeta \bar{g}^{\gamma-1} \bar{c}^{\gamma-1}}{\left(\bar{c}^{\gamma}+\zeta \bar{g}^{\gamma}\right)^{2}}, \\
\nu_{u}(\bar{u})=\chi \\
\nu_{u u}(\bar{u})=0 .
\end{gathered}
$$

And the expression for the welfare cost is:

$$
x=1-\frac{\left\{\exp \left[\gamma \Xi+\ln \left(\bar{c}^{\gamma}+\zeta \bar{g}^{\gamma}\right)\right]-\zeta \bar{g}^{\gamma}\right\}^{\frac{1}{\gamma}}}{\bar{c}}, \gamma \neq 0 .
$$

If $\gamma=0$ the solution is given by:

$$
x=1-\frac{\exp \{\Xi+\ln \bar{c}\}}{\bar{c}} .
$$

\section{Extension: Government Consumption}

The Lagrangian of the social planner's problem is:

$\sum_{k=0}^{\infty} \beta^{t+k}\left\{u\left(a_{t+k}^{p} l_{t+k}^{p}-\varsigma^{p} v_{t+k}^{p}-g_{t+k}, g_{t+k}\right)+\nu\left(1-l_{t+k}^{p}\right)-\Omega_{t+k}^{1}\left[l_{t+k+1}^{p}-\left(1-\lambda^{p}\right) l_{t+k}^{p}-m\left(1-l_{t+k}^{p}, v_{t+k}^{p}\right)\right]\right\}$

The first order conditions are given by:

$$
\begin{gathered}
\frac{\varsigma^{p}}{q_{t}^{p}}=\beta E_{t}\left\{\frac{u_{c}\left(c_{t+1}, g_{t+1}\right)}{u_{c}\left(c_{t}, g_{t}\right)}\left[\left(1-\eta^{p}\right) a_{t+1}^{p}+\left(1-\eta^{p}\right) \frac{\nu_{u}\left(u_{t+1}\right)}{u_{c}\left(c_{t+1}, g_{t+1}\right)}+\left(1-\lambda^{p}\right) \frac{\varsigma^{p}}{q_{t+1}^{p}}-\frac{\eta^{p} \varsigma^{p} v_{t+1}^{p}}{u_{t+1}}\right]\right\} \\
u_{c}\left(c_{t}, g_{t}\right)=u_{g}\left(c_{t}, g_{t}\right) .
\end{gathered}
$$




\section{Appendix V - Bayesian estimation}

\section{Model - All Equations}

The labour market is described by the following equations:

$$
\begin{gathered}
1=l_{t}^{p}+l_{t}^{g}+u_{t}, \\
l_{t+1}^{p}=\left(1-\lambda_{t}^{p}\right) l_{t}^{p}+m_{t}^{p}, \\
l_{t+1}^{g}=\left(1-\lambda_{t}^{g}\right) l_{t}^{g}+m_{t}^{g}, \\
m_{t}^{p}=\mu^{p}\left(\left(1-s_{t}\right) u_{t}\right)^{\eta^{p}}\left(v_{t}^{p}\right)^{1-\eta^{p}}, \\
m_{t}^{g}=\mu^{g}\left(s_{t} u_{t}\right)^{\eta^{g}}\left(v_{t}^{g}\right)^{1-\eta^{g}}, \\
q_{t}^{p}=\frac{m_{t}^{p}}{v_{t}^{p}}, \\
p_{t}^{p}=\frac{m_{t}^{p}}{\left(1-s_{t}\right) u_{t}}, \\
p_{t}^{g}=\frac{m_{t}^{g}}{s_{t} u_{t}} .
\end{gathered}
$$

The marginal utility of consumption and the stochastic discount factor are:

$$
\begin{gathered}
u_{c}\left(c_{t}, g_{t}\right)=\frac{c_{t}^{\gamma-1}}{c_{t}^{\gamma}+\zeta g_{t}^{\gamma}}, \\
\nu_{u}\left(u_{t}\right)=\chi, \\
\beta_{t, t+1}=\beta \frac{u_{c}\left(c_{t+1}, g_{t+1}\right)}{u_{c}\left(c_{t}, g_{t}\right)},
\end{gathered}
$$

I define a variable $x_{t}^{i}$ as the difference between the value of working and being unemployed. I use it to re-write the equation pinning down $s_{t}$ and the Nash bargaining:

$$
\begin{aligned}
& x_{t}^{p}=W_{t}^{p}-U_{t}^{p}=w_{t}^{p}-\frac{\nu_{u}\left(u_{t}\right)}{u_{c}\left(c_{t}, g_{t}\right)}+E_{t} \beta_{t, t+1}\left(1-\lambda_{t}^{p}-p_{t}^{p}\right) x_{t+1}^{p}, \\
& x_{t}^{g}=W_{t}^{g}-U_{t}^{g}=w_{t}^{g}-\frac{\nu_{u}\left(u_{t}\right)}{u_{c}\left(c_{t}, g_{t}\right)}+E_{t} \beta_{t, t+1}\left(1-\lambda_{t}^{g}-p_{t}^{g}\right) x_{t+1}^{g},
\end{aligned}
$$




$$
\begin{gathered}
J_{t}=a_{t}^{p}-w_{t}^{p}+E_{t} \beta_{t, t+1}\left[\left(1-\lambda_{t}^{p}\right) J_{t+1}\right], \\
\frac{m_{t}^{p} E_{t}\left[x_{t+1}^{p}\right]}{\left(1-s_{t}\right)}=\frac{m_{t}^{g} E_{t}\left[x_{t+1}^{g}\right]}{s_{t}} \\
\left(1-b_{t}\right)\left(x_{t}^{p}\right)=b_{t} J_{t} .
\end{gathered}
$$

The production functions, the vacancy posting condition and the policy rules are given by:

$$
\begin{gathered}
c_{t}=a_{t}^{p} l_{t}^{p}-\varsigma^{p} v_{t}^{p}, \\
g_{t}=a_{t}^{g} l_{t}^{g}-\varsigma^{g} v_{t}^{g}, \\
\frac{\varsigma^{p}}{q_{t}^{p}}=E_{t} \beta_{t, t+1}\left[a_{t+1}^{p}-w_{t+1}^{p}+\left(1-\lambda_{t}^{p}\right) \frac{\varsigma^{p}}{q_{t+1}^{p}}\right] \\
\ln \left(v_{t}^{g}\right)=\ln \left(\bar{v}^{g}\right)+\psi^{v}\left[\frac{\sum_{i=0}^{3} \ln \left(v_{t-i}^{p}\right)}{4}-\ln \left(\bar{v}^{p}\right)\right]+\ln \left(\omega_{t}^{v}\right), \\
\ln \left(w_{t}^{g}\right)=\ln \left(\bar{w}^{g}\right)+\psi^{w}\left[\frac{\sum_{i=0}^{3} \ln \left(w_{t-1}^{p}\right)}{4}-\ln \left(\bar{w}^{p}\right)\right]+\ln \left(\omega_{t}^{w}\right),
\end{gathered}
$$

I include 6 different shocks: a shock to government vacancies, to government wages, to private and public separation rates, private sector bargaining power and to technology. These shocks are described by the following equations:

$$
\begin{gathered}
\ln \left(a_{t}^{p}\right)=\ln \left(\bar{a}^{p}\right)+\alpha\left(\ln \left(l_{t}^{g}\right)-\ln \left(\bar{l}^{g}\right)\right)+\ln \left(\omega_{t}^{a}\right) . \\
\ln \left(\omega_{t}^{v}\right)=\rho^{v} \ln \left(\omega_{t-1}^{v}\right)+\epsilon_{t}^{v}, \\
\ln \left(\omega_{t}^{w}\right)=\rho^{w} \ln \left(\omega_{t-1}^{w}\right)+\epsilon_{t}^{w}, \\
\ln \left(\omega_{t}^{a}\right)=\rho^{a} \ln \left(\omega_{t-1}^{a}\right)+\epsilon_{t}^{a}, \\
\ln \left(\lambda_{t}^{g}\right)=\left(1-\rho^{l g}\right) \ln \left(\bar{\lambda}_{t}^{g}\right)+\rho^{l g} \ln \left(\lambda_{t-1}^{g}\right)+\epsilon_{t}^{l g}, \\
\ln \left(\lambda_{t}^{p}\right)=\left(1-\rho^{l p}\right) \ln \left(\bar{\lambda}_{t}^{p}\right)+\rho^{l p} \ln \left(\lambda_{t-1}^{p}\right)+\epsilon_{t}^{l p}, \\
\ln \left(b_{t}\right)=\left(1-\rho^{b}\right) \ln (\bar{b})+\rho^{b} \ln \left(b_{t-1}\right)+\epsilon_{t}^{b} .
\end{gathered}
$$


Finally, I define that overall job-separation and job-finding rates:

$$
\begin{gathered}
f_{t}=\frac{m_{t}^{p}+m_{t}^{g}}{u_{t}}, \\
\Lambda_{t}=\frac{\lambda_{t}^{p} l_{t}^{p}+\lambda_{t}^{g} l_{t}^{g}}{l_{t}^{p}+l_{t}^{g}} .
\end{gathered}
$$

\section{Model - Steady State}

I set the steady-state government employment at $\bar{l}^{g}$. As there is no recursive way to write the steady-state variables, they solve the following non-linear system of equations:

$$
\begin{aligned}
& \bar{l}^{p}=1-\bar{l}^{g}-\bar{u}, \\
& \bar{m}^{p}=\lambda^{p} \bar{l}^{p}, \\
& \bar{m}^{g}=\lambda^{g} \bar{l}^{g}, \\
& \bar{m}^{p}=\mu^{p}((1-\bar{s}) \bar{u})^{\eta^{p}}\left(\bar{v}^{p}\right)^{1-\eta^{p}}, \\
& \bar{m}^{g}=\mu^{g}(\bar{s} \bar{u})^{\eta^{g}}\left(\bar{v}^{g}\right)^{1-\eta^{g}}, \\
& p_{t}^{p}=\frac{\bar{m}^{p}}{(1-\bar{s}) \bar{u}}, \\
& p_{t}^{g}=\frac{\bar{m}^{g}}{(\bar{s}) \bar{u}} \\
& \bar{q}^{p}=\frac{\bar{m}^{p}}{v^{p}}, \\
& \bar{x}^{g}=\frac{\bar{w}^{g}-\frac{\nu_{l}}{u_{c}}}{1-\beta\left(1-\lambda^{g}-\bar{p}^{g}\right)}, \\
& \bar{x}^{p}=\frac{\bar{w}^{p}-\frac{\nu_{l}}{u_{c}}}{1-\beta\left(1-\lambda^{p}-\bar{p}^{p}\right)}, \\
& \bar{m}^{p} \bar{x}^{p} \bar{s}=\bar{m}^{g} \bar{x}^{g}(1-\bar{s}), \\
& (1-b)\left(\bar{x}^{p}\right)=b \bar{J}, \\
& \bar{J}=\frac{\bar{a}^{p}-\bar{w}^{p}}{1-\beta\left(1-\lambda^{p}\right)}, \\
& \frac{\varsigma^{p}}{\bar{q}^{p}}\left(1-\beta\left(1-\lambda^{p}\right)\right)=\beta\left(\bar{a}^{p}-\bar{w}^{p}\right), \\
& \bar{w}^{g}=\pi \bar{w}^{p}, \\
& \bar{c}=\bar{a}^{p} \bar{l}^{p}-\varsigma^{p} \bar{v}^{p}, \\
& \bar{g}=\bar{a}^{g} \bar{l}^{g}-\varsigma^{g} \bar{v}^{g},
\end{aligned}
$$




$$
\begin{gathered}
u_{c}(\bar{c}, \bar{g})=\frac{\bar{c}^{\gamma-1}}{\bar{c}^{\gamma}+\zeta \bar{g}^{\gamma}}, \\
\nu_{u}=\chi, \\
\bar{f}=\frac{\bar{m}^{p}+\bar{m}^{g}}{\bar{u}}, \\
\bar{\Lambda}=\frac{\lambda^{p} \bar{l}^{p}+\lambda^{g} \bar{l}^{g}}{\bar{l}^{p}+\bar{l}^{g}} .
\end{gathered}
$$

\section{EstimATED LOG-LINEARIZED MODEL}

The variables with tilde are expressed in deviations from steady-state.

$$
\begin{aligned}
& 0=\bar{l} \tilde{l}_{t}^{p}+\bar{l}^{g} \tilde{l}_{t}^{g}+\bar{u} \tilde{u}_{t}, \\
& \tilde{l}_{t+1}^{p}=\left(1-\bar{\lambda}^{p}\right) \tilde{l}_{t}^{p}-\bar{\lambda}^{p} \tilde{\lambda}_{t}^{p}+\bar{\lambda}^{p} \tilde{m}_{t}^{p} \\
& \tilde{l}_{t+1}^{g}=\left(1-\bar{\lambda}^{g}\right) \tilde{l}_{t}^{g}-\bar{\lambda}^{g} \tilde{\lambda}_{t}^{g}+\bar{\lambda}^{g} \tilde{m}_{t}^{g} \\
& \tilde{m}_{t}^{p}=\eta^{p}\left(\tilde{u}_{t}-\frac{\bar{s}}{1-\bar{s}} \tilde{s}_{t}\right)+\left(1-\eta^{p}\right) \tilde{v}_{t}^{p}, \\
& \tilde{m}_{t}^{g}=\eta^{g}\left(\tilde{u}_{t}+\tilde{s}_{t}\right)+\left(1-\eta^{g}\right) \tilde{v}_{t}^{g} \\
& \tilde{q}_{t}^{p}=\tilde{m}_{t}^{p}-\tilde{v}_{t}^{p} \\
& \tilde{p}_{t}^{p}=\tilde{m}_{t}^{p}+\frac{\bar{s}}{1-\bar{s}} \tilde{s}_{t}-\tilde{u}_{t}, \\
& \tilde{p}_{t}^{g}=\tilde{m}_{t}^{g}-\tilde{s}_{t}-\tilde{u}_{t} \\
& \tilde{u}_{c}\left(\tilde{c}_{t}, \tilde{g}_{t}\right)=\tilde{c}_{t}\left(\gamma-1-\frac{\gamma \bar{c}^{\gamma}}{\bar{c}^{\gamma}+\zeta \bar{g}^{\gamma}}\right)-\tilde{g}_{t}\left(\frac{\zeta \gamma \bar{g}^{\gamma}}{\bar{c}^{\gamma}+\zeta \bar{g}^{\gamma}}\right) \\
& \tilde{\nu}_{u}\left(\tilde{u}_{t}\right)=0 \\
& \tilde{\beta}_{t, t+1}=E_{t}\left[\tilde{u}_{c}\left(\tilde{c}_{t+1}, \tilde{g}_{t+1}\right)-\tilde{u}_{c}\left(\tilde{c}_{t}, \tilde{g}_{t}\right)\right], \\
& \tilde{x}_{t}^{p}=\frac{\bar{w}^{p}}{\bar{x}^{p}} \tilde{w}_{t}^{p}-\frac{\bar{\nu}_{u}}{\bar{x}^{p} \bar{u}_{c}}\left(\tilde{\nu}_{u}-\tilde{u}_{c}\right)-\beta\left(\bar{\lambda}^{p} \tilde{\lambda}_{t}^{p}+\bar{p}^{p} \tilde{p}_{t}^{p}\right)+\beta\left(1-\bar{\lambda}^{p}-\bar{p}^{p}\right) E_{t}\left(\tilde{x}_{t+1}^{p}+\tilde{\beta}_{t, t+1}\right), \\
& \tilde{x}_{t}^{g}=\frac{\bar{w}^{g}}{\bar{x}^{g}} \tilde{w}_{t}^{g}-\frac{\bar{\nu}_{u}}{\bar{x}^{p} \bar{u}_{c}}\left(\tilde{\nu}_{u}-\tilde{u}_{c}\right)-\beta\left(\bar{\lambda}^{g} \tilde{\lambda}_{t}^{g}+\bar{p}^{g} \tilde{p}_{t}^{g}\right)+\beta\left(1-\bar{\lambda}^{g}-\bar{p}^{g}\right) E_{t}\left(\tilde{x}_{t+1}^{g}+\tilde{\beta}_{t, t+1}\right),
\end{aligned}
$$




$$
\tilde{J}_{t}=\frac{\bar{a}^{p}}{\bar{J}} \tilde{a}_{t}^{p}-\frac{\bar{w}^{p}}{\bar{J}} \tilde{w}_{t}^{p}+\beta E_{t}\left(\left(1-\bar{\lambda}^{p}\right) \tilde{\beta}_{t}+\left(1-\bar{\lambda}^{p}\right) \tilde{J}_{t+1}-\bar{\lambda}^{p} \tilde{\lambda}_{t}^{p}\right)
$$

To test the relevance of the directed search assumption, I have added the parameter $\kappa$ to the log-linearized equation that determines $\tilde{s}_{t}$

$$
\begin{aligned}
& \tilde{s}_{t}=\kappa(1-\bar{s}) E_{t}\left(\tilde{x}_{t+1}^{g}-\tilde{x}_{t+1}^{p}-\tilde{m}_{t}^{p}+\tilde{m}_{t}^{g}\right), \\
& \tilde{J}_{t}+\frac{1}{1-\bar{b}} \tilde{b}_{t}=\tilde{x}_{t}^{p} \\
& \tilde{c}_{t}=\frac{\bar{a}^{p} \bar{l}^{p}}{\bar{c}}\left(\tilde{a}_{t}^{p}+\tilde{l}_{t}^{p}\right)-\frac{\varsigma^{p} \bar{v}^{p}}{\bar{c}} \tilde{v}_{t}^{p} \\
& \tilde{g}_{t}=\frac{\bar{a}^{g} \bar{l}^{g}}{\bar{g}}\left(\tilde{a}_{t}^{g}+\tilde{l}_{t}^{g}\right)-\frac{\varsigma^{g} \bar{v}^{g}}{\bar{g}} \tilde{v}_{t}^{g} \\
& -\frac{\varsigma^{p}}{\bar{q}^{p}} \tilde{q}_{t}^{p}=\beta\left[\bar{a}^{p} \tilde{a}_{t+1}^{p}-\bar{w}^{p} \tilde{w}_{t+1}^{p}-\left(1-\bar{\lambda}^{p}\right) \frac{\varsigma^{p}}{\bar{q}^{p}} \tilde{q}_{t+1}^{p}-\bar{\lambda}^{p} \frac{\varsigma^{p}}{\bar{q}^{p}} \tilde{\lambda}_{t}^{p}+\left(\bar{a}^{p}-\bar{w}^{p}+\left(1-\bar{\lambda}^{p}\right) \frac{\varsigma^{p}}{\bar{q}^{p}}\right) \tilde{\beta}_{t}\right], \\
& \tilde{v}_{t}^{g}=\psi^{v} \frac{\tilde{v}_{t}^{p}+\tilde{v}_{t-1}^{p}+\tilde{v}_{t-2}^{p}+\tilde{v}_{t-3}^{p}}{4}+\tilde{\omega}_{t}^{v} \\
& \tilde{w}_{t+1}^{g}=\psi^{w} \frac{\tilde{w}_{t}^{p}+\tilde{w}_{t-1}^{p}+\tilde{w}_{t-2}^{p}+\tilde{w}_{t-3}^{p}}{4}+\tilde{\omega}_{t}^{w} \\
& \tilde{a}_{t}^{p}=\alpha \tilde{l}_{t}^{g}+\omega_{t}^{a} \\
& \tilde{\omega}_{t}^{v}=\rho^{v} \tilde{\omega}_{t-1}^{v}+\epsilon_{t}^{v} \\
& \tilde{\omega}_{t}^{w}=\rho^{v} \tilde{\omega}_{t-1}^{w}+\epsilon_{t}^{w} \\
& \tilde{\omega}_{t}^{a}=\rho^{v} \tilde{\omega}_{t-1}^{a}+\epsilon_{t}^{a}, \\
& \tilde{\lambda}_{t}^{g}=\rho^{l g} \tilde{\lambda}_{t-1}^{g}+\epsilon_{t}^{l g}, \\
& \tilde{\lambda}_{t}^{p}=\rho^{l p} \tilde{\lambda}_{t-1}^{p}+\epsilon_{t}^{l p} \\
& \tilde{b}_{t}=\rho^{b} \tilde{b}_{t-1}+\epsilon_{t}^{b} \\
& f_{t}=\tilde{m}_{t}^{p} \frac{\bar{m}^{p}}{\bar{m}^{p}+\bar{m}^{g}}+\tilde{m}_{t}^{g} \frac{\bar{m}^{g}}{\bar{m}^{p}+\bar{m}^{g}}-\tilde{u}_{t},
\end{aligned}
$$




$$
\tilde{\Lambda}_{t}=\left(\tilde{\lambda}_{t}^{p}+\tilde{l}_{t}^{p}\right) \frac{\bar{\lambda}^{p} \bar{l}^{p}}{\bar{\lambda}^{p} \bar{l}^{p}+\bar{\lambda}^{g} \bar{l}^{g}}+\left(\tilde{\lambda}_{t}^{g}+\tilde{l}_{t}^{g}\right) \frac{\bar{\lambda}^{g} \bar{l}^{g}}{\bar{\lambda}^{p} \bar{l}^{p}+\bar{\lambda}^{g} \bar{l}^{g}}+\tilde{u}_{t} \frac{\bar{u}}{1-\tilde{u}} .
$$

\section{DEFINITION OF OBSERVABLE VARIABLES}

$$
\begin{gathered}
\text { Differences } \\
{\left[\begin{array}{cc}
l_{t}^{g O b} & \tilde{l}_{t}^{g}-\tilde{l}_{t-1}^{g} \\
u_{t}^{O b} & \tilde{u}_{t}-\tilde{u}_{t-1} \\
w_{t}^{g O b} & \tilde{w}_{t}^{g}-\tilde{w}_{t-1}^{g} \\
w_{t}^{p O b} & \tilde{w}_{t}^{p}-\tilde{w}_{t-1}^{p} \\
\Lambda_{t}^{O b} & \tilde{\Lambda}_{t}-\tilde{\Lambda}_{t-1} \\
f_{t}^{O b} & \tilde{f}_{t}-\tilde{f}_{t-1}
\end{array}\right] \quad\left[\begin{array}{cc}
l_{t}^{g O b} & \bar{l}^{g}\left(1+\tilde{l}_{t}^{g}\right) \\
u_{t}^{O b} & \bar{u}\left(1+\tilde{u}_{t}\right) \\
w_{t}^{g O b} & \tilde{w}_{t}^{g}-\tilde{w}_{t-1}^{g} \\
w_{t}^{p O b} & \tilde{w}_{t}^{p}-\tilde{w}_{t-1}^{p} \\
\Lambda_{t}^{O b} & \bar{\Lambda}\left(1+\tilde{\Lambda}_{t}\right) \\
f_{t}^{O b} & \bar{f}\left(1+\tilde{f}_{t}\right)
\end{array}\right]}
\end{gathered}
$$

\section{MODEL WITH RANDOM SEARCH}

Equation A1-A3, A6 and A9-A11 are the same. As there is no directed search, we drop equation A15 and the matches in each sector are given by the relative vacancies:

$$
\begin{gathered}
m_{t}^{p}+m_{t}^{g}=\mu^{p}\left(u_{t}\right)^{\eta^{p}}\left(v_{t}^{p}+v_{t}^{g}\right)^{1-\eta^{p}}, \\
v_{t}^{g} m_{t}^{p}=v_{t}^{p} m_{t}^{g}, \\
p_{t}^{p}=\frac{m_{t}^{p}}{u_{t}} \\
p_{t}^{g}=\frac{m_{t}^{g}}{u_{t}}, \\
x_{t}^{p}=w_{t}^{p}-\frac{\nu_{u}\left(u_{t}\right)}{u_{c}\left(c_{t}, g_{t}\right)}+E_{t} \beta_{t, t+1}\left(\left(1-\lambda_{t}^{p}-p_{t}^{p}\right) x_{t+1}^{p}-p_{t}^{g} x_{t+1}^{g}\right), \\
x_{t}^{g}=w_{t}^{g}-\frac{\nu_{u}\left(u_{t}\right)}{u_{c}\left(c_{t}, g_{t}\right)}+E_{t} \beta_{t, t+1}\left(\left(1-\lambda_{t}^{g}-p_{t}^{g}\right) x_{t+1}^{g}-p_{t}^{p} x_{t+1}^{p}\right) .
\end{gathered}
$$

For the log-linearized model the expressions are:

$$
\begin{gathered}
\tilde{m}_{t}^{p}-\tilde{m}_{t}^{g}=\tilde{v}_{t}^{p}-\tilde{v}_{t}^{g}, \\
\tilde{m}_{t}^{p}-\tilde{v}_{t}^{p}=\eta^{p} \tilde{u}_{t}-\eta^{p}\left(\frac{\bar{m}^{p}}{\bar{m}^{p}+\bar{m}^{g}} \tilde{v}_{t}^{p}+\frac{\bar{m}^{g}}{\bar{m}^{p}+\bar{m}^{g}} \tilde{v}_{t}^{g}\right), \\
\tilde{x}_{t}^{p}=\frac{\bar{w}^{p}}{\bar{x}^{p}} \tilde{w}_{t}^{p}-\frac{\bar{\nu}_{u}}{\bar{x}^{p} \bar{u}_{c}}\left(\tilde{\nu}_{u}-\tilde{u}_{c}\right)-\beta\left(\bar{\lambda}^{p} \tilde{\lambda}_{t}^{p}+\bar{p}^{p} \tilde{p}_{t}^{p}\right)+\beta\left(1-\bar{\lambda}^{p}-\bar{p}^{p}\right) E_{t}\left(\tilde{x}_{t+1}^{p}+\tilde{\beta}_{t, t+1}\right) .
\end{gathered}
$$




\section{ESTIMATION RESULTS (LEVELS)}

Table A3: Prior and posterior distribution of structural parameters

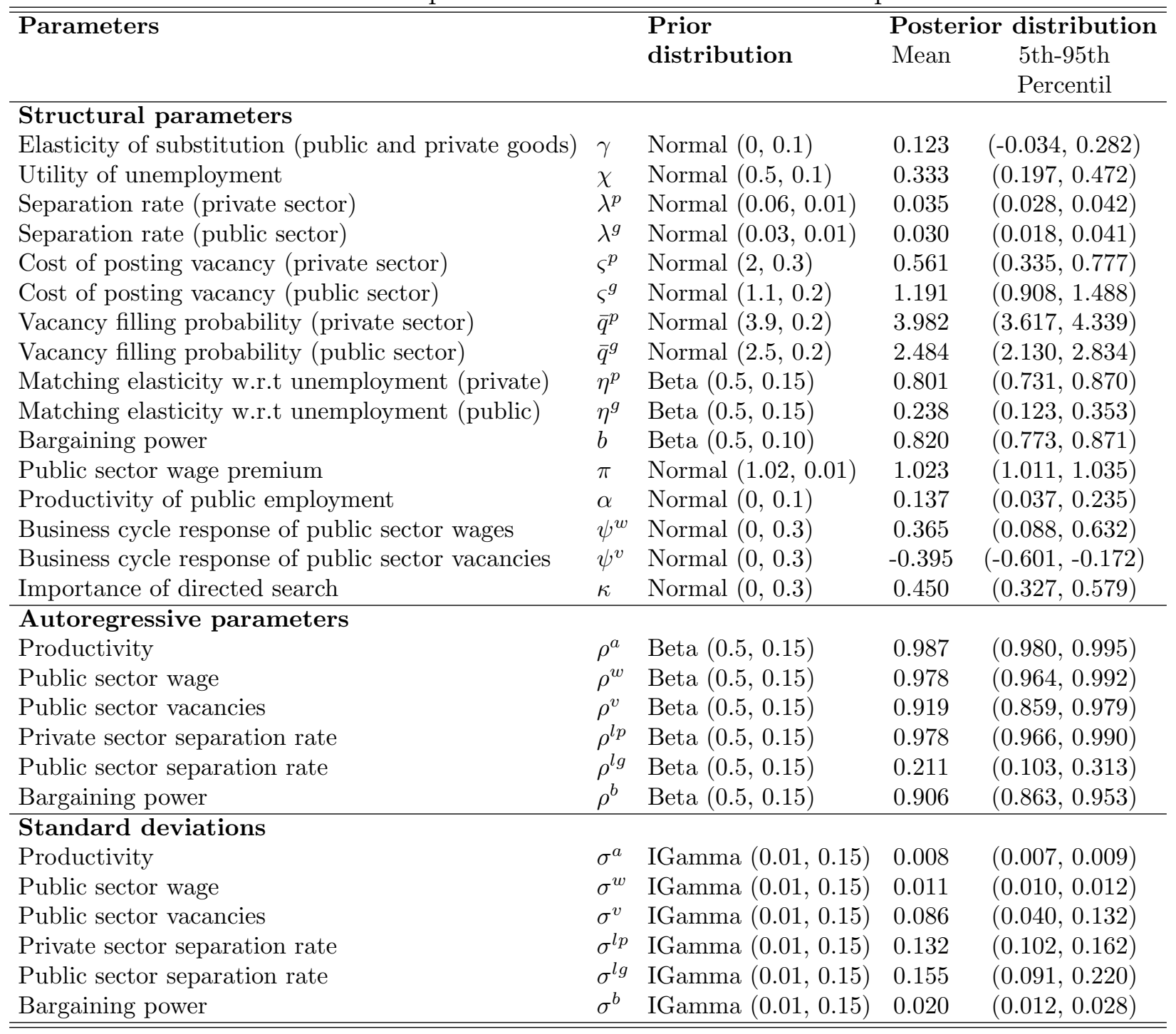

Table A4: Model Comparison (Levels)

\begin{tabular}{lccccc}
\hline \hline & $\begin{array}{c}\text { Marginal } \\
\text { Data } \\
\text { Density }\end{array}$ & $\begin{array}{c}\text { Prediction of vacancies } \\
\left.\text { Ctdd( } v^{e}\right)\end{array}$ & $\begin{array}{c}\text { Prediction of tightness } \\
\text { Correlation } \\
\left(v^{e}, v^{d}\right)\end{array}$ & $\begin{array}{c}\text { Std }\left(\frac{v}{u}\right)^{e} \\
\text { Cotd }\left(\frac{v}{u}\right)^{d}\end{array}$ & $\begin{array}{c}\text { Correlation } \\
\left(\left(\frac{v}{u}\right)^{e},\left(\frac{v}{u}\right)^{d}\right)\end{array}$ \\
\hline Directed search & 4381.7 & 2.39 & 0.40 & 0.94 & 0.58 \\
Directed search $(\kappa=0)$ & 4357.2 & 0.97 & 0.59 & 1.15 & 0.73 \\
Random search & 4345.0 & 0.71 & 0.50 & 0.76 & 0.71 \\
\hline \hline
\end{tabular}




\section{SuBSAMPLE ESTIMATION RESULTS}

Figure A14: Subsample stability of parameters
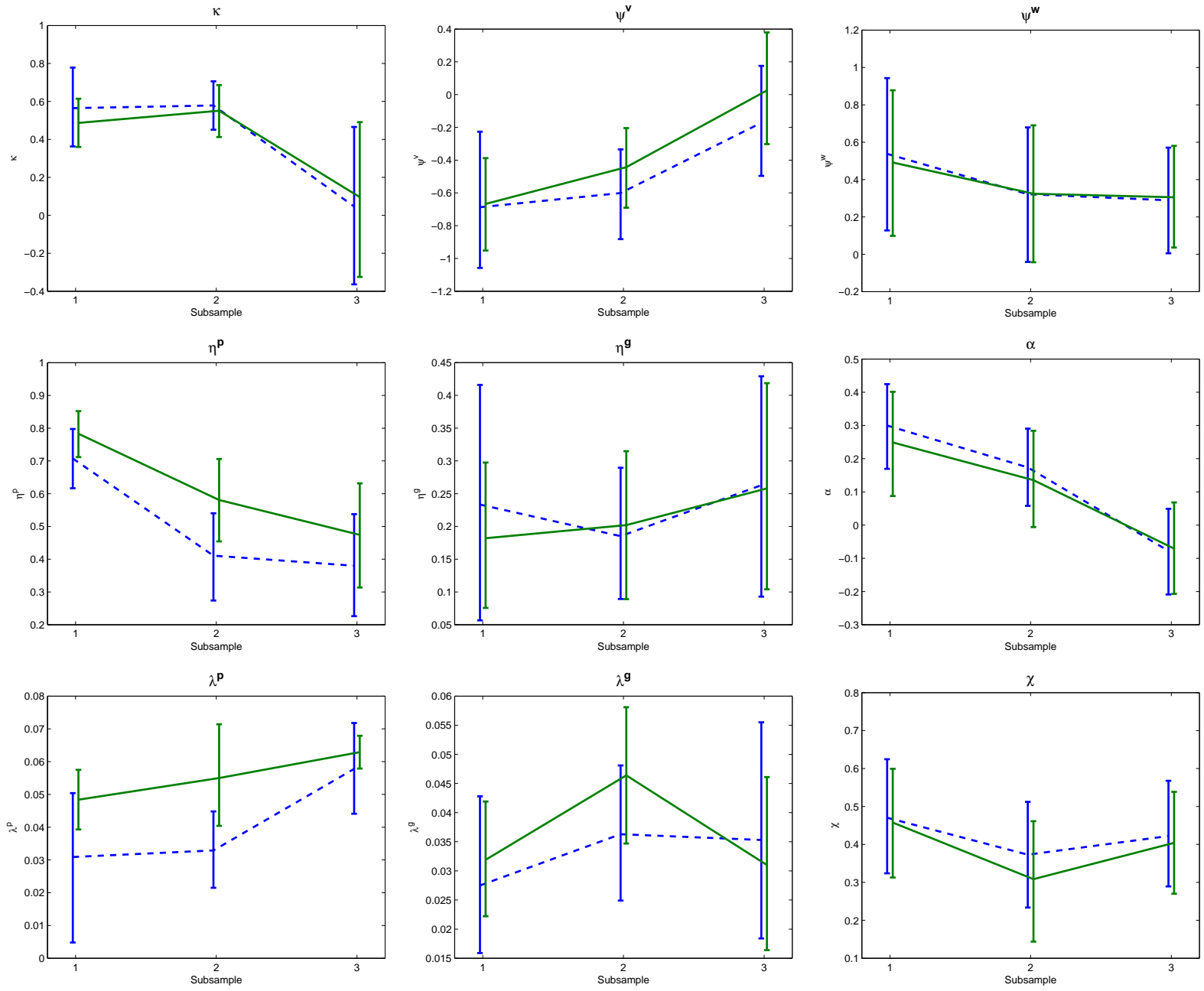

Note: Solid line is the estimation in differences and the dash line the estimation in levels. 